Prepared in cooperation with the U.S. Army Corps of Engineers

Effects of Transmitter Type, Tagging Method, Body Size, and Temperature on Behavior, Physiology, and Swimming Performance of Juvenile Chinook Salmon (Oncorhynchus tshawytscha)

Open-File Report 2018-1186 



\section{Effects of Transmitter Type, Tagging Method, Body Size, and Temperature on Behavior, Physiology, and Swimming Performance of Juvenile Chinook Salmon (Oncorhynchus tshawytscha)}

Edited by Russell W. Perry and Theresa L. Liedtke

Prepared in cooperation with the U.S. Army Corps of Engineers

Open-File Report 2018-1186

U.S. Department of the Interior

U.S. Geological Survey 


\section{U.S. Department of the Interior \\ RYAN K. ZINKE, Secretary}

U.S. Geological Survey
James F. Reilly II, Director

U.S. Geological Survey, Reston, Virginia: 2018

For more information on the USGS-the Federal source for science about the Earth, its natural and living resources, natural hazards, and the environment-visit https://www.usgs.gov/ or call 1-888-ASK-USGS (1-888-275-8747).

For an overview of USGS information products, including maps, imagery, and publications, visit https:/store.usgs.gov.

Any use of trade, firm, or product names is for descriptive purposes only and does not imply endorsement by the U.S. Government.

Although this information product, for the most part, is in the public domain, it also may contain copyrighted materials as noted in the text. Permission to reproduce copyrighted items must be secured from the copyright owner.

Suggested citation:

Entire report: Perry, R.W., and Liedtke, T.L., eds., 2018, Effects of transmitter type, tagging method, body size, and temperature on behavior, physiology, and swimming performance of juvenile Chinook salmon (Oncorhynchus tshawytscha): U.S. Geological Survey Open Report 2018-1186, 74 p., https://doi.org/10.3133/ofr20181186.

Chapter within Report:

Plumb, J.M., Perry, R.W., Fielding, S.D., Shurtleff, D.J., Lampson, S.N., and Zorich, N.A., 2018, Sustained swimming performance of in-river migrating subyearling Chinook salmon surgically implanted with dummy radio and acoustic transmitters, in Perry, R.W., and Liedtke, T.L., eds., Effects of transmitter type, tagging method, body size, and temperature on behavior, physiology, and swimming performance of juvenile Chinook salmon (Oncorhynchus tshawytscha): U.S. Geological Survey Open-File Report 2018-1186, p. 27-40, https://doi.org/10.3133/ofr20181186. 


\section{Contents}

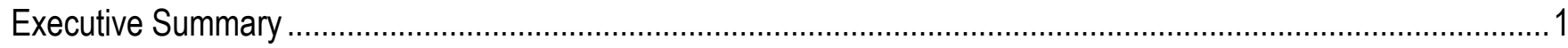

Chapter 1. Burst-Swimming, Orientation, and Behavior of Gastric- and Surgical-Tagged Yearling

Chinook Salmon Implanted with Dummy Radio and Acoustic Transmitters.................................................. 3

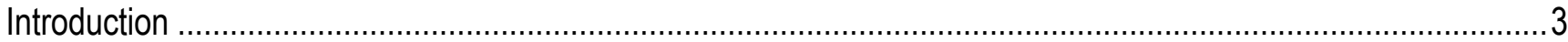

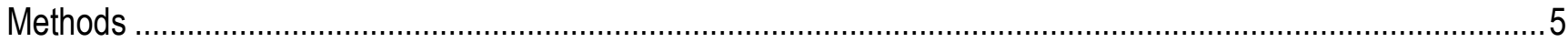

Fish Collection and Tagging ...................................................................................................

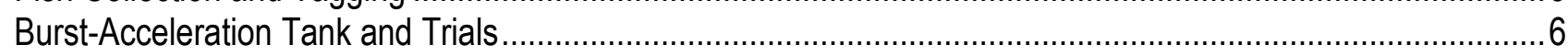

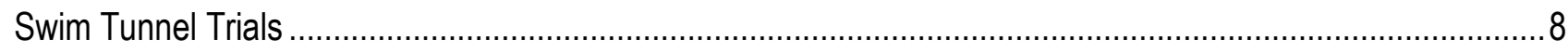

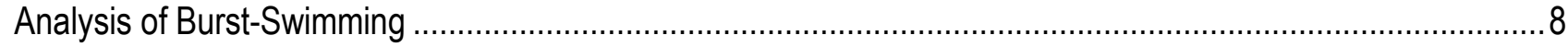

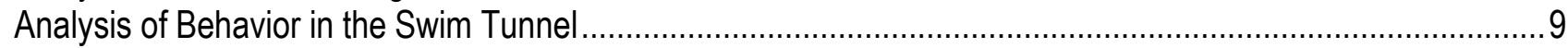

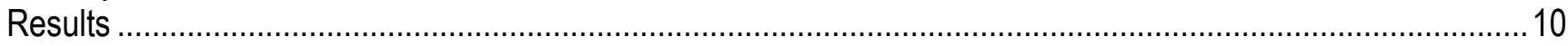

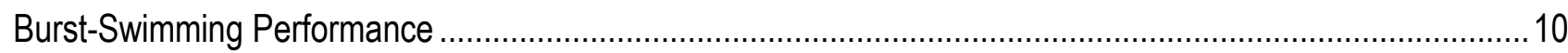

Air Gulping in the Swim Tunnel..................................................................................................

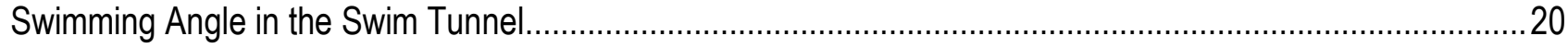

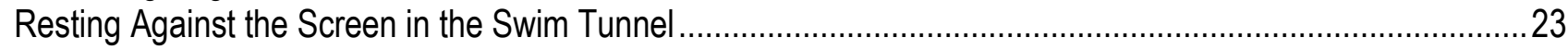

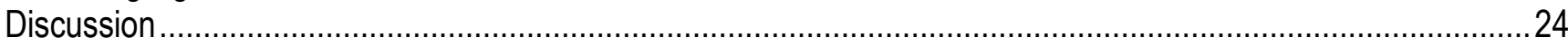

Chapter 2. Sustained Swimming Performance of In-River Migrating Subyearling Chinook Salmon

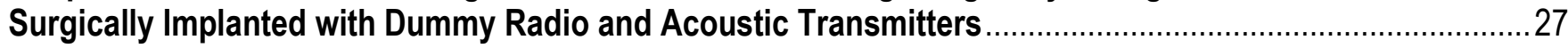

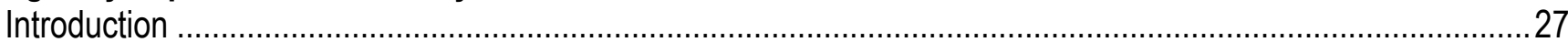

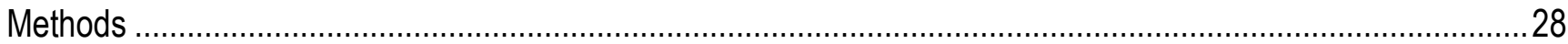

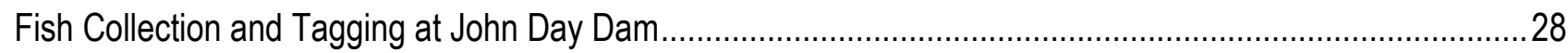

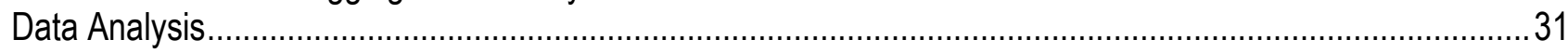

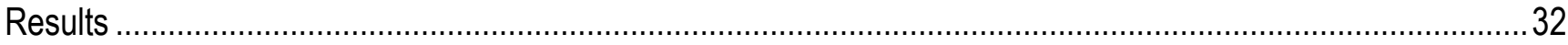

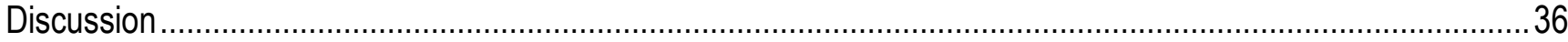

Chapter 3. Effects of Elevated Water Temperature on the Physiology, Mortality, and Swimming

Performance of Radio-Tagged Juvenile Chinook Salmon ....................................................................... 41

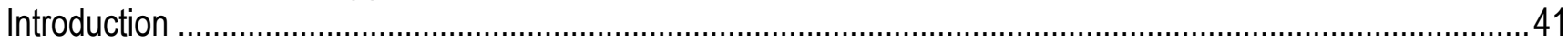

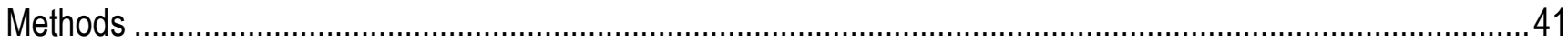

Fish Collection and Holding ......................................................................................................... 43

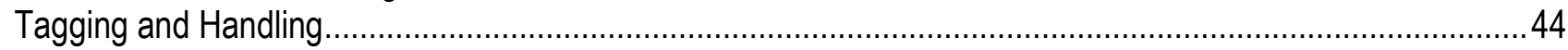

Physiological Sampling ...................................................................................................................4

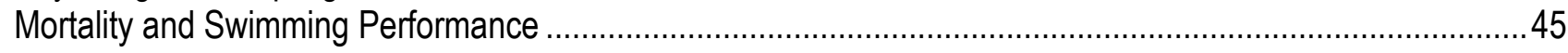

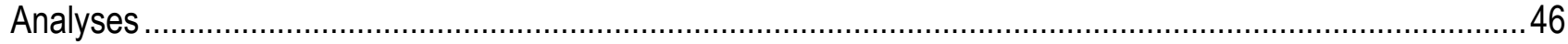

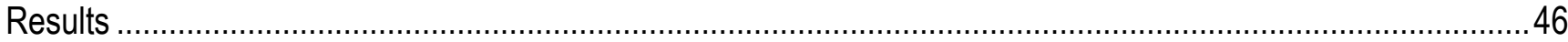

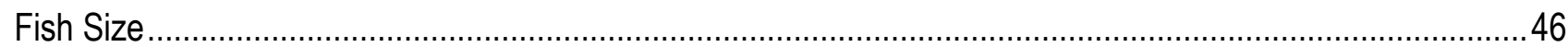

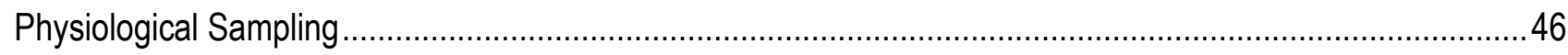

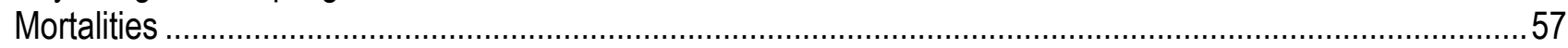

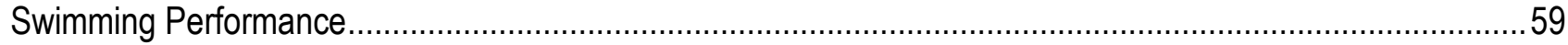

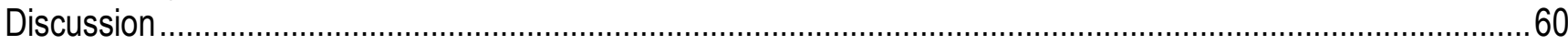




\section{Chapter 4. Effects of Antenna Length and Material on Output Power and Detection of Miniature}

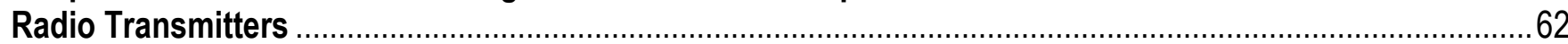

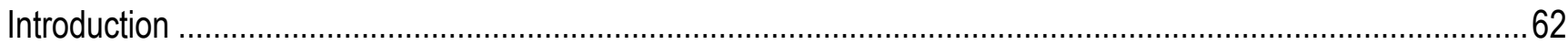

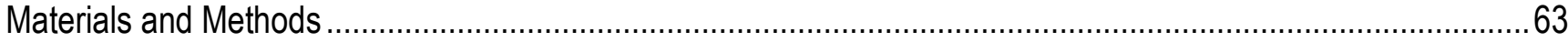

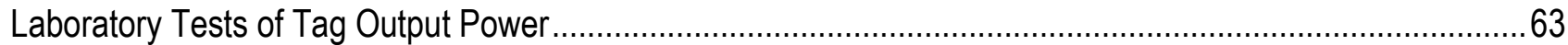

Detection Distance of Tags in Controlled Field Conditions ........................................................................63

Percent Detection of Tagged Fish at a Hydroelectric Dam .................................................................64

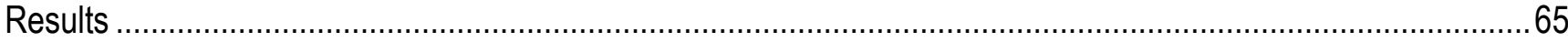

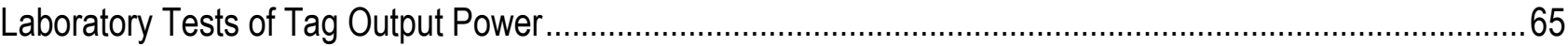

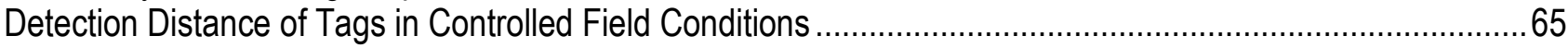

Percent Detection of Tagged Fish at a Hydroelectric Dam ……...........................................................67

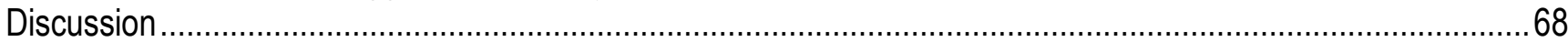

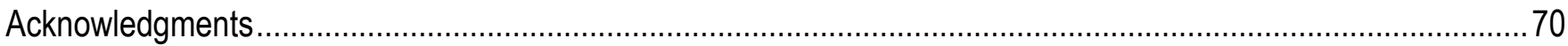

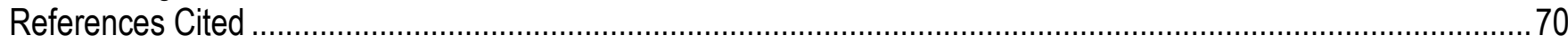

\section{Figures}

\section{Chapter 1}

Figure 1.1. Three-dimensional schematic of the burst-acceleration tank constructed from

acrylic sheet material

Figure 1.2. Graphs showing pre- and post-tagging maximum burst-swimming speeds of yearling

Chinook salmon by tagging treatment.

Figure 1.3. Graphs showing regressions of pre- and post-tagging differences [post-pre] in maximum

burst-swimming speeds on percent tag ratios for yearling Chinook salmon by tagging treatment.

Figure 1.4. Graphs showing number of yearling Chinook salmon gulping air at the surface of the swim

tunnel and the total number of air gulps during laboratory swim tunnel trials by tagging treatment

Figure 1.5. Graph showing probability and 95-percent confidence limits (dashed lines) of yearling Chinook

salmon gulping air during laboratory swim tunnel trials by tagging treatment.

Figure 1.6. Graph showing probability and 95-percent confidence limits (dashed lines) of yearling

Chinook salmon gulping air during laboratory swim tunnel trials by tagging treatments (pooled treatments

$\mathrm{CN}, \mathrm{GA}, \mathrm{GN}$ and treatment $\mathrm{SA}$ )

Figure 1.7. Graph showing probability and 95-percent confidence limits (dashed lines) of yearling

Chinook salmon gulping air during laboratory swim tunnel trials with increasing water velocity..

Figure 1.8. Graph showing probability and 95-percent confidence limits (dashed lines) of yearling

Chinook salmon gulping air during laboratory swim tunnel trials with respect to percent tag ratio.

Figure 1.9. Graph showing fish swimming angle (degrees from horizontal) and 95-percent confidence limits (dashed lines) of yearling Chinook salmon during laboratory swim tunnel trials by tagging treatment.

Figure 1.10. Graph showing fish swimming angle (degrees from horizontal) and 95-percent confidence limits (dashed lines) of yearling Chinook salmon during laboratory swim tunnel trials with increasing water velocity.

Figure 1.11. Graph showing fish swimming angle (degrees from horizontal) and 95-percent confidence limits (dashed lines) of yearling Chinook salmon during laboratory swim tunnel trials with respect to percent tag ratio. 


\section{Chapter 2}

Figure 2.1. Boxplots showing distributions of sustained swimming performance for in-river migrating subyearling

Chinook salmon by swim tube and tagging treatment at John Day Dam, Washington and Oregon, 2005

\section{Chapter 3}

Figure 3.1. Boxplots showing specific activity of gill ATPase in subyearling Chinook salmon, measured at the time of tagging at four test temperatures in the laboratory study in (a) 2004, and (b) 2005

Figure 3.2. Boxplots of specific activity of gill ATPase in subyearling Chinook salmon at the time of tagging during field study in (a) 2004, and (b) 2005

Figure 3.3. Graphs showing cortisol levels in blood plasma at various water temperatures from subyearling

Chinook salmon during laboratory study in (a) 2004, and (b) 2005

Figure 3.4. Graphs showing cortisol levels in blood plasma from subyearling Chinook salmon during time series in field study in (a) 2004, and (b) 2005

Figure 3.5. Graphs showing hsp70 levels obtained from liver tissue as a heat stress indicator in control and tagged subyearling Chinook salmon in 2004).

Figure 3.6. Graphs showing percentage of fish at each density level of Bacterial Kidney Disease (BKD), as

determined from kidney tissue in subyearling Chinook salmon during laboratory study in (a) 2004, and (b) 2005

Figure 3.7. Graphs showing percentage of fish at each density level of Bacterial Kidney Disease (BKD), as determined from kidney tissue in subyearling Chinook salmon during (a) physiological field study in 2004, and (b) field study in 2005 .

Figure 3.8. Graphs showing fraction of sampled subyearling Chinook salmon that were infected with

Favobacterium columnare (columnaris) during field study in (a) 2004, and (b) 2005 56

Figure 3.9. Graph showing swimming performance $\left(U_{\text {crit }}\right)$ of tagged and control fish at various water temperatures measured in the laboratory study in 2004

\section{Chapter 4}

Figure 4.1. Graph showing mean and 95-percent confidence intervals of relative output power (in decibels $[\mathrm{dB}]$ ) of tags with two antenna types of various lengths (in centimeters [cm]) measured in laboratory......65 Figure 4.2. Graphs showing distances at various depths for hearing and decoding tags with Type 1 and Type 2 antennas of short (closed triangle), medium (open circle), and control (closed circle) lengths from a boat-mounted receiving system in the Columbia River, Oregon and Washington. 


\section{Tables}

\section{Chapter 1}

Table 1.1. Laser distances from acclimation area in burst-acceleration tank and distances between lasers (measured to the nearest $0.05 \mathrm{~cm}$ ).

Table 1.2. Sample size of hatchery spring Chinook salmon selected for burst swimming trials.

Table 1.3. Summary statistics for pre- and post-tagging maximum burst-swimming speeds $(\mathrm{cm} / \mathrm{s})$ of yearling Chinook salmon by tagging treatment: (1) controls (CN),(2) surgically implanted tag with antenna (SA),

(3) gastrically implanted tag with antenna (GA), and (4) gastrically implanted tag without antenna (GN)

Table 1.4. Statistical results for paired $t$-tests of pre- and post-tagging differences in maximum burst-swimming speeds $(\mathrm{cm} / \mathrm{s})$ for yearling Chinook salmon by tagging treatment: (1) controls $(\mathrm{CN}),(2)$ surgically implanted tag with antenna (SA), (3) gastrically implanted tag with antenna (GA), and (4) gastrically implanted tag without antenna (GN).

Table 1.5. The number of yearling Chinook salmon that were selected for swim tunnel trials by tagging method and tag type treatments.

Table 1.6. Logistic comparison of the probability of a yearling Chinook salmon gulping air by tagging treatment: (1) controls (CN), (2) surgically implanted tag with antenna (SA), (3) gastrically implanted tag with antenna (GA), and (4) gastrically implanted tag without antenna (GN). The time elapsed (5 min intervals) during swim tunnel trials was treated as a categorical predictor with each time interval in contrast to time $=0$.

Table 1.7. Logistic comparison of the probability of a yearling Chinook salmon gulping air by tagging treatment: (1) controls and gastric-tagged fish (CN, GA, and GN treatments pooled) and (2) surgically implanted tag with antenna (SA), percent tag ratio (\%), and water velocity (B//s).

Table 1.8. Results of generalized linear model (identity link function) comparing the swimming angle of yearling Chinook salmon by tagging treatment: (1) controls (CN), (2) surgically implanted tag with antenna (SA), (3) gastrically implanted tag with antenna (GA), and 4) gastrically implanted tag without antenna (GN), and the percent of tag ratio and water velocity (Bl/s).

Table 1.9. Results of generalized linear model (logit link function) comparing the probability of yearling Chinook salmon resting against the screen at the back of the swim tunnel by tagging treatment: (1) gastric implanted tag with antenna (GA), (2) gastric implanted tag without antenna (GN), and (4) surgically implanted tag with antenna (SA).

\section{Chapter 2}

Table 2.1. The weight in air $(\mathrm{g})$, weight in water $(\mathrm{g})$, volume $(\mathrm{mL})$, and antenna length $(\mathrm{cm})$ for dummy radio (with antenna) and acoustic (without antenna) transmitters implanted into in-river migrating subyearling Chinook salmon at John Day Dam during 2005.

Table 2.2. Summary statistics of weight $(\mathrm{g})$ and fork length ( $\mathrm{mm}$; in parentheses) for in-river migrating subyearling Chinook salmon used in sustained swimming performance tests at John Day Dam during 2005.

Table 2.3. Summary statistics for sustained swimming speeds, $U_{\text {crit }}$, of subyearling Chinook salmon at John Day by swim tube and tagging treatment: (1) untagged controls (CN), (2) surgical-tagged fish with tag having an antenna (SA), and (3) surgical-tagged fish with tag not having an antenna (SN) during downstream migration in 2005].

Table 2.4. An analysis of covariance table showing the sum of squares (SS), degrees of freedom (df), mean square (MS), $F$-statistic, $P$-value, and $r$ square of the multiple regression predicting swimming performance $\left(\mathrm{U}_{\text {crit, }} \mathrm{cm} / \mathrm{s}\right)$ of subyearling Chinook salmon at John Day Dam during 2005

Table 2.5. Statistical results for analysis of covariance comparing critical swimming speeds $\left(U_{\text {crit }} \mathrm{cm} / \mathrm{s}\right)$ of subyearling Chinook salmon between swim tubes (TUBE), tagging treatments (TRT; surgical-tagged fish with an antenna, SA, and surgical-tagged fish without an antenna, SN), water temperature (TEMP, ${ }^{\circ} \mathrm{C}$ ), and fish weight (WT, g) that passed John Day Dam during 2005 


\section{Chapter 3}

Table $3.1 \mathrm{~A}$ list of dates and number of samples taken for all the trials during the (a) laboratory and (b and c) field study in 2004 and 2005

Table 3.2. A list of indicators and the times each indicator was measured during the laboratory and field studies, both in 2004 (gray dots) and 2005 (white dots).

Table 3.3. Mean fork length and weight of subyearling Chinook salmon at the time of tagging in (a) the laboratory study and (b) the field study for each trial in 2004 and 2005. In the field study (b), the mean river temperature $\left({ }^{\circ} \mathrm{C}\right)$ for each trial is listed in parentheses

Table 3.4. The number $(N)$ and percent (\%) of mortalities in groups of tagged and control subyearling Chinook salmon 24 and $96 \mathrm{~h}$ after tagging in the (a) laboratory study and (b) field study in 2004 and 2005

\section{Chapter 4}

Table 4.1. Distances $(\mathrm{m})$ tags were heard or decoded using a boat-mounted receiving system.

Table 4.2. Summary of radio-tagged subyearling Chinook salmon tagged and released to test effects of antenna length and material on detection percentage as fish passed a hydroelectric dam

\section{Conversion Factors}

International System of Units to Inch/Pound

\begin{tabular}{|c|c|c|}
\hline Multiply & By & To obtain \\
\hline \multicolumn{3}{|c|}{ Length } \\
\hline centimeter $(\mathrm{cm})$ & 0.3937 & inch (in.) \\
\hline millimeter (mm) & 0.03937 & inch (in.) \\
\hline meter $(\mathrm{m})$ & 3.281 & foot $(\mathrm{ft})$ \\
\hline kilometer (km) & 0.6214 & mile (mi) \\
\hline meter $(\mathrm{m})$ & 1.094 & yard $(y d)$ \\
\hline \multicolumn{3}{|c|}{ Volume } \\
\hline milliliter $(\mathrm{mL})$ & 0.033814 & ounce, fluid (fl. oz) \\
\hline liter (L) & 0.2642 & gallon (gal) \\
\hline cubic meter $\left(\mathrm{m}^{3}\right)$ & 264.2 & gallon (gal) \\
\hline cubic meter $\left(\mathrm{m}^{3}\right)$ & 35.31 & cubic foot $\left(\mathrm{ft}^{3}\right)$ \\
\hline \multicolumn{3}{|c|}{ Flow rate } \\
\hline centimeter per second $(\mathrm{cm} / \mathrm{s})$ & 0.393701 & inch per second (in/s) \\
\hline liter per minute $(\mathrm{L} / \mathrm{min})$ & 0.264172 & gallon per minute (gal/min) \\
\hline \multicolumn{3}{|c|}{ Mass } \\
\hline milligram (mg) & 0.00003527 & ounce, avoirdupois (oz) \\
\hline $\operatorname{gram}(\mathrm{g})$ & 0.03527 & ounce, avoirdupois (oz) \\
\hline
\end{tabular}

Temperature in degrees Celsius $\left({ }^{\circ} \mathrm{C}\right)$ may be converted to degrees Fahrenheit $\left({ }^{\circ} \mathrm{F}\right)$ as follows:

${ }^{\circ} \mathrm{F}=\left(1.8 x^{\circ} \mathrm{C}\right)+32$

Specific conductance is given in microsiemens per centimeter at 25 degrees Celsius $\left(\mu \mathrm{S} / \mathrm{cm}\right.$ at $\left.25^{\circ} \mathrm{C}\right)$.

Concentrations of chemical constituents in water are given either in milligrams per liter (mg/L) or nanograms per liter ( $\mathrm{ng} / \mathrm{L})$. 


\section{Abbreviations}

$\begin{array}{ll}\text { ANCOVA } & \text { analysis of covariance } \\ \text { ANOVA } & \text { analysis of variance } \\ \text { BI/s } & \text { body lengths per second } \\ \text { BKD } & \text { bacterial kidney disease } \\ \text { CL } & \text { confidence limits } \\ \text { CN } & \text { untagged controls } \\ \text { df } & \text { degrees of freedom } \\ \text { ELISA } & \text { enzyme-linked immunosorbent assay } \\ \text { FL } & \text { fork length } \\ \text { GA } & \text { gastrically implanted tags with an antenna } \\ \text { GN } & \text { gastrically implanted tags without an antenna } \\ \text { GPS } & \text { Global Positioning System } \\ \text { hsp } & \text { heat shock protein } \\ \text { Hz } & \text { hertz } \\ \text { MHz } & \text { megahertz } \\ \text { PIT tag } & \text { passive integrated transponder tag. } \\ r^{2} & \text { coefficient of determination } \\ \text { SA } & \text { surgically implanted tags with an antenna } \\ \text { SE } & \text { standard error } \\ \text { SN } & \text { surgically implanted tags without an antenna } \\ \text { VIE } & \text { Visible Implant Elastomer } \\ \end{array}$




\title{
Effects of Transmitter Type, Tagging Method, Body Size, and Temperature on Behavior, Physiology, and Swimming Performance of Juvenile Chinook Salmon (Oncorhynchus tshawytscha)
}

\author{
Edited by Russell W. Perry and Theresa L. Liedtke
}

\section{Executive Summary}

Considerable research has been done on the effects of transmitters on juvenile salmonids. Despite the extensive body of available tagging research, many questions remain unanswered, including those about transmitter effects over a range of fish sizes and temperatures for different transmitter types (i.e., radio or acoustic), and tagging methods (i.e., surgical or gastric implantation). Thus, researchers and managers must choose among available technologies (i.e., radio or acoustic), and balance uncertain tag effects with other constraints of the available technologies such as capital investments, detection probabilities, and the ability to obtain the desired information (e.g., routespecific passage at dams). Therefore, the objective of this study was to assess the impact of different tagging methods and transmitter types on juvenile salmonid behavior, mortality, physiology, and swimming performance over a range of water temperatures and fish sizes.

Potential impacts of different transmitter types and tagging methods on the behavior of hatchery-reared yearling Chinook salmon (Oncorhynchus tshawytscha) over a range in fish size are described in Chapter 1. Two laboratory experiments were conducted to assess maximum burstswimming speeds, the probability of gulping air, swimming angles, and the probability of resting on a screen in a swim tunnel. Sustained swimming speeds $\left(U_{c r i t}\right)$ of in-river migrating subyearling Chinook salmon at John Day Dam, Washington and Oregon, are described in Chapter 2.The effects of water temperature on the physiology, mortality, and swimming performance of juvenile Chinook salmon in laboratory and field experiments are discussed in Chapter 3. A study exploring the relation between antenna material, length, and tag output power is described in Chapter 4.

In the laboratory experiment comparing burst-swimming speeds of yearling Chinook salmon (Chapter 1), we noted a slightly reduced (about 3 centimeters per second $[\mathrm{cm} / \mathrm{s}]$ ), but statistically significant difference in burst-swimming speeds for gastric- and surgical-tagged fish implanted with dummy radio and acoustic transmitters. Specifically, gastric-tagged fish implanted with dummy acoustic transmitters and surgical-tagged fish implanted with dummy radio transmitters showed reduced burst-swimming ability, but gastric-tagged fish implanted with dummy radio transmitters were similar to untagged controls. Surgical-tagged fish implanted with dummy radio transmitters were the only treatment group to indicate a significant decrease in burst-swimming speed with decreasing fish size and increasing tag ratio (i.e., tag weight divided by fish weight). The trend for surgical-tagged fish seemed to be linear and lacked a clear breakpoint indicative of a fish size "threshold" where transmitters begin to affect fish physiology and behavior. 
In the second laboratory experiments (Chapter 1), we measured and compared behavior of tagged and untagged fish exposed to increasing water velocities within a swim tunnel. Specifically, we measured the probability of visiting the surface to gulp air, the mean swimming angle, and the probability of resting on the screen at the back of the swim tunnel. Surgical-tagged fish were one-half as likely to gulp air at the surface of the swim tunnel as untagged and gastric-tagged fish. The mechanisms behind this behavior are unknown, although a higher perceived vulnerability to surface predation as a consequence of being injured from the surgical procedure, or the posterior location of the transmitter and its effect on center of mass and buoyancy also could lead to lower surface visitation and the desire to fill the air bladder. We observed higher probabilities of fish gulping air at the surface for fish with tag ratios greater than 5 percent, suggesting that smaller fish required greater adjustment to their buoyancy than larger fish. We also observed that gastric-tagged fish had, on average, steeper swimming angles than untagged and surgical-tagged fish in the swim tunnel. This result was likely a consequence of the gastric implant shifting the fish's center of mass towards the anterior, thereby requiring the fish to maintain higher angles from horizontal to account for an altered center of mass.

Swimming performance tests conducted at John Day Dam were specifically designed to test for transmitter effects on sustained swimming ability (Chapter 2). At John Day Dam, we conducted a field-based laboratory experiment on the sustained swimming performance (i.e., critical swimming speed or $U_{\text {crit }}$ ) of in-river migrating subyearling Chinook salmon that were surgically implanted with dummy radio and acoustic transmitters. Statistical tests indicated a significant reduction (about 8.3 $\mathrm{cm} / \mathrm{s}$ or $1 \mathrm{Bl} / \mathrm{s}$ ) in sustained swimming performance for fish implanted with either transmitter type. However, we found little evidence that a 18 -centimeter [cm] external antenna reduced swimming performance more than the effect of a transmitter without an external antenna. We also found a significant reduction in $U_{\text {crit }}$ of $-1.38 \mathrm{~cm} / \mathrm{s}$ for every 1 degree Celsius $\left({ }^{\circ} \mathrm{C}\right)$ increase in temperature. Perhaps most importantly, however, we did not find a significant difference in the slope of $U_{c r i t}$ between tagged and untagged fish over the range in temperature, indicating that temperatures beyond the species' thermal optimum do not disproportionately affect swimming performance of tagged fish more than untagged fish.

We examined the effects of water temperature on the physiology, mortality, and swimming performance of juvenile Chinook salmon in laboratory and field experiments (Chapter 3). Juvenile Chinook salmon generally showed elevated stress response, elevated mortality, and reduced swimming performance as water temperature increased. We concluded that the water temperature threshold for handling and tagging fish with minimal impacts seems to be near $23{ }^{\circ} \mathrm{C}$. At $25^{\circ} \mathrm{C}$, we documented very high mortality and dramatically reduced swimming performance of tagged fish relative to controls. Telemetry studies conducted at $25^{\circ} \mathrm{C}$ would not meet the critical assumption that the transmitter has minimal impacts on the study fish.

In the final chapter (Chapter 4), we evaluated the effects of changing antenna length and material on the subsequent tag output power, reception, and detection of tagged fish. In a laboratory, we compared the relative signal strengths in water of $150-\mathrm{MHz}$ transmitters over a range of antenna lengths (from 6 to $30 \mathrm{~cm}$ ) and materials (one weighing about one-half of the other). The peak relative signal strengths were at 20 and $22 \mathrm{~cm}$, which are about 1 wavelength underwater at the test frequency. The peak relative signal strengths at these antenna lengths were about 50 percent greater than those of $30-\mathrm{cm}$ antennas, a length commonly used in fisheries research. Few significant differences were present in distances for the operator to hear or the telemetry receiver to decode transmitters from a boat-mounted receiving system based on antenna length, but the percentage of tagged fish detected passing a hydroelectric dam fitted with an array of receiving systems was significantly greater at the antenna length with peak output power in laboratory tests. This study indicates that careful choice of antenna length and material of small transmitters can be used to reduce weight and possible antenna effects on animal behavior, to maximize tag output power and detection, or to balance these factors based on the needs of the application. 


\title{
Chapter 1. Burst-Swimming, Orientation, and Behavior of Gastric- and Surgical-Tagged Yearling Chinook Salmon Implanted with Dummy Radio and Acoustic Transmitters
}

\author{
By John M. Plumb, Russell W. Perry, Scott D. Fielding, Gabriel S. Hansen, Dana J. Shurtleff, and Sarah N. \\ Lampson
}

\section{Introduction}

In the 1990s, radio and acoustic transmitters became available in sizes small enough to implant in juvenile salmonids (120-200 mm FL). Since then, there has been an increasing use of biotelemetry technology to estimate behavior, passage, and survival of juvenile salmonids as they pass through hydroelectric dams on the Snake and Columbia Rivers migrating towards the ocean. Concurrent with this increasing use of telemetry technology, information on the potential impacts of transmitter attachment to juvenile salmonids has become increasingly important because the assumption that transmitters and tagging methods have minimal impact to the fish is central to all tagging studies.

A recent review (Bridger and Booth, 2003) provides little support for transmitter-induced effects on buoyancy, orientation, swimming, feeding, hematological response, predation, gonad development or gamete production of rainbow trout (Oncorhynchus mykiss), Atlantic salmon (Salmo salar), Atlantic cod (Gadus morhua), or largemouth bass (Micropterus salmoides). Minimal effects of transmitter attachment, however, may be expected for larger fish sizes because existing technology provides transmitters that are relatively small compared to most adult fish species. A general guideline of less than 2 percent of transmitter-to-fish weight has been recommended by Winter (1996), but rapid advances in transmitter design in conjunction with more recent research suggests that transmitters may be much larger (heavier) ( $<5$ percent weight by Adams and others, 1998a; 6-12 percent weight by Brown and others, 1999) in relation to fish size (weight). Thus, although there is a general consensus that smaller ratios of tag-to-fish weight will have smaller impacts on fish behavior and survival, there is great uncertainty as to the appropriate tag ratio guideline for fish telemetry studies. This level of uncertainly is especially true for studies using small fish such as subyearling Chinook salmon (Oncorhynchus tshawytscha), where small changes in the acceptable weight guidelines could greatly alter the range of fish sizes and the proportion of the population that could be investigated.

A critical uncertainty for small-fish telemetry studies is whether their results for behavior and survival apply to the entire population or only that fraction of the population represented by larger individuals that could be tagged. To address this uncertainty, researchers should use transmitters that can be implanted in smaller individuals, thereby representing a greater proportion of the population. For juvenile salmonids, this transmitter would have the smallest possible size and physical properties that minimize impacts on fish behavior and survival. One working hypothesis is that acoustic transmitters may have fewer impacts than radio transmitters because acoustic transmitters lack an external antenna. However, there is little empirical data showing radio transmitters affect fish behavior more than acoustic transmitters. If external antennas negatively affect fish behavior, then using acoustic transmitters may minimize these effects. To date, acoustic technology has not been widely used to estimate route-specific passage and survival. Therefore, managers and researchers must balance tag effects against other issues of the available technology such as capital investments, detection probabilities of tagged fish, and the ability to determine route-specific passage and survival at dams. 
Advancements in design of both acoustic and radio transmitters may allow tagging of smaller individuals. Existing transmitters weigh as little as $0.5 \mathrm{~g}$, but radio and acoustic transmitters weighing even less are likely to be available soon (2016). Assuming that the transmitter with the least effects can be implanted in the smallest fish, the use of transmitters smaller than those now used may enable data collection on and inference to a larger proportion of the population. Thus, when choosing among the available technologies, researchers face two important questions:

1. Which transmitter design has the least effect on juvenile salmonids?

2. What is the minimum size of fish that can be tagged with negligible effects on behavior and swimming performance?

Although these questions are straightforward, past research has not provided clear guidance. For example, the absence of an antenna on acoustic transmitters may reduce the impact of the transmitter on fish behavior, but only antennas $30 \mathrm{~cm}$ or more in length have been shown to reduce swimming performance (Murchie and others, 2004), so there are few data to support this hypothesis. Most studies have compared a single transmitter type (radio or acoustic) with that of a control using fish within a specific size range for field studies (Adams and others, 1998a, 1998b; Perry and others, 2001; Anglea and others, 2004). Past research also has provided conflicting recommendations of the minimum fish size for a given transmitter size (Winter, 1996; Adams and others, 1998a, 1998b; Brown and others, 1999). Few studies have explicitly incorporated fish size as a factor to identify a size threshold where transmitters begin to affect fish physiology and behavior. This shortcoming also has been explicitly acknowledged in the literature. Jepsen and others (2002, p. 242) stated, "Few studies have systematically investigated the effects of different tag/body weight ratios, and recommendations on maximum tag ratios often seem to be unproved statements."

Our primary objectives were to explicitly test for the effects of fish size, tag type (i.e., acoustic without an antenna and radio with an antenna), and tagging method (gastric compared to surgical implantation) on the behavior and swimming performance of juvenile Chinook salmon. Our first laboratory experiment measured and compared maximum burst-swimming speeds. Fish likely use burst-swimming (i.e., anaerobic swimming at high speeds for short bursts) during downstream migration and dam passage to avoid predators or impingement on screens or other structures. Understanding how tag type and method may affect burst-swimming over a range in fish sizes should provide a better understanding of how transmitters may affect swimming performance of juvenile salmonids as they pass dams and encounter predators or drastic changes in water velocity.

Our second laboratory experiment monitored fish behavior in a swim tunnel over a range of water velocities to examine how water velocity affects tagged and untagged fish over a range of fish sizes. We investigated three aspects of swim tunnel behavior: (1) the probability that fished gulped air, (2) the swimming angles that fish maintained, and (3) the probability that fish rested on the screens. We used air gulping as an indicator of the ability of fish to compensate for tagging-related changes in buoyancy. Fish swimming angles in the swim tunnel were used as an indicator of the effects of tagging on fish buoyancy and center of mass. Finally, we measured the probability of fish resting on a screen at the back of the swim tunnel as an indicator of the effects of transmitter types and tagging methods on the swimming ability and stamina of fish. We have observed that small tagged fish with a percent tag ratio greater than 5 "pitch" in a head-up position. Furthermore, the drag of a 24-cm antenna on an 11$\mathrm{cm}$ fish may be biologically significant. Anglea and others (2004) used a similar rationale as one factor supporting the use of acoustic transmitters, which have no external antenna, for studies on juvenile Chinook salmon.

Ultimately, this information should provide researchers with a better understanding of the effects of different transmitters and tagging methods on fish behavior over a relatively wide range in fish sizes, thereby providing an assessment of the central assumption for all studies that use tagged juvenile salmonids. 


\section{Methods}

\section{Fish Collection and Tagging}

Hatchery-reared spring Chinook salmon (age 0) were obtained from the Little White Salmon National Fish Hatchery in Cook, Washington. Fish were held and reared outdoors in 1,400-L circular tanks supplied with heated well water (mean $=11.0^{\circ} \mathrm{C}$; range, $9.2-11.6^{\circ} \mathrm{C}$ ). Subsets of the fish (about 50 fish) were weighed periodically to monitor fish growth in the tanks. Fish were fed various rations (maintenance ration of 1 percent body weight, growth ration of 2-3 percent body weight, or unrestricted food quanities to yield the desired range (5.0-33.3 g) in fish sizes for laboratory tests.

This study was conducted from October 27, 2004, to February 25, 2005, at the Columbia River Research Laboratory in Cook, Washington. Fish selected for laboratory tests were collected from rearing tanks and were free of visible injuries and disease and had 20 percent or less scale loss with no other abnormalities. All fish were injected with VIE pigment (Northwest Marine Technology, Incorporated $^{\mathbb{O}}$, Shaw Island, Washington) for identification purposes. Three $0.03-\mathrm{cm}^{3}$ injection syringes were filled with red, green, or blue elastomer pigments and loaded into hand injectors. Elastomer pigments were not mixed with curing agent, as fish retained their VIE tags sufficiently during holding and testing. To implant the elastomer pigments, fish were anesthetized using buffered tricane methanesulfonate (MS-222) at a dosage of $50 \mathrm{mg} / \mathrm{L}$. Once fish began to lose equilibrium, they were removed from the anesthetic bucket, placed in a weigh boat sprayed with diluted Stress Coat ${ }^{\circledR}$ (Aquarium Pharmaceuticals, Incorporated ${ }^{\mathcal{C}}$, Chalfont, Pennsylvania), and weighed to the nearest $0.1 \mathrm{~g}$. Appropriately sized fish received 1 of 12 possible combinations of VIE tags: a single red, green, or blue tag in the jaw tissue or between the pelvic or ventral fin rays; two marks of red or green within the jaw tissue; or a single red tag above the eye. Following VIE tagging, fish were placed in individual 19$\mathrm{L}$ perforated buckets and allowed to recover for $15-24 \mathrm{~h}$ in 260 -L indoor tanks with a flow rate of 1.9 $\mathrm{L} / \mathrm{min}$.

We conducted two laboratory experiments. The first experiment investigated the burstswimming ability of fish and the second experiment investigated the behavior of fish exposed to different velocities within a swim tunnel. Treatments for the experiments were:

1. Untagged controls $(\mathrm{CN})$,

2. Gastrically implanted tags with an antenna (GA),

3. Gastrically implanted tags without an antenna (GN), and

4. Surgically implanted tags with an antenna (SA).

All tags were dummy radio transmitters supplied by Lotek Wireless Incorporated ${ }^{\complement}$, Newmarket, Ontario, Canada, and weighed $0.5 \mathrm{~g}$ in air and $0.3 \mathrm{~g}$ in water, and had a volume of $0.2 \mathrm{~mL}$. Antenna length for the dummy radio transmitters was $24 \mathrm{~cm}$.

To surgically implant tags, fish were individually anesthetized using buffered MS-222 at a dosage of $70 \mathrm{mg} / \mathrm{L}$. One minute after losing equilibrium, fish were removed from the anesthetic solution, placed in a weigh boat, sprayed with diluted Stress Coat ${ }^{\mathbb{B}}$ weighed to the nearest $0.1 \mathrm{~g}$ and measured to the nearest millimeter (FL). Fish were then surgically tagged using methods similar to those described by Adams and others (1998a, 1998b). 
To gastrically implant tags, fish were anesthetized using buffered MS-222 at a dosage of 50 $\mathrm{mg} / \mathrm{L}$. Once fish began to lose equilibrium, they were removed from the anesthetic bucket, placed in a weigh boat sprayed with diluted Stress Coat ${ }^{\circledR}$, and weighed to the nearest $0.1 \mathrm{~g}$. Fish were then submerged in a tray filled with water and Stress Coat ${ }^{\mathbb{B}}$, measured to the nearest millimeter (FL), and gastrically implanted using methods described by Adams and others (1998a, 1998b). Implantation of transmitters without an antenna followed the same procedure, but surgical suture was threaded through a monofilament loop attached to the transmitter and served to replace the antenna during insertion. The suture material was removed once the tag was seated. To reduce regurgitation rates, gastric implanted transmitters were fitted with small orthodontic rubber bands wrapped twice around the body of the tag. The weight of each rubber band was about $0.02 \mathrm{~g}$ in air and was considered to add an insignificant weight to the tags.

Immediately following tagging procedures, fish were placed in recovery buckets filled with $7 \mathrm{~L}$ of water and supplied with bottled oxygen for a minimum of $10 \mathrm{~min}$. Fish were then transferred to 1,400-L, 94-L, or 260-L holding tanks and held 17-38 h before testing. All fish were held at a density of 9 or less fish per tank.

\section{Burst-Acceleration Tank and Trials}

A $304.8 \times 24.5 \times 25.5 \mathrm{~cm}$ burst-acceleration tank was constructed with 0.635 -cm-thick extruded acrylic sheet material (fig. 1.1). The tank was supplied with water through a 2.5 -cm-diameter pipe with six $0.635-\mathrm{cm}$ holes. A 5.08-cm bulkhead fitting was placed in the bottom of the strip to allow a continuous flow of water. A stand pipe was installed to produce a flow rate of $3.7 \mathrm{~L} / \mathrm{min}$ and a water depth of $10.8 \mathrm{~cm}$.

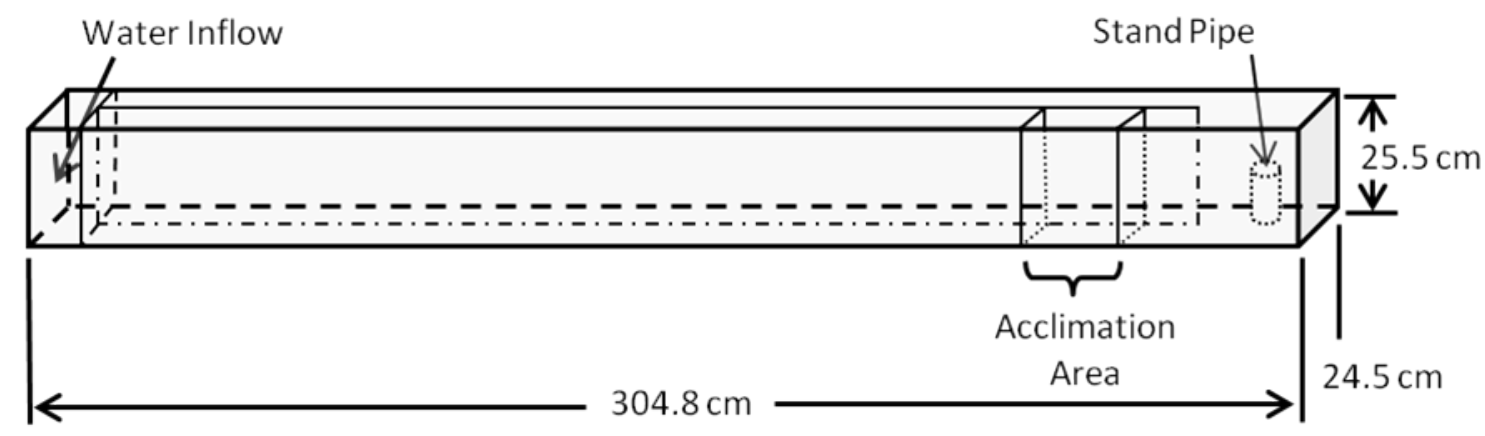

Figure 1.1. Three-dimensional schematic of the burst-acceleration tank constructed from acrylic sheet material. Tank is portable and partitions inside tank allow for swim area to be adjusted for various fish sizes.

Ten LT Laser Diode Modules (Lasermate Group, Incorporated, Pomona, California) with PMACS-MB3 mounting brackets were affixed to Bosch ${ }^{\mathrm{TM}}$ aluminum tubing to allow for adjustments in height and distance from burst-acceleration tank. The laser diodes consisted of three-element glass collimating lenses with antireflective coating, elliptical beam profiles, and five 50-megawatt power outputs with operating ranges of 4.5-9.0 volts. The ten lasers were spaced over $132.6 \mathrm{~cm}$ (table 1.1). The lasers were connected to a PowerPac ${ }^{\mathrm{TM}} 1000$ power source (BIO RAD Laboratories Incorporated $^{\odot}$, Hercules, California) and produced a refracted beam. 
Table 1.1. Laser distances from acclimation area in burst-acceleration tank and distances between lasers (measured to the nearest 0.05 centimeters).

\begin{tabular}{ccc}
\hline $\begin{array}{c}\text { Laser } \\
\text { No. }\end{array}$ & $\begin{array}{c}\text { Distance between } \\
\text { lasers } \\
\text { (centimeters) }\end{array}$ & $\begin{array}{c}\text { Distance from laser to } \\
\text { acclimation area } \\
\text { (centimeters) }\end{array}$ \\
\hline 1 & 0.0 & 61.4 \\
2 & 2.5 & 66.5 \\
3 & 5.1 & 61.4 \\
4 & 7.5 & 66.4 \\
5 & 10.0 & 61.3 \\
6 & 12.5 & 66.4 \\
7 & 15.0 & 61.4 \\
8 & 20.0 & 61.4 \\
9 & 25.1 & 61.6 \\
10 & 34.9 & 62.1 \\
\hline
\end{tabular}

Ten light-detecting boards, $1.27 \times 25.4 \mathrm{~cm}$, were constructed using 0.05-cm acrylic. Precision Optoschmitt Detectors (Honeywell Sensing and Control, Golden Valley, Minnesota) were glued 0.95 cm apart using Weld-on ${ }^{\circledR}$ \#4 Acrylic Cement (IPS ${ }^{\circledR}$ Corporation, Compton, California) to create a 13.97-cm vertical light board. WinDaq ${ }^{\circledR}$ software (DATAQ ${ }^{\circledR}$ Instruments, Akron, Ohio) was used to detect decreases in voltage as fish passed through the lasers. To enhance the sensitivity of the light boards, the experiment was conducted at low ambient light levels.

A $2.74 \times 0.255 \mathrm{~m}$ adjustable center divider also was constructed to allow for varying tank widths. Perforated gates were placed on both ends of the acclimation area to provide flow through the acclimation area. The width of the acclimation area was set at $10.7 \mathrm{~cm}$ with the length of the acclimation area adjusted to the body length of any given fish. The gate was operated manually with a pulley and rope system.

On preliminary trials, multiple stimulation techniques were attempted to produce a consistent startle reaction to the stimulus. We attempted using a stick or wooden pole similar to the technique used by Harper and Blake (1990) in which the stick was thrust toward the head to produce a response. An electrified screen was placed in the rear of the acclimation area, similar to the screen used by Webb (1975) that produced a shock. After multiple failed attempts with the stick and electrified grid, we fabricated electrical probes to stimulate the acclimation area. The stimulation consisted of an electrical charge supplied by two AA batteries and a capacitor. Two probes were placed at the rear of the acclimation area, at which point the capacitor was charged for 2-3 s and then discharged to the probes. The voltage generated from the capacitor ranged from 180 to 220 volts. In preliminary trials, this approach produced a much more consistent response than those reported by Webb (1975) and Harper and Blake (1990). Therefore, we chose to use this technique in all burst-swimming trials. Inconsistency in response arose from unavoidable differences in orientation within the acclimation chamber regardless of the stimulus applied.

To control for inherent differences in swimming ability among individuals, burst-swimming trials were conducted on all fish prior tagging, transmitters were then implanted in fish and all fish were again subjected to burst-swimming trials. Specifically, fish were collected, VIE tagged for identification, and placed in 19-L perforated buckets. After a 19-24-h holding period, individual fish (untagged) were placed in the acclimation area for $30 \mathrm{~min}$ prior to each trial. Following the 30 -min acclimation period, WinDaq ${ }^{\circledR}$ software was started and set to record drops in voltages as fish passed 
through the refracted laser beams. Once this refracted beam was broken by a bursting fish, WinDaq ${ }^{\circledR}$ recorded data 10 milliseconds (ms) prior to the actual act of breaking the refracted beam. After each trial, fish were returned to the acclimation area for a minimum of $10 \mathrm{~min}$ before initiating subsequent trials. A total of four trials were conducted for each fish. After completing the four trials, fish were held in a 110-L tank and fed for 2 days, not fed on day 3, and were tagged on day 4. After tagging, fish were placed in 19-L perforated buckets and held for 19-24 h before testing in the burst-acceleration tank. The post-tagging trials followed the same methods as the pre-tagging trials.

\section{Swim Tunnel Trials}

A swim tunnel was used to determine the effects of transmitters on the behavior of juvenile spring Chinook salmon. We modified a large, adult fish, recirculation-type swim tunnel with a 5horsepower variable speed motor to accommodate juvenile fish sizes (73-138 mm). Specifically, the swim area was reduced to a size of $48.26 \times 24.28 \times 27.94 \mathrm{~cm}$. A false floor was constructed from acrylic sheet material so fish were tested at the same depth as the holding buckets. A fine mesh screen was placed at either end of the swim area to keep fish within the desired swim area. The overall volume of the swim tunnel was approximately 33 L. Flow was determined by using a SonTek ${ }^{\circledR}$, Acoustic Doppler Velocimeter (ADV; San Diego, California) and was measured at different depths. This ADV enabled us to produce a regression line of motor speed in hertz to water velocity in the swim tunnel. A table was then produced relating body lengths per second to a given motor speed (hertz). A video camera was used to record fish behavior and performance during each trial.

To evaluate the effects of transmitters on juvenile salmonids, we investigated fish behavior as a function of tag ratio and flow. The percent tag ratio (tag weight $\div$ fish weight) was calculated and ranged from 2 to 9 percent. Fish were tested at four different velocities over five 5-min time periods: (1) $0 \mathrm{Bl} / \mathrm{s}$ from 0 to $5 \mathrm{~min}$, (2) $1.2 \mathrm{Bl} / \mathrm{s}$ from 5 to $10 \mathrm{~min}$, (3) $2.4 \mathrm{Bl} / \mathrm{s}$ from 10 to $15 \mathrm{~min}$, (4) $3.6 \mathrm{Bl} / \mathrm{s}$ from 15 to $20 \mathrm{~min}$, and (5) $0 \mathrm{Bl} / \mathrm{s}$ from 20 to $25 \mathrm{~min}$. The treatments tested were the same as those used during the burst-swimming trials: (1) control (non-tagged fish, $\mathrm{CN}$ ), (2) gastric implanted tags with antennas (GA), (3) gastric implanted tags without antennas (GN), and (4) surgical implanted tags with antennas (SA). Treatments were assigned randomly within each weight group and fish were tagged using the methods described by Adams and others (1998a, 1998b). Following tagging, fish were held in 19-L perforated buckets for 19-24 h prior to testing. Fish were placed in the swim tunnel and allowed to acclimate for 1 hour. Environmental conditions were recorded at this time. A video camera was perpendicular to the swim tunnel to record fish behavior at each velocity. After 55 min of acclimation, the video camera was set to record. Following $5 \mathrm{~min}$ of video at the initial velocity $(0$ $\mathrm{Bl} / \mathrm{s}$ ), the velocity was then increased by $1.2 \mathrm{Bl} / \mathrm{s}$ in successive 5 -min intervals for each of the five velocity increments.

\section{Analysis of Burst-Swimming}

Following completion of all trials in the burst-acceleration tank, data were proofed for accuracy and analyzed for reduction in voltage indicating the time at which a fish passed through the laser beam. Voltage data for each laser/detector pair was recorded every $2 \mathrm{~ms}$ over a 2 -s period, resulting in 1,000 lines of data per file. Fish were considered to have passed between a laser/detector pair if two or more consecutive cells contained voltages 0.10 or less volts. Segments of low voltages indicating fish presence were then labeled for analysis and used to calculate swimming speeds. Burst-swimming speed was calculated as the distance traveled between laser beams per unit time. The maximum observed swimming speed for each fish then became the focus for analysis. 
Data were analyzed for pre- and post-tagging effects on burst-swimming performance. We compared maximum pre- and post-tagging burst-swimming speeds over all trials for each fish. Fish with maximum swimming speeds of more than $30 \mathrm{Bl} / \mathrm{s}$ were excluded from the analysis because these velocities were not considered biologically possible. Paired $t$-tests were conducted to compare the difference between pre- and post-tagging maximum swimming speeds within each of the treatments. To compare differences in pre- and post-tagging maximum burst-swimming speeds among the tagging treatments, we used ANCOVA. Specifically, differences in pre- and post-tagging maximum burstswimming speeds $(\mathrm{cm} / \mathrm{s})$ were compared using treatment (i.e., $\mathrm{CN}, \mathrm{GA}, \mathrm{GN}$, and SA treatments) as a class factor and percent tag ratio as the covariate.

\section{Analysis of Behavior in the Swim Tunnel}

Once a trial was completed, each video (about $25 \mathrm{~min}$ ) was downloaded to a computer as an *.AVI file for further analysis. Videos for analyzing angles and behavior in the swim tunnel were converted to a series of *.jpg still digital frames using Frame Shots ${ }^{\mathcal{O}}$ software (Version 2.0.1.0, ${ }^{\mathbb{C}}$ 2004, EOF Productions, Denver, Colorado), with one still frame created for each second of digital video. A stratified subsample of still frames was randomly selected using SAS ${ }^{\circledR}$ software (Version 8.01, SAS Institute, Cary, North Carolina). Five still frames were selected for each test velocity. Using Image J digitizing software (Version 1.32j, public domain), $\mathrm{x}$ and $\mathrm{y}$ coordinates were determined for the head and tail of the fish for each randomly selected frame. By also determining the $\mathrm{x}$ and $\mathrm{y}$ coordinates of several pre-selected reference points for each video, we were able to calculate the angle of the fish from horizontal for each still frame. Mean angles for each fish were determined from the empirical mean vector (Cain, 1989).

To analyze behavior, videos were watched in their entirety, and the occurrence and frequency of visits to the surface to fill the air bladder and resting against the back screen were recorded. Records were uploaded and processed using $\mathrm{SAS}^{\circledR}$ software, and statistical analyses were conducted using $\mathrm{R}$ software (R Development Core Team, 2006). We used Generalized Linear Models (GLMs; Quinn and Keough, 2005) to analyze behavioral data during the swim tunnel trials. This analytical framework uses likelihood methods and provides flexibility in specifying a probability distribution for the response variable while also providing continuity among many different analyses. This approach enables the error structure for different data structures (e.g., binomial or normal) to be better accounted for than by using least-squares methods. Furthermore, both categorical and continuous predictors can be used to test hypotheses and assess linear trends between response and predictor variables. Data on the occurrence of fish gulping air and resting on the screen were binomially distributed and bound between 0 and 1, and, therefore, a logit link function was specified to compare both of these behaviors. Conversely, the swimming angle of fish in the swim tunnel did not markedly depart from a normal distribution; therefore, an identity link function with a Gaussian distribution was specified to compare the swimming angle of fish.

To compare behavior data with a binomial error structure (i.e., the probability of fish gulping air or resting on the screen), a " 1 " was recorded for each fish that indicated air gulping or resting on the screen. If the fish did not show this behavior, a "0" was recorded for the fish. We compared fish behavior within each successive 5 -min interval and $1.2 \mathrm{Bl} / \mathrm{s}$ increase in water velocity. Treatments were treated as categorical predictors and comparisons among treatments were made in contrast to the control (untagged, $\mathrm{CN}$ ) treatment. We also included time, water velocity, and the percent tag ratio of the fish as continuous predictors. However, if preliminary diagnostic plots indicated departure from linearity, the predictor was treated as categorical in the model to better illustrate the observed trend in the data. In cases where percent tag ratio was treated as a categorical predictor, the data were discretized into 1-percent intervals by rounding the percent tag ratio to the nearest whole percentage. All modeling was done by first assessing the potential for interaction; if either the interaction term or predictor was not significant $(\alpha=0.05)$, then the term was removed from the model. When modeling 
binomial data, we used the Wald $t$ statistic, which is analogous to the $t$ statistic in least-squares regression, to test for statistical differences. The Wald $t$ statistic is compared to the standard normal $z$ distribution. When modeling normally distributed data, we used the $t$ statistic that is typically used in least-squares regressions.

\section{Results}

\section{Burst-Swimming Performance}

A total of 173 fish were selected and assigned to a treatment for burst-swimming trials (table 1.2). Of these fish, 28 percent (19 of 67) with gastric tags with an antenna (GA) expelled their tags, but just 17 percent ( 7 of 42 ) with gastric tags without an antenna (GN) were expelled. Thus, the percentage of fish expelling a gastrically implanted transmitter with an antenna was nearly twice that of fish expelling a gastrically implanted transmitter without an antenna. We did not observe any 24-h posttagging mortalities. One fish in the $\mathrm{CN}$ treatment, 0 fish in the SA treatment, 7 fish in the GA treatment, and 4 fish in the GN treatment did not respond to the burst-stimulus during either the pre- or post-tagging trial. These fish could not be used for analysis of paired differences. Importantly, we attribute much of the variation in the data to an inability to create a consistent response to the burststimulus. In particular, a consistent fish orientation within the acclimation chamber prior to trials was not often possible, thereby contributing to variation in the measured response.

Maximum burst-swimming speeds between pre- and post-tagging trials varied among tagging methods and tag types. The mean maximum burst-swimming speed during pre-tagging trials ranged from $13.6 \mathrm{~cm} / \mathrm{s}(\mathrm{SE}=0.68 \mathrm{~cm} / \mathrm{s})$ to $16.1 \mathrm{~cm} / \mathrm{s}(\mathrm{SE}=0.85 \mathrm{~cm} / \mathrm{s}$; table 1.3$)$, whereas the mean maximum burst-swimming speed during post-tagging trials ranged from $10.6 \mathrm{~cm} / \mathrm{s}(\mathrm{SE}=0.85 \mathrm{~cm} / \mathrm{s})$ to $13.3 \mathrm{~cm} / \mathrm{s}$ $(\mathrm{SE}=0.99 \mathrm{~cm} / \mathrm{s})$. Based on mean differences [post-pre] between pre- and post-tagging trials in each treatment, maximum burst-swimming speeds were, on average, slightly slower (range $=-1.5$ to -3.7 $\mathrm{cm} / \mathrm{s}$ ) during post-tagging trials than during pre-tagging trials (fig. 1.2). Statistical tests confirmed that post-tagging maximum burst-swimming speeds for fish in the SA and GN treatments were, on average, significantly $(P<0.0050$; table 1.4$)$ slower (about $3 \mathrm{~cm} / \mathrm{s})$ than pre-tagging maximum burst-swimming speeds. Although fish in the GA and CN treatments were observed with slightly slower (about -1.1 to $1.7 \mathrm{~cm} / \mathrm{s}$ ) post-maximum burst-swimming speeds, the mean differences for these treatments did not differ significantly from zero $(P>0.10$; table 1.4$)$.

Pre- and post-tagging differences in maximum burst-swimming speeds showed a significant (ANCOVA, $\mathrm{df}=3, \mathrm{~F}_{1}=5.04, P=0.0025$ ) interaction between tagging treatment and percent tag ratio, thereby precluding further interpretation of pre- and post-tagging differences. Investigation into the nature of the interaction using regression analyses within the individual treatments indicated that the interaction was owing to different slopes over the range in percent tag ratio (fig. 1.3). Differences in slope were especially apparent between the SA and GA treatments (i.e., surgically and gastrically tagged fish with antennas). The slope of pre- and post-tagging differences in maximum burstswimming speeds on percent tag ratio did not differ significantly $\left(r^{2}<0.02\right.$, df $\left.>29, P>0.39\right)$ from zero for the $\mathrm{CN}$ (slope=41.6, $\mathrm{SE}=47.5$ ) and $\mathrm{GN}$ (slope=-27.7, $\mathrm{SE}=47.6)$ treatments (i.e., control and gastrictagged fish without antennas). In contrast, the slopes for SA (slope=-131.2, $\mathrm{SE}=45.6$ ) and GA (slope $=117.5, \mathrm{SE}=44.1)$ treatments differed significantly $\left(r^{2}>0.15, \mathrm{df}>32, P<0.01\right)$ from zero, and showed opposing trends from each other over the range in percent tag ratio. Thus, the significant interaction can be attributed to the lack of trend in the $\mathrm{CN}$ and GN treatments and the opposing trend for the SA treatment with respect to the GA treatment (fig. 1.3). Stomach ruptures (as indicated by post-trial necropsies) for gastric-tagged fish could not account for the significant interaction among treatments. When gastric-tagged fish with ruptured stomachs were excluded from the ANCOVA, a significant (ANCOVA, $\mathrm{df}=3, \mathrm{~F}_{1}=4.05, P=0.0089$ ) interaction between treatment and percent tag ratio was still apparent (fig. 1.3). 
Table 1.2. Sample size of hatchery spring Chinook salmon selected for burst-swimming trials by tagging treatment.

[Tagging treatment: $\mathrm{CN}$, untagged controls; GA, gastrically implanted tags with antenna; GN, gastrically implanted tags without antenna; SA, surgically implanted tags with antenna. Tags expelled: Number of expelled tags (gastric only).

Mortalities: 24-hour post-tagging mortality. Fish tested: Total number subjected to test trials. Fish compared: Number of fish available for comparison. The difference between the total number and the number compared represents the number of fish in which a burst-response was unobtainable. n/a, not applicable]

\begin{tabular}{ccccccc}
\hline $\begin{array}{c}\text { Tagging } \\
\text { treatment }\end{array}$ & $\begin{array}{c}\text { Number } \\
\text { of fish } \\
\text { selected }\end{array}$ & $\begin{array}{c}\text { Tags } \\
\text { expelled }\end{array}$ & $\begin{array}{c}\text { Ruptured } \\
\text { stomachs }\end{array}$ & Mortalities & $\begin{array}{c}\text { Fish } \\
\text { tested }\end{array}$ & $\begin{array}{c}\text { Fish } \\
\text { compared }\end{array}$ \\
\hline CN & 31 & $\mathrm{n} / \mathrm{a}$ & $\mathrm{n} / \mathrm{a}$ & 0 & 31 & 30 \\
$\mathrm{SA}$ & 33 & 0 & $\mathrm{n} / \mathrm{a}$ & 0 & 33 & 33 \\
$\mathrm{GA}$ & 67 & 19 & 5 & 0 & 48 & 41 \\
GN & 42 & 7 & 5 & 0 & 35 & 31 \\
Total & 173 & 26 & 10 & 0 & 147 & 135 \\
\hline
\end{tabular}

Table 1.3. Statistics for pre- and post-tagging maximum burst-swimming speeds of yearling Chinook salmon by tagging treatment.

[Tagging treatment: CN, untagged controls; GA, gastrically implanted tags with antenna; GN, gastrically implanted tags without antenna; SA, surgically implanted tags with antenna. N, Number of fish in trial]

\begin{tabular}{cllcccccc}
\hline \multirow{2}{*}{$\begin{array}{c}\text { Tagging } \\
\text { treatment }\end{array}$} & \multicolumn{1}{c}{ Trial } & \multirow{N}{*}{$\mathbf{N}$} & \multicolumn{6}{c}{ Maximum burst-swimming speeds, in centimeters per second } \\
\cline { 5 - 9 } & & & Median & Mean & $\begin{array}{c}\text { Standard } \\
\text { deviation }\end{array}$ & $\begin{array}{c}\text { Standard } \\
\text { error }\end{array}$ & Maximum & Minimum \\
\hline \multirow{2}{*}{ CN } & Pre-tagging & 30 & 15.2 & 15.9 & 5.42 & 0.99 & 28.8 & 4.8 \\
& Post-tagging & & 13.3 & 14.3 & 5.42 & 0.99 & 26.3 & 2.7 \\
SA & Pre-tagging & 33 & 13.6 & 14.8 & 3.88 & 0.68 & 23.7 & 7.9 \\
& Post-tagging & & 10.6 & 11.7 & 4.85 & 0.85 & 23.6 & 4.3 \\
GA & Pre-tagging & 41 & 14.9 & 14.6 & 5.74 & 0.90 & 29.7 & 0.2 \\
& Post-tagging & & 13.2 & 13.5 & 6.00 & 0.94 & 28.6 & 4.6 \\
GN & Pre-tagging & \multirow{2}{*}{31} & 16.1 & 15.8 & 4.72 & 0.85 & 29.1 & 7.0 \\
& Post-tagging & & 12.6 & 12.4 & 5.36 & 0.96 & 27.2 & 2.9 \\
\hline
\end{tabular}




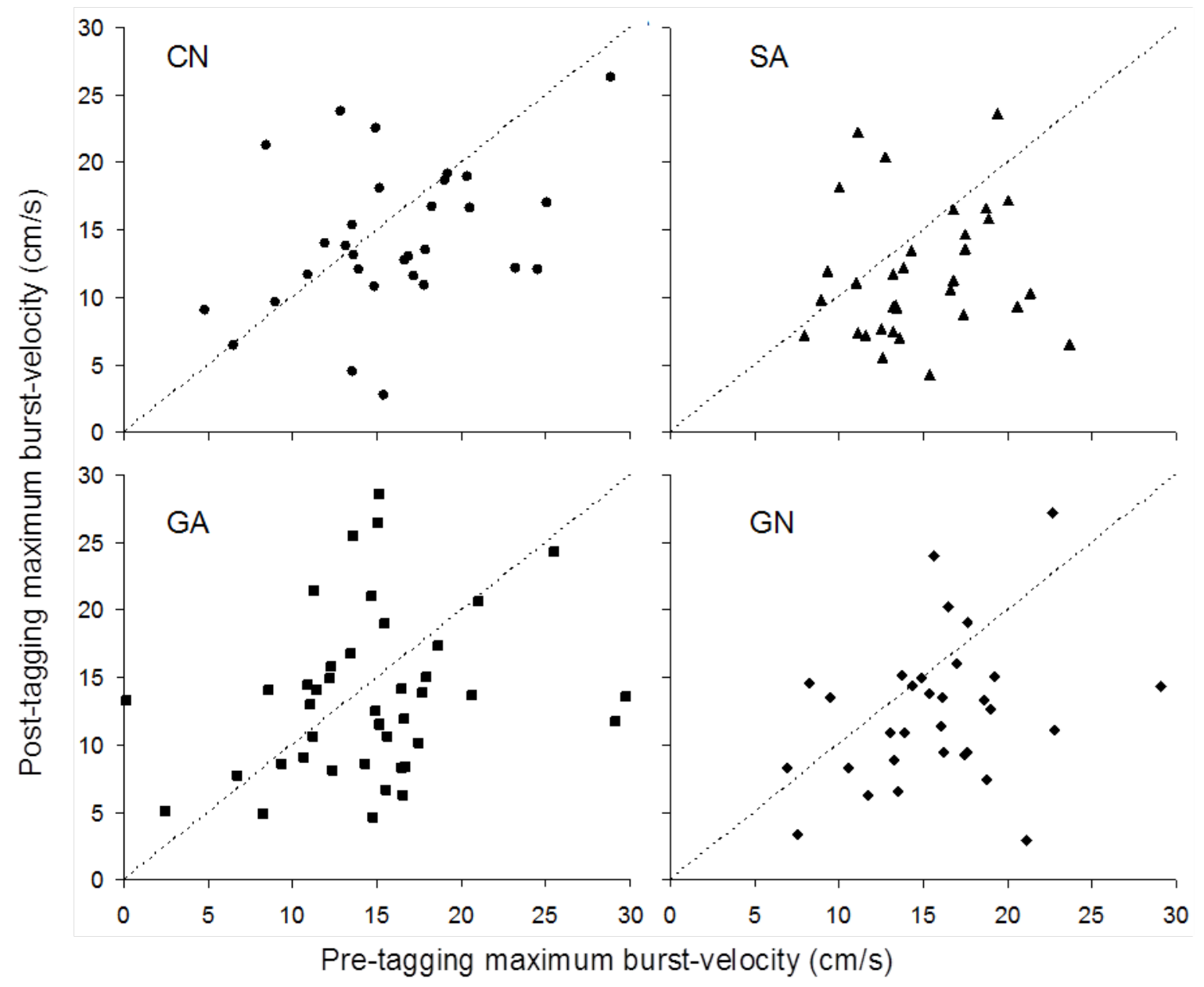

Figure 1.2. Graphs showing pre- and post-tagging maximum burst-swimming speeds of yearling Chinook salmon by tagging treatment. $\mathrm{CN}$, untagged controls; $\mathrm{SA}$, surgically implanted tags with antenna; GA, gastrically implanted tags with antenna; and GN, gastrically implanted tags without antenna.

Table 1.4. Statistical results for paired $t$-tests of pre- and post-tagging differences in maximum burst-swimming speeds for yearling Chinook salmon by tagging treatment.

[Tagging treatment: $\mathrm{CN}$, untagged controls; GA, gastrically implanted tags with antenna; GN, gastrically implanted tags without antenna; SA, surgically implanted tags with antenna]

\begin{tabular}{cccccccc}
\hline \multirow{2}{*}{$\begin{array}{c}\text { Tagging } \\
\text { treatment }\end{array}$} & \multicolumn{7}{c}{ Maximum burst-swimming speeds, in centimeters per second } \\
\cline { 2 - 8 } & $\begin{array}{c}\text { Degrees of } \\
\text { freedom }\end{array}$ & $\begin{array}{c}\text { Mean } \\
\text { difference }\end{array}$ & $\begin{array}{c}\text { Standard } \\
\text { Error }\end{array}$ & $\begin{array}{c}\text { Minimum } \\
\text { difference }\end{array}$ & $\begin{array}{c}\text { Maximum } \\
\text { difference }\end{array}$ & t-value & $P$-value \\
\hline CN & 29 & -1.7 & 1.10 & -12.6 & 12.8 & -1.51 & 0.1400 \\
SA & 32 & -3.0 & 1.00 & -17.2 & 11.1 & -3.05 & $0.0046^{*}$ \\
GA & 40 & -1.1 & 1.13 & -17.5 & 13.4 & -0.94 & 0.3500 \\
GN & 30 & -3.3 & 1.08 & -18.2 & 8.3 & -3.09 & $0.0043^{*}$ \\
\hline
\end{tabular}

Asterisks (*) indicate tests with a mean difference significantly different from zero. 

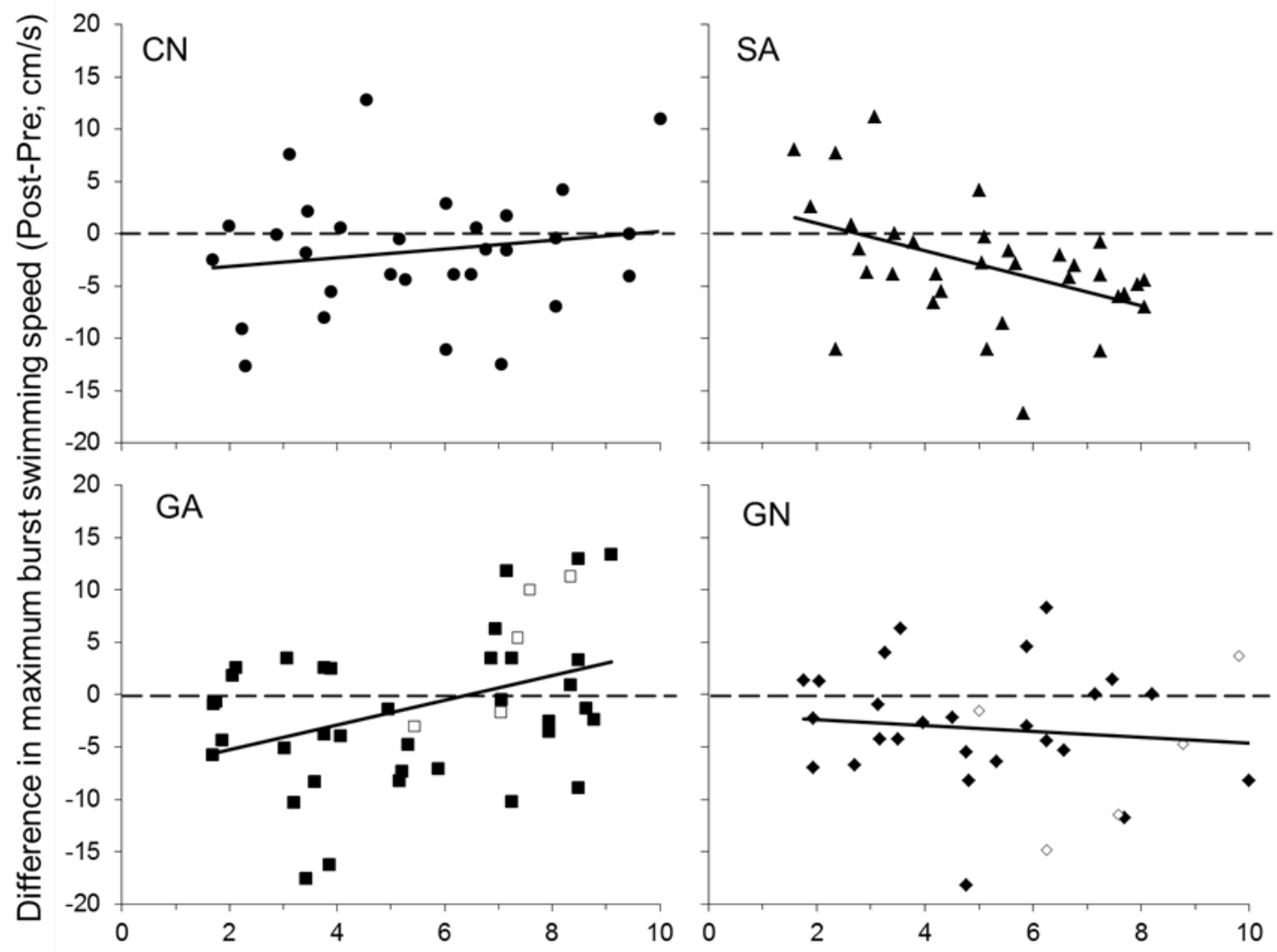

Percent tag ratio

Figure 1.3. Graphs showing regressions of pre- and post-tagging differences [post-pre] in maximum burstswimming speeds on percent tag ratios for yearling Chinook salmon by tagging treatment. $\mathrm{CN}$, untagged controls;GA, gastrically implanted tags with antenna, GN, gastrically implanted tags without antenna and SA, surgically implanted tags with antenna. Open symbols indicate gastric-tagged fish with ruptured stomachs as determined from post-trial necropsies. Dashed reference line indicates no difference between pre- and posttagging maximum burst-swimming speeds, and solid line is the regression line.

\section{Air Gulping in the Swim Tunnel}

We measured the number of air gulps and swimming angle over a range of water velocities (in body lengths per second) for 126 yearling Chinook salmon including $28 \mathrm{CN}, 33 \mathrm{GN}, 35 \mathrm{GA}$, and 30 SA (table 1.5). Of these fish, 35 percent (21 of 60) of the GA tags were expelled, but just 10 percent (4 of 40) of the GN tags were expelled. Thus, the likelihood of expelling a gastrically implanted tag with an antenna was about 3.5 times that of having a gastric tag without an antenna expelled. There were four 24-h post-tagging mortalities, all of which were from the GA treatment. Therefore, additional fish were selected throughout subsequent trials, resulting in a minimum sample size of 28 or more fish per treatment. More fish were tagged in anticipation of expelling the tag, resulting in slightly larger sample sizes ( $2-7$ fish) for tagged fish than untagged fish. 
Table 1.5. Number of yearling Chinook salmon selected for swim tunnel trials by tagging treatment.

[ Tagging treatment: CN, untagged controls; GA, gastrically implanted tags with antenna; GN, gastrically implanted tags without antenna; SA, surgically implanted tags with antenna. Tags expelled: Number of expelled tags (gastric only).

Ruptured stomachs: Ruptured stomachs (gastric only). Tagging mortalities: Number of 24-hour post-tagging mortality. Fish excluded: Number of fish excluded from the trials (expelled tags + mortalities). Fish compared: Number of fish used for comparison. $\mathrm{n} / \mathrm{a}$, not applicable]

\begin{tabular}{ccccccc}
\hline $\begin{array}{c}\text { Tagging } \\
\text { treatment }\end{array}$ & $\begin{array}{c}\text { Number } \\
\text { of fish } \\
\text { selected }\end{array}$ & $\begin{array}{c}\text { Tags } \\
\text { expelled }\end{array}$ & $\begin{array}{c}\text { Ruptured } \\
\text { stomachs }\end{array}$ & $\begin{array}{c}\text { Tagging } \\
\text { mortalities }\end{array}$ & $\begin{array}{c}\text { Fish } \\
\text { excluded }\end{array}$ & $\begin{array}{c}\text { Fish } \\
\text { compared }\end{array}$ \\
\hline CN & 28 & $\mathrm{n} / \mathrm{a}$ & $\mathrm{n} / \mathrm{a}$ & 0 & 0 & 28 \\
$\mathrm{GN}$ & 40 & 4 & 8 & 0 & 4 & 33 \\
$\mathrm{GA}$ & 60 & 21 & 2 & 4 & 25 & 35 \\
$\mathrm{SA}$ & 30 & $\mathrm{n} / \mathrm{a}$ & $\mathrm{n} / \mathrm{a}$ & 0 & 0 & 30 \\
Total & 158 & 25 & 10 & 4 & 29 & 126 \\
\hline
\end{tabular}

The number of fish that did not gulp air during the swim tunnel trials was 7 in the $\mathrm{CN}$ treatment, 7 in the GA treatment, 8 in the GN treatment, and 17 in the SA treatment. Thus, surgicaltagged fish appeared less likely to fill their air bladder than fish treated with the other tagging methods and transmitter types. Gastric-tagged fish (i.e., GA and GN treatments) exhibited the highest total number of air gulps at the surface of the swim tunnel (fig. 1.4). For example, the total number of fish that gulped air more than 20 times was 0 for the $\mathrm{CN}$ treatment, 1 for the SA treatment, 2 for the GA treatment, and 3 for the GN treatment. The highest number of gulps exhibited by fish was 15 for the $\mathrm{CN}$ treatment, 20 for the SA treatment, 37 for the GA treatment, and 40 for the GN treatment. Thus, a small number of gastric-tagged fish likely had difficulty in filling their air bladder relative to untagged and surgical-tagged fish. Fish with ruptured stomachs (based on post-trial necropsies) could not account for the large number of total air gulps by gastric-tagged fish (fig. 1.4). Fish with ruptured stomachs typically had a low total number of air gulps ( $<7$ gulps). 


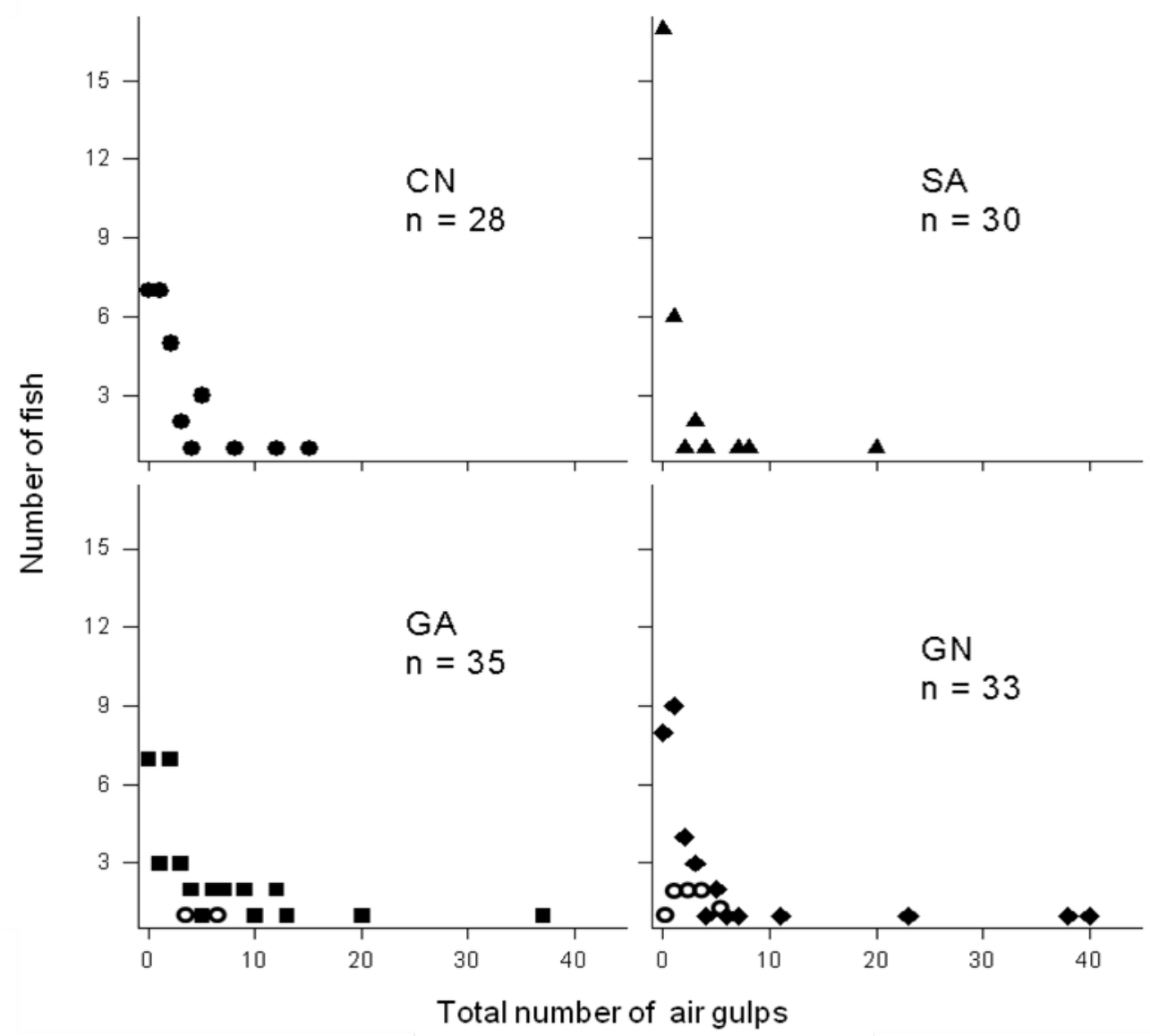

Figure 1.4. Graphs showing number of yearling Chinook salmon gulping air at the surface of the swim tunnel and the total number of air gulps during laboratory swim tunnel trials by tagging treatment. $\mathrm{CN}$, untagged controls; $\mathrm{GA}$, gastric implanted tags with antenna, and GN, gastric implanted tags without antenna and SA, surgical implanted tags with antenna. Open symbols indicate total number of air gulps for fish with ruptured stomachs based on posttrial necropsies.

We investigated the likelihood of fish gulping air over the 5-min time increments and increases in water velocity. We found no significant interaction between time and treatment $(P>0.39)$, so we removed the interaction term from the model. As expected from the overall probabilities of gulping air, fish in the SA treatment demonstrated a significantly $(P=0.027)$ lower probability of air gulping than untagged controls, but gastric-tagged fish did not differ significantly from untagged controls $(P>0.090$; table 1.6). The odds ratio for fish in the SA treatment was about 0.51 (95-percent confidence limits $[C L]=0.280$ to 0.926 ; table 1.6 and fig. 1.5), indicating that surgical-tagged fish gulped air about onehalf as much as controls and gastric-tagged fish. 
Table 1.6. Comparison of the probability of a yearling Chinook salmon gulping air by tagging treatment as a function of elapsed time from start of trial.

[Tagging treatment coefficients: Time elapsed (5-minute intervals) during swim tunnel trials was treated as a categorical predictor with each time interval in contrast to time $=0 . \mathrm{CN}$, untagged controls; GA, gastrically implanted tags with antenna; GN, gastrically implanted tags without antenna; SA, surgically implanted tags with antenna. Odds ratio: 95-percent confidence limits (CL) about the odds ratio for each time interval and treatment, representing the likelihood of gulping air relative to not gulping air.]

\begin{tabular}{lccccccc}
\hline $\begin{array}{c}\text { Tagging treatment } \\
\text { coefficients }\end{array}$ & Estimate & $\begin{array}{c}\text { Stan- } \\
\text { dard } \\
\text { error }\end{array}$ & z-value & P-value & Odds ratio & $\begin{array}{c}\text { Odds ratio } \\
-95 \text {-percent } \\
\text { CL }\end{array}$ & $\begin{array}{c}\text { Odds ratio } \\
\text { +95-percent } \\
\text { CL }\end{array}$ \\
\hline Intercept $(\mathrm{CN})$ & -0.658 & 0.257 & -2.560 & $0.010^{*}$ & 0.518 & 0.313 & 0.857 \\
Time-10 min & -0.900 & 0.301 & -2.993 & $0.003^{*}$ & 0.406 & 0.225 & 0.733 \\
Time-15 min & -0.649 & 0.288 & -2.248 & $0.025^{*}$ & 0.523 & 0.297 & 0.920 \\
Time-20 min & -0.649 & 0.288 & -2.248 & $0.025^{*}$ & 0.523 & 0.297 & 0.920 \\
Time-25 min & -0.148 & 0.272 & -0.543 & 0.587 & 0.863 & 0.506 & 1.470 \\
Treatment-GA & 0.433 & 0.255 & 1.695 & 0.090 & 1.542 & 0.935 & 2.543 \\
Treatment-GN & 0.182 & 0.264 & 0.692 & 0.489 & 1.200 & 0.716 & 2.011 \\
Treatment-SA & -0.675 & 0.305 & -2.212 & $0.027^{*}$ & 0.509 & 0.280 & 0.926 \\
\hline
\end{tabular}

Asterisks $(*)$ indicate tests with a mean difference significantly different from zero.

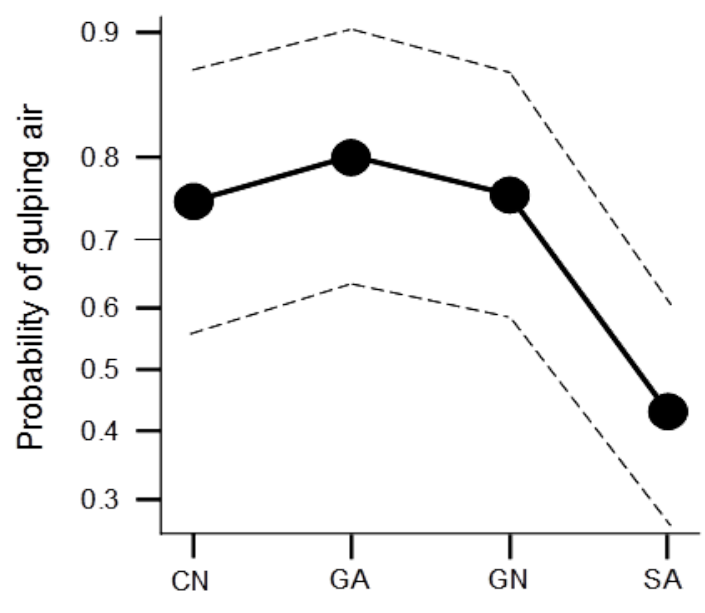

Tagging treatment

Figure 1.5. Graph showing probability and 95-percent confidence limits (dashed lines) of yearling Chinook salmon gulping air during laboratory swim tunnel trials by tagging treatment. $\mathrm{CN}$, untagged controls; $\mathrm{GA}$, gastrically implanted tags with antenna; GN, gastrically implanted tag without antenna, and SA, surgically implanted tags with antenna. The y-axis has been adjusted to account for non-linearity in showing probability estimates on the observed scale. 
The non-significant difference between gulping air at time $=25 \mathrm{~min}$ (i.e., velocity $=0 \mathrm{Bl} / \mathrm{s}$ ) and time $=5 \mathrm{~min}$ (i.e., velocity $=0 \mathrm{Bl} / \mathrm{s}$ ) indicated that fish were more likely to gulp air at times when water velocities were $0 \mathrm{Bl} / \mathrm{s}$ during swim tunnel trials. Therefore, we estimated the probability of gulping air between the treatments as a function of water velocity (in body lengths per second) and percent tag ratio. We pooled the GA, GN, and $\mathrm{CN}$ treatments because these treatments were not found to differ significantly. We treated water velocity and percent tag ratio as categorical predictors to statistically compare the probability of fish gulping air during the swim tunnel trials. Statistical results indicated a significant contribution for all factors, although not all levels of each factor were significant (table 1.7). As in previous comparisons, surgical-tagged fish had a significantly $(P<0.001)$ lower probability of gulping air during the swim tunnel trials than other tagging treatments. The odds of surgical-tagged fish gulping air relative to not gulping air was 0.40 (95-percent $C L=0.24$ to 0.66 ), supporting the conclusion that surgical-tagged fish were about one-half as likely to gulp air as untagged controls and gastric-tagged fish (fig. 1.6).

Table 1.7. Logistical comparison of the probability of a yearling Chinook salmon gulping air between tagging treament coefficients as a function of water velocity and percent tag ratios.

[Tagging treatment coefficients: Intercept, coefficient for untagged controls $(\mathrm{CN})$, gastrically implanted tags with antenna (GA), and gastrically implanted tags without antenna (GN) at a velocity of 0 body lengths per second (Bl/s) and tag ratio of 2 percent. SA, surgically implanted tags with antenna. $Z$-value: coefficient estimate divided by the standard error. Odds ratio: 95 -percent confidence limits $(\mathrm{CL})$ about the odds ratio for each time interval and treatment, representing the likelihood of gulping air relative to not gulping air]

\begin{tabular}{lccccccc}
\hline $\begin{array}{c}\text { Tagging treatment } \\
\text { coefficients }\end{array}$ & Estimate & $\begin{array}{c}\text { Standard } \\
\text { error }\end{array}$ & z-value & P-value & $\begin{array}{c}\text { Odds } \\
\text { ratio }\end{array}$ & $\begin{array}{c}\text { Odds ratio } \\
\text {-95-percent } \\
\text { CL }\end{array}$ & $\begin{array}{c}\text { Odds ratio } \\
\text { +95-percent } \\
\text { CL }\end{array}$ \\
\hline Intercept & -0.565 & 0.298 & -1.896 & 0.058 & 0.57 & 0.32 & 1.02 \\
Treatment-SA & -0.926 & 0.260 & -3.557 & $0.000^{*}$ & 0.40 & 0.24 & 0.66 \\
Velocity-1.2 Bl/s & -0.865 & 0.276 & -3.140 & $0.002^{*}$ & 0.42 & 0.25 & 0.72 \\
Velocity-2.4 Bl/s & -0.604 & 0.262 & -2.305 & $0.021^{*}$ & 0.55 & 0.33 & 0.91 \\
Velocity-3.6 Bl/s & -0.604 & 0.262 & -2.305 & $0.021^{*}$ & 0.55 & 0.33 & 0.91 \\
Tag ratio-3\% & -0.078 & 0.395 & -0.197 & 0.844 & 0.93 & 0.43 & 2.01 \\
Tag ratio-4\% & -1.068 & 0.415 & -2.577 & $0.010^{*}$ & 0.34 & 0.15 & 0.77 \\
Tag ratio-5\% & -0.178 & 0.393 & -0.452 & 0.651 & 0.84 & 0.39 & 1.81 \\
Tag ratio-6\% & 0.608 & 0.365 & 1.669 & 0.095 & 1.84 & 0.90 & 3.75 \\
Tag ratio-7\% & 0.543 & 0.356 & 1.525 & 0.127 & 1.72 & 0.86 & 3.46 \\
Tag ratio-8\% & 0.352 & 0.357 & 0.983 & 0.325 & 1.42 & 0.71 & 2.86 \\
Tag ratio-9\% & 0.843 & 0.596 & 1.415 & 0.157 & 2.32 & 0.72 & 7.47 \\
\hline
\end{tabular}

Asterisks $(*)$ indicate coeficients significantly different from zero.

Increases in water velocity had a negative non-linear effect on the probability of fish gulping air during the swim tunnel trials (table 1.7; fig 1.7). Based on the odds ratios and associated 95-percent confidence limits, fish had a similar probability of gulping air when water velocities were greater than $0 \mathrm{Bl} / \mathrm{s}$. Therefore, the probability of a fish gulping air was significantly $(P<0.02$; table 1.7$)$ higher when water velocities were equal to $0 \mathrm{Bl} / \mathrm{s}$ compared to when water velocities were greater than $0 \mathrm{Bl} / \mathrm{s}$. Thus, there appeared to be a water velocity threshold for gulping air, whereby a small change in water velocity (about $1.2 \mathrm{Bl} / \mathrm{s}$ ) resulted in a significant decrease in the probability of fish gulping air at the surface of the swim tunnel. 


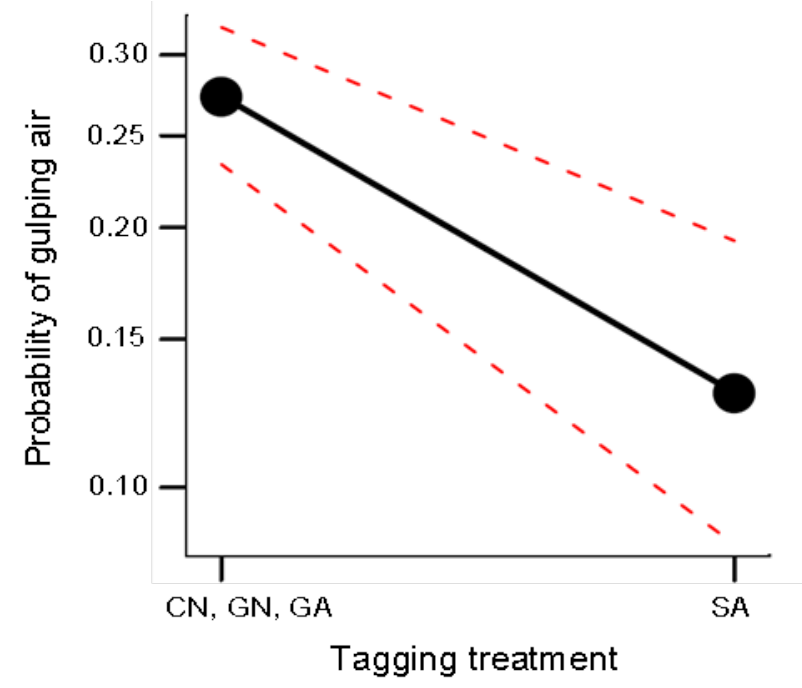

Figure 1.6. Graph showing probability and 95-percent confidence limits (dashed lines) of yearling Chinook salmon gulping air during laboratory swim tunnel trials by tagging treatments (pooled treatments $\mathrm{CN}, \mathrm{GA}, \mathrm{GN}$ and treatment SA). CN, untagged controls; GA, gastrically implanted tags with antenna; GN, gastrically implanted tag without antenna, and surgically implanted tag with antenna (SA). The $y$-axis has been adjusted to account for non-linearity in showing probability estimates on the observed scale.

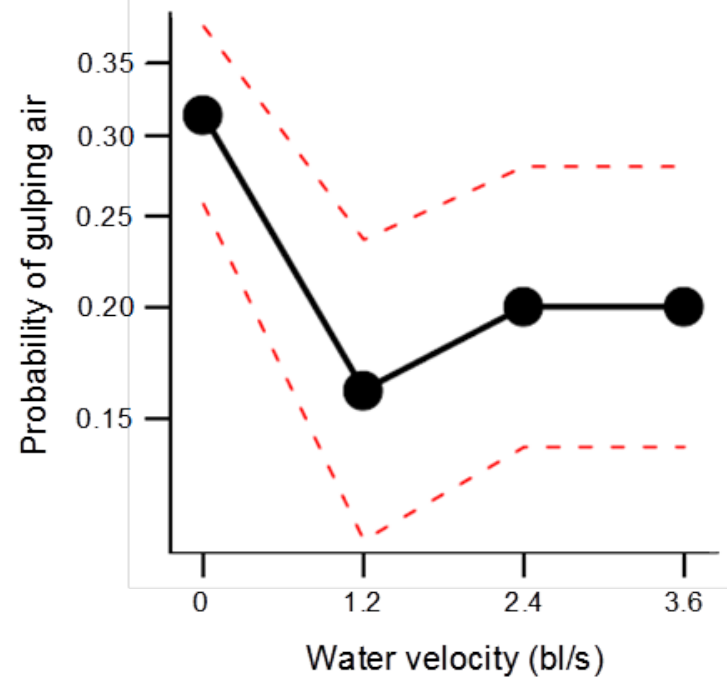

Figure 1.7. Graph showing probability and 95-percent confidence limits (dashed lines) of yearling Chinook salmon gulping air during laboratory swim tunnel trials with increasing water velocity. The y-axis has been adjusted to account for non-linearity in showing probability estimates on the observed scale. 
The probability of gulping air with respect to percent tag ratio indicated that fish with a 4 percent tag ratio gulped significantly less air during the swim tunnel trials than fish with lower or higher percent tag ratios (table 1.7; fig. 1.8). It is uncertain why fish with a 4 percent tag ratio gulped less air, and a number of potential unknowns could account for this observation. There was, however, a tendency for a higher probability of fish gulping air at higher percent tag ratios ( $>5$ percent) than at lower ( $<5$ percent) percent tag ratios, suggesting that smaller fish had greater difficulty in filling their air bladder than larger fish.

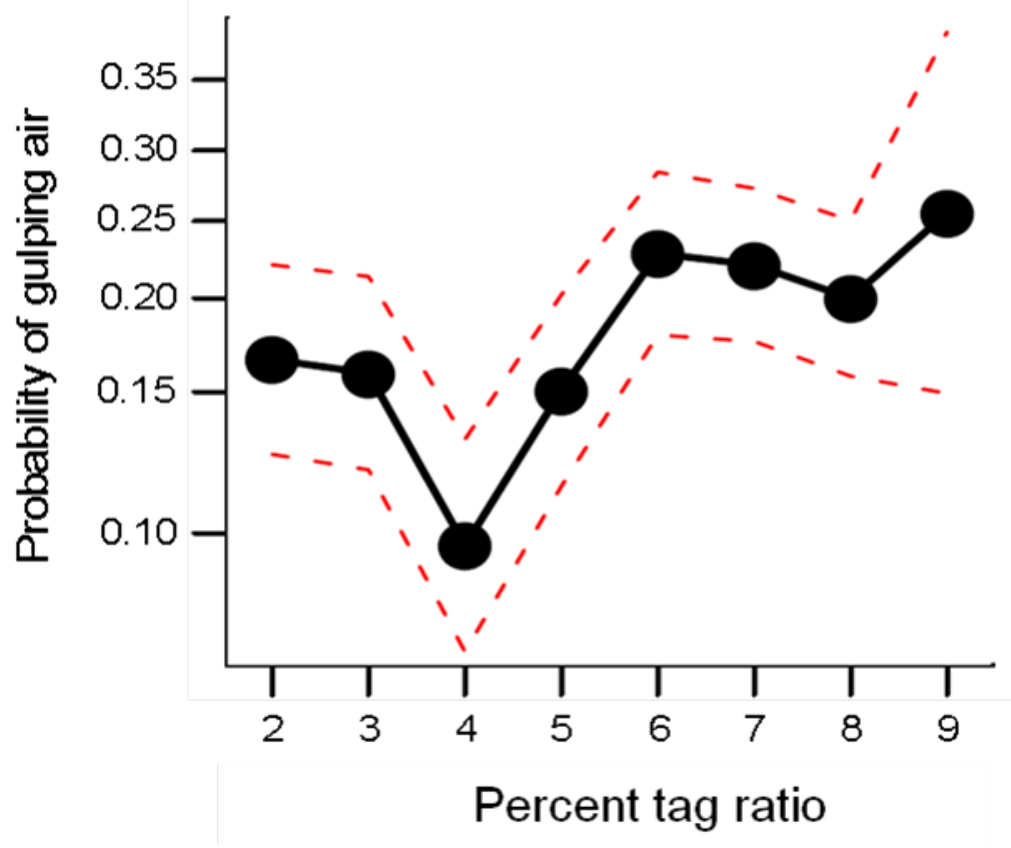

Figure 1.8. Graph showing probability and 95-percent confidence limits (dashed lines) of yearling Chinook salmon gulping air during laboratory swim tunnel trials with respect to percent tag ratio. The y-axis has been adjusted to account for non-linearity in showing probability estimates on the observed scale. 


\section{Swimming Angle in the Swim Tunnel}

Investigation of swimming angles of fish indicated significant effects of tagging treatment, water velocity, and percent tag ratio (table 1.8). Interaction $(P>0.13)$ between water velocity and treatment were not significant, and, therefore, the interaction term was removed from the model. Preliminary diagnostic plots indicated marked departure from linearity when velocity was treated as a continuous predictor; therefore, we treated velocity as a categorical predictor in the model. In this final model, mean swimming angle was significantly $(P<0.0380$; table 1.8) higher for gastric-tagged fish (i.e., GA and GN treatments) than for untagged fish (fig. 1.9). Fish in the SA treatment did not differ significantly $(P=0.3376$; table 1.8) from untagged controls, indicating that surgical implants had little effect on the swimming angle of fish. Estimates of swimming angle for gastric-tagged fish indicated that fish in the GA treatment had, on average, a $6.3^{\circ}$ increase in swimming angle over fish in the $\mathrm{CN}$ treatment, and although this was significant $(P=0.04)$, fish in the GN treatment had, on average, a much smaller $\left(2.4^{\circ}\right)$ increase in swimming angle compared to fish in the $\mathrm{CN}$ treatment. Thus, the greater swimming angle for gastric-tagged fish suggests that gastric tagging had an effect on swimming angle, but the more apparent increase in swimming angle for fish in the GA treatment suggests that the presence of an oral-protruding antenna may further alter swimming angles.

An increase in water velocity from 0 to $1.2 \mathrm{Bl} / \mathrm{s}$ resulted in a significant $(<0.0001)$ decrease in the swimming angle of fish. Water velocities of $1.2 \mathrm{Bl} / \mathrm{s}$ or greater resulted in a decrease in swimming angle of about $23.22-30.14^{\circ}$ (table 1.8 ). Thus, a small increase in water velocity of just $1.2 \mathrm{Bl} / \mathrm{s}$ greatly decreased the swimming angle of the fish (fig. 1.10).

Table 1.8. Generalized linear model (identity link function) comparing the swimming angle of yearling Chinook salmon by tagging treatment coefficient as a function of water velocity and percent tag ratios.

[Tagging treatment: $\mathrm{CN}$, untagged controls, GA, gastrically implanted tags with antenna, GN, gastrically implanted tags without antenna, SA, surgically implanted tags with antenna, water velocity (in body length per second [B1/s]), and percent tag ratio $(\%) .<$, less than]

\begin{tabular}{lccrrrr}
\hline $\begin{array}{c}\text { Tagging treatment } \\
\text { coefficients }\end{array}$ & Estimate & $\begin{array}{c}\text { Standard } \\
\text { error }\end{array}$ & $\begin{array}{c}\text {-95-percent } \\
\text { CL }\end{array}$ & $\begin{array}{c}\text { +95-percent } \\
\text { CL }\end{array}$ & t-value & P-value \\
\hline Intercept $(\mathrm{CN})$ & 26.23 & 1.53 & 23.24 & 29.23 & 17.17 & $<0.0001$ \\
Treatment-GA & 6.32 & 1.31 & 3.75 & 8.89 & 4.820 & $<0.0001$ \\
Treatment-GN & 2.47 & 1.18 & 0.15 & 4.79 & 2.085 & 0.0376 \\
Treatment-SA & 1.21 & 1.26 & -1.26 & 3.68 & 0.960 & 0.3376 \\
Velocity-1.2 Bl/s & -23.22 & 1.17 & -25.51 & -20.92 & -19.838 & $<0.0001$ \\
Velocity-2.4 Bl/s & -27.79 & 1.20 & -30.14 & -25.44 & -23.163 & $<0.0001$ \\
Velocity-3.6 B1/s & -30.14 & 1.23 & -32.55 & -27.72 & -24.455 & $<0.0001$ \\
Percent tag ratio (\%) & 0.62 & 0.22 & 0.19 & 1.06 & 2.788 & 0.0055 \\
\hline
\end{tabular}




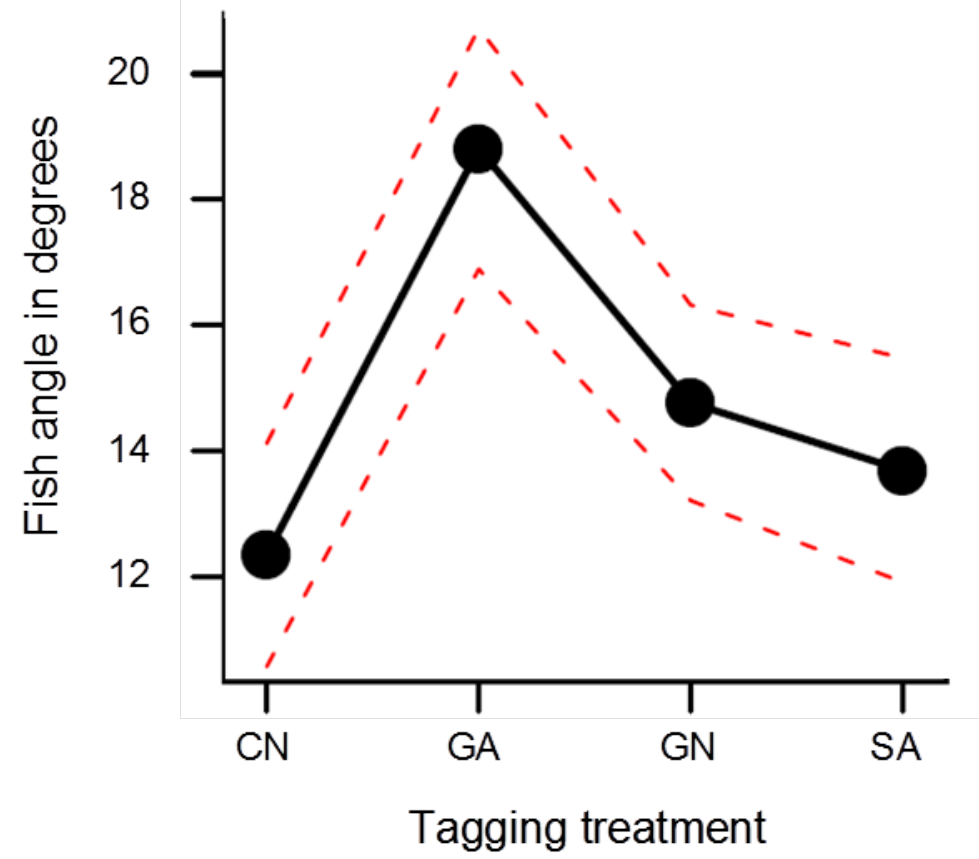

Figure 1.9. Graph showing fish swimming angle (degrees from horizontal) and 95-percent confidence limits (dashed lines) of yearling Chinook salmon during laboratory swim tunnel trials by tagging treatment. Controls $(\mathrm{CN})$, gastric implanted tags with antenna (GA), gastric implanted tags without antenna (GN), and surgically implanted tags with antenna (SA). 


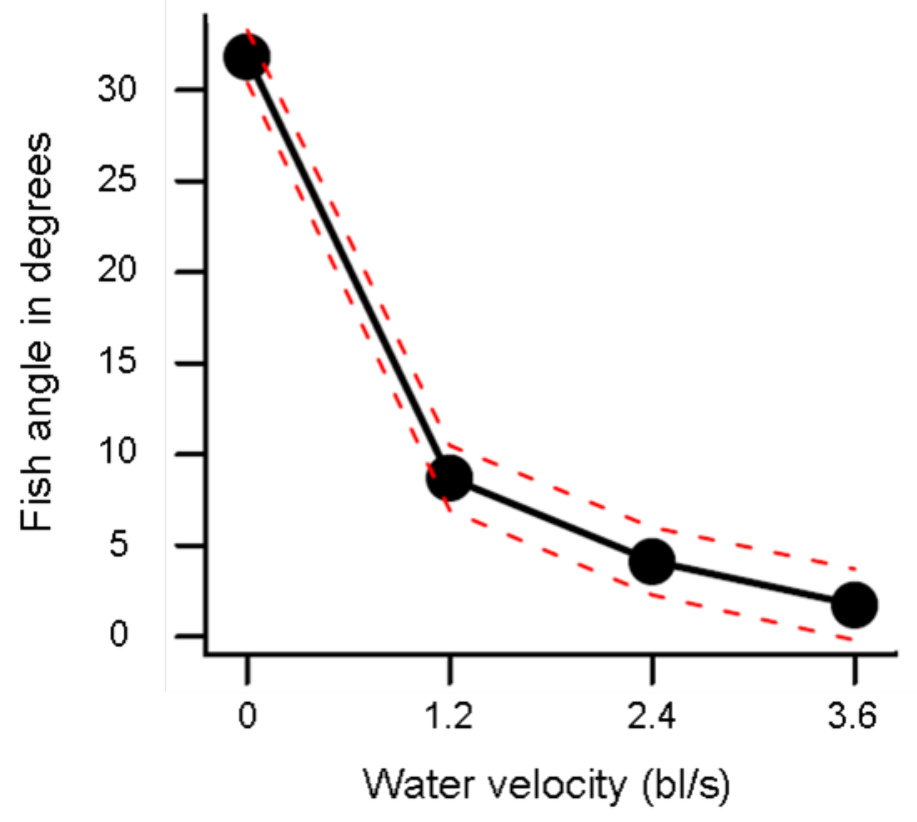

Figure 1.10. Graph showing fish swimming angle (degrees from horizontal) and 95-percent confidence limits (dashed lines) of yearling Chinook salmon during laboratory swim tunnel trials with increasing water velocity.

We found a significant $(P=0.0055)$ and positive effect of percent tag ratio on the swimming angle of fish (table 1.8). However, the effect of percent tag ratio on the swimming angle of fish was relatively small, with just a $0.62^{\circ}(\mathrm{SE}=0.22)$ increase in swimming angle for every 1 percent increase in percent tag ratio. Over the range of percent tag ratio, we observed an increase in swimming angle of about $4^{\circ}$ (fig. 1.11). 


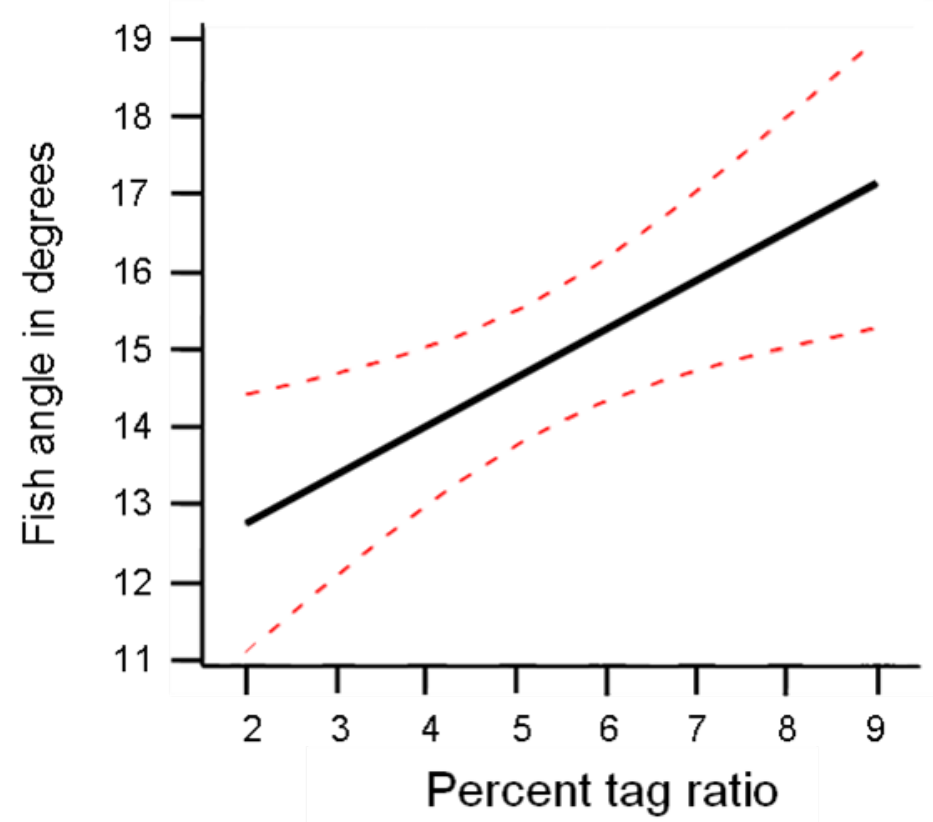

Figure 1.11. Graph showing fish swimming angle (degrees from horizontal) and 95-percent confidence limits (dashed lines) of yearling Chinook salmon during laboratory swim tunnel trials with respect to percent tag ratio.

\section{Resting Against the Screen in the Swim Tunnel}

Probabilities of fish resting against the screen at the back of the swim tunnel among the tagging treatments did not differ significantly $(P>0.180)$ from untagged controls (table 1.9). The effect of time (i.e., 5-min intervals) on the probability of fish resting against the screen at the back of the swim tunnel showed a significant $(P=0.002)$ difference between the 5-min time interval from 20 to $25 \mathrm{~min}$ compared to the time interval from 0 to $5 \mathrm{~min}$ (table 1.9). Thus, probabilities of resting against the screen at the back of the swim tunnel were not just a result of changes in water velocity, but also were likely dependent on the degree of exercise during the swim tunnel trials.

Table 1.9. Generalized linear model (logit link function) comparing the probability of yearling Chinook salmon resting against the screen at the back of the swim tunnel by tagging treatment coefficient.

[ Tagging treatment: $\mathrm{CN}$, untagged controls, GA, gastrically implanted tags with antenna, GN, gastrically implanted tags without antenna, SA, surgically implanted tags with antenna, water velocity (in body length per second [Bl/s], and percent tag ratio. $<$, less than]

\begin{tabular}{lccccccc}
\hline $\begin{array}{c}\text { Tagging treatment } \\
\text { coefficients }\end{array}$ & Estimate & $\begin{array}{c}\text { Standard } \\
\text { error }\end{array}$ & z-value & P-value & $\begin{array}{c}\text { Odds } \\
\text { ratio }\end{array}$ & $\begin{array}{c}\text { Odds ratio } \\
\text {-95-percent } \\
\text { CL }\end{array}$ & $\begin{array}{c}\text { Odds ratio } \\
\text { +95-percent } \\
\text { CL }\end{array}$ \\
\hline Intercept (CN) & -1.11 & 0.46 & -2.432 & 0.015 & 0.33 & 0.13 & 0.81 \\
Treatment-GA & -0.34 & 0.30 & -1.125 & 0.261 & 0.71 & 0.40 & 1.28 \\
Treatment-GN & -0.28 & 0.30 & -0.947 & 0.344 & 0.75 & 0.42 & 1.35 \\
Treatment-SA & -0.41 & 0.30 & -1.336 & 0.182 & 0.67 & 0.37 & 1.21 \\
Time-10 min & 2.79 & 0.40 & 7.002 & $<0.0001$ & 16.34 & 7.47 & 35.70 \\
Time-15 min & 3.82 & 0.42 & 9.179 & $<0.0001$ & 45.52 & 20.14 & 102.87 \\
Time-20 min & 4.41 & 0.44 & 10.056 & $<0.0001$ & 82.25 & 34.82 & 194.27 \\
Time-25 min & 1.27 & 0.42 & 3.037 & 0.002 & 3.55 & 1.57 & 8.04 \\
Percent tag ratio (\%) & -0.24 & 0.05 & -4.464 & $<0.0001$ & 0.79 & 0.71 & 0.88 \\
\hline
\end{tabular}


We also observed a significant $(P<0.0001)$ decrease in the probability of fish resting on the screen for a given increase in the percent tag ratio (table 1.9). Based on the odds ratio, there was 0.79 less chance of resting on the screen than not resting on the screen for every 1 percent increase in tag ratio. Thus, at a 2 percent tag ratio, the probability of resting against the screen was 0.65 , but at a 9 percent tag ratio, the probability of resting against the screen was 0.28 . This finding is a reasonable observation given that larger fish sizes inherently have higher drag and solid blocking effects (Bell and Terhune, 1970), which cause larger fish to experience higher velocities and greater resistance for a given water velocity than smaller fish. Thus, by virtue of size, larger fish, on average, appeared to be less efficient swimmers than smaller fish. Lower swimming efficiency for larger fish sizes would result in greater exhaustion, and, thus, higher probabilities of resting against the screen for larger fish.

\section{Discussion}

We conducted two laboratory tests that investigated the potential effects of transmitter type, tagging method, and fish body size on burst-swimming, swimming angle, air gulping, and exhaustive resting in yearling Chinook salmon. This study identified, however, that the effect of the tagging treatments depended on the behavioral response of interest. Pre- and post-tagging maximum burstswimming speeds differed among transmitter types and tagging methods, but the effects of transmitter type and tagging method on burst-swimming differed over the range in fish size. During the swim tunnel trials, surgical-tagged fish were significantly less likely to gulp air than control fish, but gastrictagged fish showed significantly greater swimming angles than control fish. Although we found significant effects of percent tag ratio on fish behavior, we found limited support for a size threshold where large effects on fish behavior may be expected above a given breakpoint in percent tag ratio. Based on post-trial necropsies of tagged fish, we did not observe any ruptured stomachs for gastrictagged fish with tag ratios less than 5 percent, and much of the differences in behavior over the range in percent tag ratios were observed for fish with tag ratios greater than 5 percent. Given this information, this study supports the conclusions of Adams and others (1998a, 1998b) that percent tag ratios of 5 percent or less likely have minimal impacts on juvenile Chinook salmon.

Estimation of burst-swimming speeds is perhaps the most ecologically relevant measure of swimming performance. Differences in burst-swimming speed may be directly related to the ability of a fish to avoid predators or areas of high water velocity near a dam. Post-tagging burst-swimming velocities were significantly slower than pre-tagging burst-swimming velocities for the SA and GN treatments, but we found no significant difference in pre- and post-tagging burst-swimming velocities for the $\mathrm{CN}$ and GA treatments. Although definitive conclusions cannot be made, small decreases in burst-swimming speed may be expected for acoustic and radio transmitters implanted into juvenile Chinook salmon using either gastric or surgical methods.

Differences in burst-swimming also were apparent. Fish in the SA and GN treatments had significant, but opposing trends in the difference between post- minus pre-burst-swimming speed over the range in percent tag ratio. The observation of a significant $\left(r^{2}=0.15, \mathrm{df}=40, P=0.01\right)$ increase in the differences in burst-swimming with increasing tag ratio within the GN treatment could have been spurious, which seems reasonable given the variation observed in the untagged controls. This observation also may indicate that we had an unidentified difficulty in estimating burst-swimming speeds when fish had an anterior protruding radio antenna. In contrast, surgical-tagged fish had a much stronger and more significant decrease $\left(r^{2}=0.21, \mathrm{df}=32, P=0.007\right)$ in burst-swimming speed after tagging than what was observed for gastric-tagged fish. There are several reasons one might expect a stronger relation between burst-swimming performance and fish size for surgical-tagged fish. First, surgical implantation was an invasive procedure and the proportion of wound size (incision length) 
relative to fish size was inherently larger for smaller fish. Thus, smaller fish had larger surgical wounds relative to larger fish. Second, the stomach and surrounding area are designed to accommodate some degree of expansion while feeding, whereas the peritoneal cavity is not. Surgical implantation of transmitters and the resulting peritoneal cavity expansion may have affected burst-swimming ability. Additionally, surgically tagged fish showed a stronger and more distinct decrease in burst-swimming performance with increasing tag ratio than gastrically tagged fish, especially within $1 \mathrm{~d}$ of tagging. Irrespective of the mechanisms, surgically tagged fish showed a distinct decrease of about $3.5 \mathrm{~cm} / \mathrm{s}$ in burst-swimming speed for every 1 percent increase in tag ratio. Although we could not detect departure from a linear trend, only fish with tag ratios less than 5 percent demonstrated post-tagging burst-swimming speeds greater than pre-tagging burst-swimming speeds. Based on this observation and the observation that surgical-tagged fish demonstrated a significant decrease in burst-swimming ability, surgical-tagged fish with tag ratios greater than 5 percent will likely have decreased burstswimming ability than those with tag ratios less than 5 percent. Thus, gastric and surgical treatments and radio and acoustic transmitters may cause slight decreases in burst-swimming speed, but decreased burst-swimming speed is most certain for surgical-tagged fish with tag ratios greater than 5 percent. In the swim tunnel trials, surgical-tagged fish gulped less air than untagged control or gastrictagged fish. We did not measure the amount of air that was gulped, but rather measured the occurrence of fish breaking the air-water interface at the surface of the swim tunnel. Therefore, this finding strongly infers that surgical-tagged fish were less likely to approach the surface as well as increase their air bladder volume. One hypothesis to explain this observation is a difference in perceived risk of predation. An injured fish (such a surgical-tagged fish) may be less likely to approach surface waters because of increased vulnerability to predators (because of injury) in an area (i.e., surface waters) where the risk of predation is perceived as high. This makes sense given that (1) an injured fish is likely more vulnerable to predators; (2) the perceived risk of predation can have an effect on animal behavior that is just as large, if not larger than, the actual act of predation itself (Lima and Dill, 1990); and (3) surface waters are more risky than deeper waters (i.e., they have more light and higher visibility for avian and piscivorous predators). Another hypothesis to explain lower probabilities of gulping air and surface visitation is that a transmitter could limit the expansion or impinge upon the posterior end of the air bladder, causing disproportionately less buoyancy at the posterior end of the fish. Thus, it is conceivable that if air bladder expansion is restricted towards the posterior, then filling the air bladder would disproportionately increase air bladder expansion and buoyancy towards the anterior, thereby promoting lift and the tendency for surgically tagged fish to pitch upwards when facing into current. Under this scenario, a surgically tagged fish would be less likely to fill its air bladder to avoid excess lift and pitching upwards when facing current. However, this hypothesis is not supported by our observation that smaller size fish with higher tag ratios were more likely to gulp surface air than were larger fish. Fish with tag ratios greater than 5 percent had higher probabilities of gulping air at the surface than fish with tag ratios less than 5 percent. Even though we are uncertain of the mechanisms that lead to reduced air gulps and surface visitation, our results clearly indicate that surgical-tagged juvenile Chinook salmon were less likely to gulp air and visit the surface of the swim tunnel than untagged control and gastric-tagged fish. 
Gastric-tagged fish, especially those with an antenna, exhibited significantly higher swimming angles (on average about 2.5-6 $6^{\circ}$ ) than untagged control fish. The finding that gastric-tagged fish without an antenna demonstrated higher (about $2.5^{\circ}$ ) swimming angles than untagged control fish suggests that the location of a gastric implant slightly shifts the center of mass of a fish towards the anterior. Furthermore, gastric-tagged fish with orally protruding antennas exhibited the highest mean swimming angles relative to untagged control fish. This result was not unexpected because greater pitch in the "head-up" direction would be needed to create extra lift and compensate for the extra drag and anterior weight of the antenna (Webb, 1975). Thus, gastric placement of a transmitter with an antenna appears to further shift a fish center of mass towards the anterior. Despite this observation, we did not find differences in the probability of gulping air or resting on the screen for gastric-tagged fish relative to untagged controls, suggesting that gastrictagging has little impact on the ability of a fish to fill its air bladder, visit the surface, or swim.

Other studies have concluded that surgical and gastric tagging has minimal impact on juvenile salmonids, and those that found differences were largely for gastric-tagged fish. McCleave and Stred (1975) found that sustained swimming performance of gastric-tagged juvenile Atlantic salmon, Salmo salar, was not affected for fish greater than $20 \mathrm{~cm}$, but swimming performance was reduced for larger tags and smaller fish. Similarly, Moser and others (1990) concluded that swimming performance, feeding, and aggressive behavior was unaltered in gastric-tagged juvenile coho salmon, $O$. kisutch, but the authors recommended that the smallest tag be used, because recovery-time for fish with relatively large transmitters was increased. Jepsen and others (2001) found that blood cortisol, lactate, and glucose levels in juvenile Chinook salmon spiked within $1 \mathrm{~d}$ of gastric and surgical tagging, but that blood chemistry returned to normal levels within $7 \mathrm{~d}$ of tagging.

Martinelli and others (1998) found few differences between surgical-tagged, gastric-tagged, and untagged juvenile Chinook salmon within $5 \mathrm{~d}$ of tagging, but after $21 \mathrm{~d}$, gastric-tagged fish had significantly lower plasma protein levels and growth compared to surgical-tagged and untagged fish. Similarly, Adams and others (1998a) noted that surgical- and gastric-tagged juvenile Chinook salmon less than $120 \mathrm{~mm}$ had significantly lower swimming speeds than untagged controls both 1 and $21 \mathrm{~d}$ after tagging. In contrast, gastric-tagged fish greater than $120 \mathrm{~mm}$ swam as well as controls $1 \mathrm{~d}$, but not at $21 \mathrm{~d}$, after tagging, whereas surgical-tagged fish swam as well as controls $21 \mathrm{~d}$, but not $1 \mathrm{~d}$, after tagging. Martinelli and others (1998) also concluded that travel times of gastric- and surgical-tagged juvenile Chinook salmon were similar through three reservoirs and dams on the Columbia River.

Although in situ travel times were slightly faster for gastric-tagged juvenile Chinook salmon, Hockersmith and others (2003) found little difference between gastric-tagged, surgical-tagged, and PIT-tagged travel times and survival within $6 \mathrm{~d}$ of release in the lower Snake River, but travel times were slightly faster for gastric-tagged fish than the other tagged groups. Thus, short-term effects on gastric-tagged juvenile salmonids likely are small, but long-term effects on growth and condition may be expected for gastric-tagged fish. In contrast, short-term effects on surgical-tagged fish may be expected, but surgical-tagged fish may perform better over longer periods. Thus, gastric tagging may be more suitable for short-term studies, but surgical tagging may be the preferred method for long-term studies. Our study supports the conclusion that gastric and surgical tagging has minimal impacts on the behavior and swimming performance of juvenile Chinook salmon, especially when tag ratios are less than 5 percent. 


\title{
Chapter 2. Sustained Swimming Performance of In-River Migrating Subyearling Chinook Salmon Surgically Implanted with Dummy Radio and Acoustic Transmitters
}

\author{
By John M. Plumb, Russell W. Perry, Scott D. Fielding, Dana J. Shurtleff, Sarah N. Lampson, and Nathan A. \\ Zorich
}

\section{Introduction}

Radio and acoustic telemetry can provide information on fish behavior over a range of spatial and temporal scales that are currently unobtainable through other methods. Furthermore, high detection capabilities and flexibility of use in the field make radio and acoustic telemetry attractive tools for fishery researchers. The primary assumption, however, for all telemetry studies is that the tagging method and transmitter have minimal impact on the animal being studied. Therefore, a number of studies have focused their attention on the potential impacts of transmitter attachment, especially on small fish (<200 mm) such as juvenile salmonids (McCleve and Stred, 1975; Fried and others, 1976; Moore and others, 1990; Moser and others, 1990; Adams and others, 1998a, 1998b; Brown and others, 1999; Jepsen and others, 2001; Perry and others, 2001; Anglea and others, 2004).

Most of the existing studies on transmitter effects were conducted in the laboratory, and provide limited information on the effects of transmitters on juvenile salmonids in the wild. During migration, juvenile salmonids undergo profound physiological changes and are faced with more challenging conditions than fish in the laboratory; therefore, tagging effects observed in the wild may differ from those observed in the laboratory. Two studies have investigated the impacts of transmitter attachment on juvenile salmonids in the wild (Martinelli and others, 1998; Hockersmith and others, 2003), and although very useful and informative, the scale and behavioral measures (i.e., travel time and survival over hours, days, and kilometers) of these studies are difficult to relate to other measures of behavior and performance commonly obtained in the laboratory (e.g., sustained or critical swimming speed).

The decision to use either radio or acoustic technology requires the trade-off between detection capabilities, the desired spatial resolution, and the effect of a given transmitter on the fish. For example, acoustic transmitters should provide greater detection capabilities because attenuation of sound waves through water is negligible in comparison to radio waves, thereby resulting in higher detection probabilities of acoustic transmitters compared to radio transmitters. Alternatively, acoustic telemetry cannot currently provide route-specific passage and survival estimates for fish passing through hydroelectric dams, yet radio telemetry can. The impact on fish behavior that antenna-less acoustic tags have relative to radio tags with external antennas also is subject to debate. If an antenna negatively impacts fish behavior, then absence of an antenna may reduce these impacts. Thus, researchers and managers must balance other issues of the available technology against uncertain transmitter effects. 
Sustained swimming performance has long been used as a proxy estimate for general fish health and well-being (Hammer,1995). It generally is assumed that maximum oxygen uptake occurs at the critical swimming speed (i.e., $U_{c r i t}$; Brett, 1964), and, thus, provides an indirect, but relatively close estimate of aerobic capacity of fish, enabling the quantification of sublethal effects on fish physiology and performance. Therefore, sustained swimming ability has been a primary measure used to judge the effects of transmitters on fish. Despite its common acceptance and use, however, sustained swimming ability is artificially produced, and is unlikely to be shown by fish in the wild. As a result, there is much difficulty in relating swimming performance tests obtained in the laboratory to observations of fish behavior in the wild.

Of the numerous studies that have investigated the effects of transmitters on sustained swimming ability of juvenile salmonids, only one study investigated fish from the wild (Robertson and others, 2003). However, this study was focused on transmitter effects on wild Atlantic salmon parr, Salmo salar, and did not investigate swimming performance during seaward migration. Atlantic salmon have demonstrated drastically different swimming abilities between parr and smolt status (Peake and McKinley, 1998). Out-migration to the ocean as a subyearling is a unique life history strategy for subyearling Chinook salmon (Oncorhynchus tshawytscha). Instead of overwintering and remaining in freshwater until spring, such as "stream-type" spring Chinook salmon do, the "oceantype" fall Chinook salmon out-migrates shortly after hatching, typically traveling and feeding in shallow and littoral areas while migrating towards the ocean during the summer months (i.e., late May-late July; Sauter and others, 2001; Connor and others, 2005). As a result, subyearling fall Chinook salmon are exposed to much higher water temperatures and lower water velocities than spring migrants. In addition to overcoming these environmental challenges, subyearling Chinook also must undergo smoltification, the profound changes in morphology, behavior, and physiology associated with readiness for the marine environment in salmonids. Given these environmental and physiological challenges, much is uncertain about how radio and acoustic transmitters may alter the in situ behavior and performance of subyearling Chinook salmon.

This research was designed to address these uncertainties by comparing critical swimming speeds of in-river migrating subyearling Chinook salmon tagged with dummy transmitters with (radio) and without (acoustic) external antennas to untagged controls over a range in fish size. Furthermore, this study used laboratory methods in a field-based setting to estimate critical swimming speeds of inriver migrating subyearling Chinook salmon. Thus, commonly used laboratory measures of fish performance were applied to fish in the wild, thereby providing insight into the impacts of different transmitter types on in situ performance of this unique salmonid life history.

\section{Methods}

\section{Fish Collection and Tagging at John Day Dam}

This field-based laboratory study was conducted at the John Day Juvenile Bypass Facility on the Columbia River. John Day Dam is located about 347 river kilometers from the Pacific Ocean in Washington and Oregon. The study was conducted from June 27, 2005, to August 11, 2005. Subyearling Chinook salmon were obtained from Juvenile Bypass personnel as part of normal daily operations at the facility. 
Fish selected for the study were held in 19-L buckets submerged in recovery tanks supplied with flowing river water for about 19-29 h prior to tagging. Fish selected for test trials were held at densities of 0.16 fish/L or less. All study tanks were supplied with flowing river water, and fish containers for all experiments were perforated to ensure water circulation. Temperatures increased gradually during the study, and ranged from 18.4 to $23.4{ }^{\circ} \mathrm{C}$ with a mean temperature of $21.1^{\circ} \mathrm{C}$ $(\mathrm{SE}=0.10)$. Fish of appropriate size were considered suitable for tagging if they were free of visible injuries and disease (e.g., gas bubble trauma), 20 percent or less of them were descaled, and they had no other abnormalities. Fish were assigned to a size category and then randomly allocated among the treatments and swim tubes.

Fish were tagged with dummy radio transmitters supplied by Lotek Wireless Incorporated ${ }^{\complement}$, Newmarket, Ontario, Canada (table 2.1). We weighed the mass in air, water, and volume of the individual dummy transmitters, and found slightly different weights and volumes between the transmitter types (i.e., radio with antenna compared to acoustic without antenna). Dummy transmitters without an antenna were, on average, $0.08 \mathrm{~g}$ (or 16 percent) heavier and $0.04 \mathrm{~mL}$ (or 18 percent) larger than dummy transmitters with an antenna.

Table 2.1. Weight in air and water,and volume, and antenna length for dummy radio (with antenna) and acoustic (without antenna) transmitters implanted into in-river migrating subyearling Chinook salmon at John Day Dam, Oregon and Washington, 2005.

[Standard error about the mean specification is shown in parentheses. n/a, not applicable. Dummy transmitters were supplied by Lotek Wireless Incorporated ${ }^{\odot}$, New Market Ontario, Canada]

\begin{tabular}{llllc}
\hline \multicolumn{1}{c}{ Transmitter model } & $\begin{array}{c}\text { Weight } \\
\text { in air } \\
\text { (grams) }\end{array}$ & $\begin{array}{c}\text { Weight } \\
\text { in water } \\
\text { (grams) }\end{array}$ & $\begin{array}{c}\text { Volume } \\
\text { (milliliters) }\end{array}$ & $\begin{array}{c}\text { Antenna } \\
\text { length } \\
\text { (centimeters) }\end{array}$ \\
\hline $\begin{array}{l}\text { NTC-M-2-ANT } \\
\text { (Tag with S1 antenna) }\end{array}$ & $0.42(0.01)$ & $0.24(0.02)$ & $0.18(0.02)$ & 18 \\
$\begin{array}{l}\text { NTC-M-2-NOANT } \\
\text { (Tag without antenna) }\end{array}$ & $0.50(0.04)$ & $0.28(0.03)$ & $0.22(0.01)$ & $\mathrm{n} / \mathrm{a}$ \\
\hline
\end{tabular}

To surgically implant dummy transmitters, fish were individually anesthetized using buffered tricane methanesulfonate (MS-222) at a dosage of $60 \mathrm{mg} / \mathrm{L}$. One minute after losing equilibrium, fish were removed from the anesthetic solution, placed in a weigh boat sprayed with diluted Stress Coat ${ }^{\circledR}$, weighed to the nearest $0.1 \mathrm{~g}$, and measured to the nearest millimeter (fork length, FL). Fish were then surgical tagged using methods similar to those described by Adams and others (1998a). Immediately following the tagging procedure, fish were individually placed in recovery buckets filled with $7 \mathrm{~L}$ of water and supplied with bottled oxygen for a minimum of $10 \mathrm{~min}$. To recover from tagging, buckets containing fish were submerged in outdoor insulated holding tanks (3,100 L) supplied with flowing river water and were held for 19-32 h before testing. 
Two Blazka type respirometers with 0.5-horsepower variable speed motors were used to test run-of-the-river subyearling Chinook salmon at the John Day Juvenile Bypass Facility. The swimming area of the two tubes measured $1.65 \mathrm{~L}$ (tube A) and $1.95 \mathrm{~L}$ (tube B). To calculate velocities at seven different motor speeds, we used pitot tubes and Bernoulli's equation:

$$
V=\sqrt{2 g H v}
$$

where

$$
\begin{aligned}
\mathrm{g} & \text { is } 9.8 \mathrm{~m} / \mathrm{s} \text { and } \\
\mathrm{Hv} & \text { is velocity in meters of head. }
\end{aligned}
$$

Water velocity was then related to motor speed with a linear regression equation.

For measuring the swimming performance of subyearling Chinook, we tested four groups based on fish size:

1. $83-90 \mathrm{~mm}(5.9-7.7 \mathrm{~g})$,

2. $90-102 \mathrm{~mm}(7.7-11.1 \mathrm{~g})$,

3. $102-123 \mathrm{~mm}(11.1-20.0 \mathrm{~g})$, and

4. $123-144 \mathrm{~mm}(20.0-33.3 \mathrm{~g})$.

Fish were placed in the swim tubes to acclimate for $30 \mathrm{~min}$ at water velocities of $2.0 \mathrm{Bl} / \mathrm{s}$. We used the ramped $U_{\text {crit }}$ protocol established by Jain and others (1997). Under this protocol, velocities are initially increased at a constant rate from $2.0 \mathrm{Bl} / \mathrm{s}$ to between 3.0 and $5.0 \mathrm{Bl} / \mathrm{s}$ over a period of $8-15 \mathrm{~min}$. Velocities are then increased by $0.5 \mathrm{Bl} / \mathrm{s}$ every $15 \mathrm{~min}$ until fish reached fatigue. To calculate $U_{\text {crit }}$ (in centimeters per second) we used the following equation:

$$
U_{\text {crit }}=\mathrm{V}_{\mathrm{p}}+\left(\left(\mathrm{t}_{\mathrm{f}} / \mathrm{t}_{\mathrm{i}}\right) \cdot \mathrm{V}_{\mathrm{i}}\right)
$$

where

$$
\begin{array}{ll}
V_{i} & \text { is the velocity increment in centimeters per second, } \\
V_{p} & \text { is the maximum velocity where the fish swam the entire interval in centimeters per } \\
& \text { second, } \\
t_{f} & \text { is the elapsed time from the velocity increase to fatigue in minutes, and } \\
t_{i} & \text { is the time interval in minutes. }
\end{array}
$$

Because the existing literature commonly presents $U_{\text {crit }}$ in both centimeters per second and body lengths per second $(\mathrm{Bl} / \mathrm{s})$, we present $U_{\text {crit }}(\mathrm{Bl} / \mathrm{s})$ by dividing $U_{\text {crit }}$ (centimeters per second ) by the fork length (centimeters) of the fish. We did not correct for solid blocking (Bell and Terhune, 1970) because cross-sectional areas for all our fish were less than 10 percent of the cross-sectional area of the swim tubes (Brett, 1964). 


\section{Data Analysis}

We used analysis of covariance (ANCOVA) to investigate factors affecting critical swimming speeds (i.e., $U_{\text {crit }}$, in centimeters per second) of in-river migrating subyearling Chinook salmon at John Day Dam. We chose to model $U_{\text {crit }}$ in centimeters per second rather than body lengths per second because division of absolute swimming speeds by the length of the fish inherently introduces dependence (i.e., lack of independence) between the response and morphological predictors (i.e., fish length or weight) in the model. Including fish size as a predictor to explain $U_{\text {crit }}$ in body lengths per second can inadvertently alter and drive a relation between the response and predictor that is not necessarily the result of a measured effect. Moreover, absolute swimming speeds may be more ecologically relevant than relative swimming speeds. For example, the outcome of predator-prey interactions is more likely to depend on the absolute ability of a fish to swim a given distance than its ability to swim relative to its size over a given distance. Because of this, we chose to model $U_{\text {crit }}$ in centimeters per second rather than body lengths per second, but because much of the literature is reported in body lengths per second, we also present $U_{\text {crit }}$ in body lengths per second in summary statistics.

We used ANCOVA for analysis because boxplots of the data and statistical tests did not indicate a marked departure from normality (Shapiro-Wilk test, $W=0.989, P=0.223$ ) within each treatment or difference in variance (Bartlett's test, $K^{2}=3.463, \mathrm{df}=2, P=0.177$ ) among treatments. We used continuous and categorical predictors to test hypotheses and assess linear trends between the response and predictor variables. We tested the hypothesis that variation in $U_{\text {crit }}$ (centimeters per second) of surgical-tagged subyearling Chinook salmon would not differ from untagged controls. The tagging treatments were (1) untagged controls $(\mathrm{CN}),(2)$ surgical-tagged fish with a tag with an antenna (SA), and (3) surgical-tagged fish with a tag without an antenna (SN). The effect of tagging was treated as a class factor with three levels. The untagged fish (CN treatment) were used as the reference for comparison, so conclusions from statistical tests are based on the differences between the tagged fish in contrast to the untagged control fish.

Critical swimming performance and the effects of transmitter attachment on juvenile salmonids also may be explained by fish size (Brett, 1964; Hammer, 1995; Adams and others, 1998a, 1998b; Mesa and others, 2004). We could not use a relative measure of tag size to fish size in our comparisons involving untagged controls because the different sized dummy transmitters precluded a common numerator in estimating a tag ratio for the untagged controls. Therefore, we included fish weight as a continuous covariate in our analysis. Given that the transmitter types were of slightly different weights, differences in $U_{c r i t}$ as a result of transmitter differences should be apparent over the range in fish weight. Including either fish weight or length in the analysis was equivocal because fish weight and length are inherently related. We chose to include only weight in the same analysis to avoid collinearity between length and weight.

We also considered swim tube (A or B), water temperature, and day of the year as additional factors to include the analysis. Swim tube was included as a class factor with two levels (i.e., tubes A and B) to account for possible tube effects because of their slightly different size. Water temperature was included in our analysis because physiology, behavior, and fitness of temperate freshwater fishes are known to be affected by the temperatures that fish occupy (Magnuson and others, 1979; Crowder and Magnuson, 1983). Although change over time in physiology and travel time have been documented for in-river migrating juvenile salmonids (Zaugg and Wagner, 1973; Muir and others, 1994), we did not include day of year in the analysis. On initial inspection of the data, we determined that water temperature and day of year were highly correlated, which resulted in high variance inflation factors (>10; Quinn and Keough, 2005) and a likely problem with collinearity. Moreover, attempts to center these variables relative to their mean did not reduce the variance inflation factors. 
Therefore, we chose to include water temperature in the analysis rather than day of year because water temperatures are known to be important to sustained swimming ability of fish (Brett, 1967; Bernatchez and Dodson, 1985; Hammer, 1995; Webb, 1998) as well as fish physiology, behavior, and fitness (Magnuson and others, 1979; Crowder and Magnuson, 1983; Jepsen and others, 2001). Inclusion of these categorical and continuous predictors in the analysis yielded the following model:

$$
U_{\text {crit }}=(\beta 0)+\mathrm{WT}(\beta 1)+\mathrm{TRT}(\beta 2)+\mathrm{TUBE}(\beta 3)+\mathrm{TEMP}(\beta 4) .
$$

where
$U_{\text {crit }}$
is the mean response for critical swimming performance, in centimeters per second,
$\beta_{0}$
$\beta_{1-4}$ is the intercept, and
WT are the respective model coefficients for fish weight, in grams,
TRT is tagging treatment (i.e., $\mathrm{CN}, \mathrm{SA}$, and $\mathrm{SN}$ ),
TEMP is swim tube (A or B), TUBE and is water temperature, in degrees Celsius).

We also checked for interactions among the predictors by including the following interaction terms: (1) TRT*TUBE, (2) TRT*WT, (3) TRT*TEMP, (4) TUBE*TEMP, (5) TUBE*WT, and (6) $\mathrm{WT}^{*} \mathrm{TEMP}$. Interaction terms are inherently related to other variables within the model; therefore, when including interaction terms in a model, one introduces the potential for problems with collinearity. Initial diagnostics of the model including all predictors and interactions indicated variance inflation factors greater than 200 and a problem with collinearity. To address this, we centered the continuous predictors relative to their mean, resulting in variance inflation factors of 8 or less, and greatly resolving potential problems with collinearity.

To assess whether the small difference $(0.08 \mathrm{~g})$ between the dummy acoustic and radio transmitters might confound our conclusions with respect to an "antenna effect", we subset the data to include just the tagged individuals. We then used the same statistical approach and procedures as above, but used the ratio of tag weight (in air) to fish weight (in air; hereinafter referred to as tag ratio) in the analysis instead of fish weight. The tag ratio was estimated by dividing the weight of the transmitters (table 2.1) by the weight of the fish. Using tag ratio instead of fish weight in the analysis controls for differences in tag weight with respect to fish size and thus eliminates confounding between differences in tag weight and presence or absence of an antenna. Taking into account tag weight relative to fish weight also provides an assessment of whether or not the small difference in tag weight between the transmitter types might alter our conclusions.

\section{Results}

Over the course of the study, we tested sustained swimming performance in 56 untagged controls, 55 surgical-tagged fish with an antenna, and 56 surgical-tagged fish without an antenna. Our total 24-h post-tagging mortality was three subyearling Chinook salmon. Of these mortalities, one was implanted with a dummy transmitter with an antenna, and two mortalities were implanted with dummy transmitters without an antenna. Fish sizes were similar among tagging treatments, and ranged from 5.5 to $29.8 \mathrm{~g}$ (table 2.2). A statistical comparison of fish weights indicated no significant interaction between tagging treatment and swim tube $(\mathrm{F} 2,161=0.40, P=0.669)$, no significant difference in fish weight between tagging treatments $(\mathrm{F} 2,161=0.35, P=0.707)$, and no significant difference in weight between swim tubes $(\mathrm{F} 2,161=0.13, P=0.718)$. 
Overall, sustained swimming performance of subyearling Chinook salmon ranged from 39.6 to $100.5 \mathrm{~cm} / \mathrm{s}$ for untagged control fish, from 46.3 to $86.4 \mathrm{~cm} / \mathrm{s}$ for surgical-tagged fish with an antenna, and from 41.6 to $83.1 \mathrm{~cm} / \mathrm{s}$ for surgical-tagged fish without an antenna (table 2.3). Mean sustained swimming speeds in each swim tube and treatment suggested little difference between swim tubes (table 2.3, fig. 2.1). However, boxplots of the data suggested slightly lower minimum, maximum, and median $U_{\text {crit }}$ for both treatments of tagged fish compared to untagged controls (fig. 2.1). Thus, summary statistics suggested no effect of swim tube, but an effect of the transmitter on the swimming performance of subyearling Chinook salmon.

Statistical results of the full model including all predictors and interaction terms suggested significant main effects of tagging treatment, fish weight, and temperature on swimming performance. Importantly, none of the interactions were significant $(P>0.24$ for all interactions except for Tube*Temperature, where $P=0.054)$. Specifically, we did not find a significant interaction between temperature and treatment, indicating that temperatures beyond the thermal optimum of the species do not disproportionately affect the swimming performance of tagged fish more than that of untagged fish. Therefore, we removed interaction terms from the analysis and ran the ANCOVA again with only the main effects and continuous predictors on the observed scale (i.e., not centered about the mean). Although this final model was significantly $(P<0.0001)$ fit to the data, it explained just one-fifth of the variation $\left(r^{2}=0.20\right.$; table 2.4), suggesting a large degree of individual-specific variation in sustained swimming performance.

Table 2.2. Summary statistics of weight and fork length for in-river migrating subyearling Chinook salmon used in sustained swimming performance tests at John Day Dam, Washington and Oregon, 2005.

[Tagging treatment: $\mathrm{CN}$, untagged controls, SA, surgical-tagged fish with an antenna, and SN, surgical-tagged fish without an antenna]

\begin{tabular}{|c|c|c|c|c|c|c|}
\hline \multirow{2}{*}{$\begin{array}{l}\text { Tagging } \\
\text { treatment }\end{array}$} & \multirow{2}{*}{ Swim tube } & \multirow{2}{*}{$\begin{array}{l}\text { Number } \\
\text { of fish } \\
\text { tested }\end{array}$} & \multicolumn{4}{|c|}{ Weight (grams) and fork length (millimeters, in parentheses) } \\
\hline & & & Mean & $\begin{array}{l}\text { Standard } \\
\text { deviation }\end{array}$ & Minimum & Maximum \\
\hline \multirow[t]{2}{*}{$\mathrm{CN}$} & A & 22 & $15.0(107.5)$ & $7.3(16.1)$ & $6.8(85)$ & $29.7(135)$ \\
\hline & B & 34 & $13.5(103.8)$ & $6.6(16.1)$ & $5.5(84)$ & $25.4(132)$ \\
\hline \multirow[t]{2}{*}{ SA } & A & 25 & $14.7(106.0)$ & $6.5(15.9)$ & $7.1(81)$ & $27.5(133)$ \\
\hline & B & 30 & $15.7(108.6)$ & $7.8(18.4)$ & $7.2(86)$ & $29.8(139)$ \\
\hline \multirow[t]{2}{*}{ SN } & A & 33 & $15.0(108.0)$ & $6.9(15.9)$ & $6.9(85)$ & $29.2(136)$ \\
\hline & B & 23 & $14.6(106.1)$ & $8.1(18.0)$ & $6.3(84)$ & $29.6(136)$ \\
\hline
\end{tabular}


Table 2.3. Summary statistics for sustained swimming speeds, $U_{\text {crit }}$, of subyearling Chinook salmon at John Day Dam, Washington and Oregon, during downstream migration in 2005.

[Tagging treatment: $\mathrm{CN}$, untagged controls, SA, surgical-tagged fish with an antenna, and SN, surgical-tagged fish without an antenna]

\begin{tabular}{|c|c|c|c|c|c|c|}
\hline \multirow{2}{*}{$\begin{array}{l}\text { Tagging } \\
\text { treatment }\end{array}$} & \multirow{2}{*}{ Swim tube } & \multirow{2}{*}{$\begin{array}{l}\text { Number of } \\
\text { fish tested }\end{array}$} & \multicolumn{4}{|c|}{$\begin{array}{l}\text { Sustained swimming speeds, in centimeters per second } \\
\text { (in body lengths per second in parentheses) }\end{array}$} \\
\hline & & & Mean & $\begin{array}{l}\text { Standard } \\
\text { deviation }\end{array}$ & Minimum & Maximum \\
\hline $\mathrm{CN}$ & $\begin{array}{l}\text { A } \\
\text { B }\end{array}$ & $\begin{array}{l}22 \\
34\end{array}$ & $\begin{array}{c}71.0 \\
(7.0) \\
73.7 \\
(7.3)\end{array}$ & $\begin{array}{l}14.5 \\
(1.6) \\
12.3 \\
(1.5)\end{array}$ & $\begin{array}{c}39.6 \\
(4.4) \\
45.0 \\
(5.0)\end{array}$ & $\begin{array}{c}89.9 \\
(10.3) \\
100.5 \\
(10.8)\end{array}$ \\
\hline SA & $\begin{array}{l}\text { A } \\
\text { B }\end{array}$ & $\begin{array}{l}25 \\
30\end{array}$ & $\begin{array}{l}62.7 \\
(6.3) \\
65.9 \\
(6.3)\end{array}$ & $\begin{array}{c}10.8 \\
(0.9) \\
9.7 \\
(1.1)\end{array}$ & $\begin{array}{c}46.3 \\
(4.3) \\
47.8 \\
(4.1)\end{array}$ & $\begin{array}{c}85.8 \\
(7.8) \\
86.4 \\
(8.5)\end{array}$ \\
\hline SN & $\begin{array}{l}\text { A } \\
\text { B }\end{array}$ & $\begin{array}{l}33 \\
23\end{array}$ & $\begin{array}{c}63.6 \\
(6.3) \\
65.0 \\
(6.3) \\
\end{array}$ & $\begin{array}{c}11.8 \\
(1.0) \\
10.8 \\
(1.1)\end{array}$ & $\begin{array}{c}41.6 \\
(4.1) \\
44.4 \\
(3.6) \\
\end{array}$ & $\begin{array}{c}80.7 \\
(8.2) \\
83.1 \\
(8.3) \\
\end{array}$ \\
\hline
\end{tabular}

Table 2.4. Analysis of covariance showing the sum of squares, degrees of freedom, mean square, $F$-statistic, $P$ value, and coefficient of determination $\left(r^{2}\right)$ of the multiple regression predicting swimming performance $\left(U_{\text {crit, }}\right)$ of subyearling Chinook salmon at John Day Dam, Washington and Oregon, 2005.

$\left[\boldsymbol{r}^{2}\right.$, coefficient of determination]

\begin{tabular}{lrccccc}
\hline \multicolumn{1}{c}{ Source } & $\begin{array}{c}\text { Sum of } \\
\text { squares }\end{array}$ & $\begin{array}{c}\text { Degrees of } \\
\text { freedom }\end{array}$ & Mean square & F-value & $P$-value & $\boldsymbol{r}^{2}$ \\
\hline Model & $5,007.0$ & 5 & $1,001.4$ & 8.1 & $<0.0001$ & 0.20 \\
Residual & $19,781.6$ & 161 & 122.9 & - & - & - \\
\hline
\end{tabular}




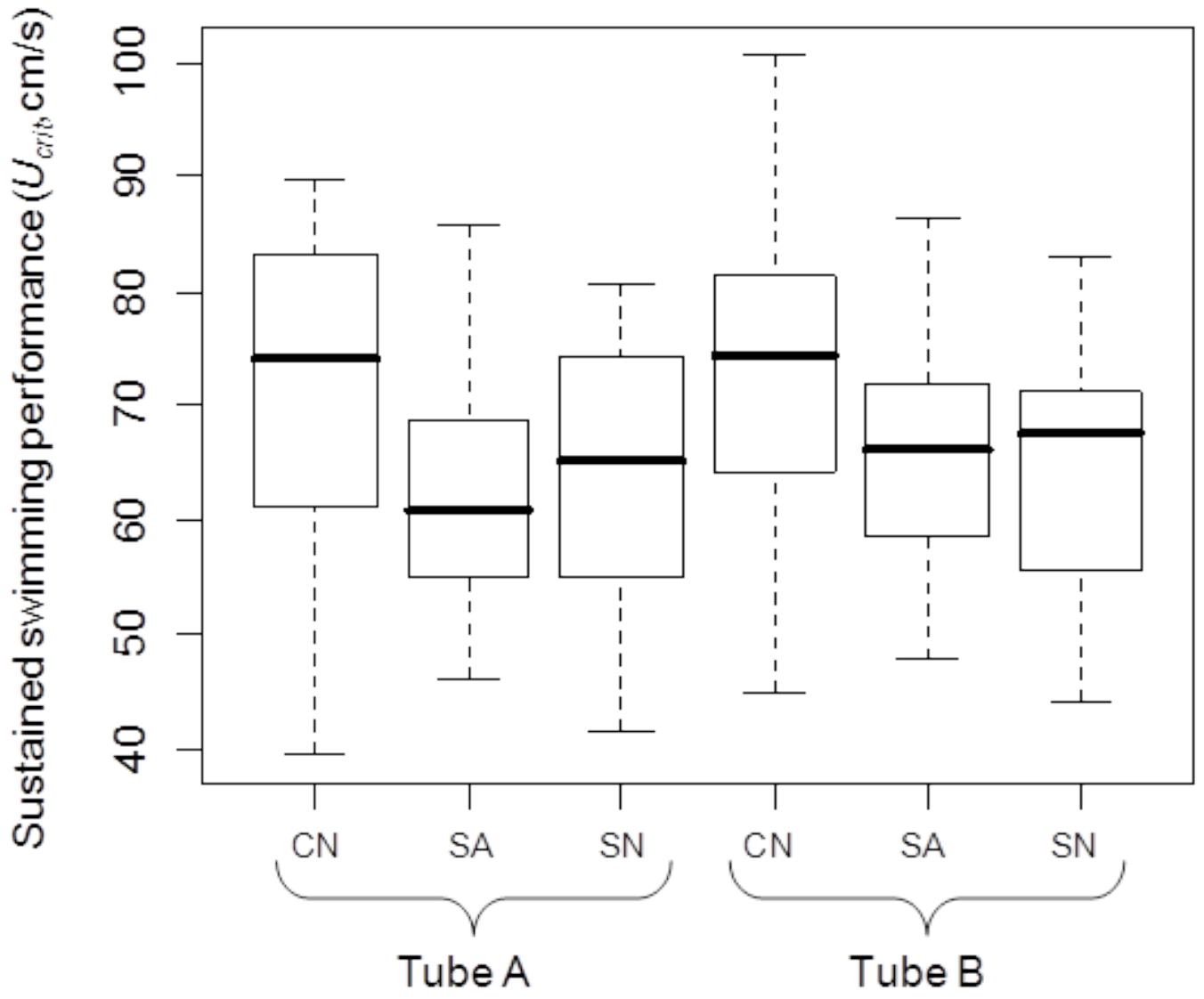

Figure 2.1. Boxplots showing distributions of sustained swimming performance for in-river migrating subyearling Chinook salmon by swim tube and tagging treatment at John Day Dam, Washington and Oregon, 2005. CN, untagged controls; (SA, surgical-tagged fish with an antenna; and SN, surgical-tagged fish without an antenna. Boxplots show the medians (thick lines within boxes), the 25th and 75th percentiles (lower and upper boundaries of boxes), and the minimum and maximum (lower and upper ends of whiskers) of each distribution.

We found a significant $(P<0.0001)$ effect of tagging on $U_{\text {crit }}$ of subyearling Chinook salmon relative to untagged controls (table 2.5). Both the SA and SN treatments had critical swimming speeds of 8.4 and $8.2 \mathrm{~cm} / \mathrm{s}$ less than untagged controls, supporting our observations from the summary statistics (table 2.3). Based on the similar parameter estimates and overlapping 95-percent CL for each of the tagging treatments relative to controls, we did not observe a significant effect of antenna presence on the swimming performance of subyearling Chinook salmon. Building a subset of our analysis to include just the surgical-tagged fish and using tag ratio to account for differences in tag size relative to fish size supported the conclusion that antenna presence had an equivocal effect on $U_{\text {crit }}$. After controlling for tag ratio, the parameter estimates from this model showed that tagged fish without an antenna exhibited mean $U_{\text {crit }}$ that was $2.2 \mathrm{~cm} / \mathrm{s}(\mathrm{SE}=1.95)$ greater than tagged fish with an antenna. However, this small difference was not statistically significant ( $\mathrm{df}=106, t=1.11, P=0.27)$. Thus, even when differences in tag size relative to fish size were accounted for, we were unable to detect an effect of an antenna on sustained swimming performance. 
Table 2.5. Statistical results for analysis of covariance comparing critical swimming speeds $\left(U_{\text {crit, }}\right)$ of subyearling Chinook salmon that passed John Day Dam, Oregon and Washington, 2005.

[Coefficients: Results for TUBE (B) are in relation to TUBE (A), and results for TRT (SA and SN) are in relation to untagged controls $(\mathrm{CN})$. WT, fish weight, in grams; TEMP, water temperature, in degrees Celsius]

\begin{tabular}{lrccccr}
\hline \multicolumn{1}{c}{ Coefficients } & Estimate & $\begin{array}{c}\text { Lower 95- } \\
\text { percent CL }\end{array}$ & $\begin{array}{c}\text { Upper 95- } \\
\text { percent CL }\end{array}$ & $\begin{array}{c}\text { Standard } \\
\text { Error }\end{array}$ & t-value & \multirow{P}{*}{-value } \\
\hline Intercept (Tube A, CN) & 92.87 & 66.10 & 119.64 & 13.7 & 6.80 & $<0.0001$ \\
TUBE (B) & 2.92 & -0.50 & 6.35 & 1.75 & 1.67 & 0.0964 \\
TRT (SA) & -8.41 & -12.55 & -4.26 & 2.11 & -3.98 & 0.0001 \\
TRT (SN) & -8.27 & -12.44 & -4.11 & 2.12 & -3.89 & 0.0001 \\
WT & 0.50 & 0.26 & 0.75 & 0.12 & 4.03 & $<0.0001$ \\
TEMP & -1.38 & -2.67 & -0.08 & 0.66 & -2.09 & 0.0383 \\
\hline
\end{tabular}

We found a significant and positive effect of fish size on critical swimming performance (table 2.5). Thus, for every $1 \mathrm{~g}$ increase in fish weight, we observed an average increase in $U_{\text {crit }}$ of $0.5 \mathrm{~cm} / \mathrm{s}$. Although the effect of fish weight on $U_{\text {crit }}$ was significant, the effect of size also was relatively small, resulting in a decrease in $U_{\text {crit }}$ of about $14 \mathrm{~cm} / \mathrm{s}$ over the total range of fish weights. We also found a decrease in critical swimming performance with increasing water temperature (table 2.5). The change in $U_{\text {crit }}$ with temperature was $-1.38 \mathrm{~cm} / \mathrm{s}$ for every increase of $1{ }^{\circ} \mathrm{C}$, resulting in a total decrease in $U_{c r i t}$ of about $6.9 \mathrm{~cm} / \mathrm{s}$ over the observed range in temperature. The range of temperature in this study, however, was relatively small $\left(5^{\circ} \mathrm{C}\right)$ and was highly correlated with day of year. Thus, it is difficult to say whether water temperature by itself leads to the decrease in $U_{\text {crit }}$ observed in this study.

Nonetheless, based on these findings, we infer that increases in water temperature (i.e., greater than the thermal optimum for this species) may contribute to decreased swimming performance during seaward migration.

\section{Discussion}

This study presents the first empirical estimates of sustained swimming performance for inriver migrating juvenile Chinook salmon tagged with dummy radio and acoustic transmitters. Our ANCOVA model explained just 20 percent of the variation in $U_{\text {crit, }}$, indicating a large degree of individual-specific variation in sustained swimming performance. Despite this variation, however, many important factors were statistically significant (table 2.5). We found a significant decrease in $U_{\text {crit }}$ (about $8.3 \mathrm{~cm} / \mathrm{s}$ or $1 \mathrm{Bl} / \mathrm{s}$ ) for tagged fish relative to untagged controls. We did not, however, find a measurable difference in $U_{\text {crit }}$ between the two tag types (i.e., dummy radio or acoustic transmitters), confirming the conclusion that an 18-cm external antenna had a small undetectable effect on sustained swimming performance. Additionally, a significant increase in $U_{c r i t}$ was observed with increasing fish size, and a statistically significant decrease in $U_{\text {crit }}$ also was identified with increasing temperature and the progression of summer. A small (about $6.9 \mathrm{~cm} / \mathrm{s}$ or $<1 \mathrm{Bl} / \mathrm{s}$ ) decrease in sustained swimming performance may be expected for subyearling Chinook salmon migrating at warmer temperatures $(>18$ ${ }^{\circ} \mathrm{C}$ ) late in the summer. 
Many factors are known to affect estimates of sustained swimming performance. Factors such as fish size, temperature, species, life history type, prior experience, metabolic condition, rearing type, transmitter attachment, parr-to-smolt transformation, and the velocity increments and time between increments used to estimate $U_{\text {crit }}$ can influence estimates of $U_{\text {crit }}$ (Brett, 1967; Hammer, 1995; Webb, 1995; Adams and others, 1998a, 1998b; Martinelli and others, 1998; Peake and McKinley, 1998; Mesa and others, 2004). Given the number of factors affecting sustained swimming performance, it is not surprising that we were able to explain just 20 percent of the variation in $U_{\text {crit }}$ among individual run-ofthe-river fish with our ANCOVA model. We attribute the high variation observed among individuals to variation in the source population (e.g., hatchery compared to wild and natal tributary), migration history, and developmental stage of fish used in our experiment. Thus, in contrast to a controlled fish source from a hatchery, our study highlights the natural variation in swimming performance than can be expected when sampling fish from many unknown sources during their natural migration period. Such variation is important to consider when determining appropriate minimum size limits for tag implantation as fish obtained directly from a hatchery may have a substantially different swimming performance compared to fish undergoing migration in the natural environment. Despite the unexplained variation in swimming performance, however, our results are consistent with the available literature.

Research suggests little to no effect of surgical implantation of radio transmitters on juvenile salmonids when tag size is small relative to fish size. Furthermore, studies able to detect a tagging effect suggest these effects are relatively small and short-term. Effects of transmitter attachment on fish behavior are founded on the tag and tagging method effect on fish physiology and stress. Jepsen and others (2001) compared physiological stress (i.e., cortisol level) in surgical-tagged juvenile Chinook salmon to untagged controls, and showed that stress owing to surgical implantation of radio tags was only apparent $1 \mathrm{~d}$ after implantation over a 14-d period. Martinelli and others (1998) also noted differences in blood volume and chemistry only within $5 \mathrm{~d}$ of surgically implanting radio tags in juvenile Chinook salmon over a 21-d period. Similarly, Adams and others (1998a) found a small difference (about $1 \mathrm{Bl} / \mathrm{s}$ ) in swimming performance within $1 \mathrm{~d}$, but not after $21 \mathrm{~d}$ of surgically implanting radio tags into juvenile Chinook salmon. We compared sustained swimming ability in subyearling Chinook salmon 1d after surgical implantation. Therefore, our relatively small difference in sustained swimming performance between tagged and untagged fish obtained $1 \mathrm{~d}$ after tagging corresponds to other physiological and behavioral studies that have investigated transmitter effects on juvenile Chinook salmon.

It has been hypothesized that the presence of an antenna on radio transmitters may result in reduced swimming performance compared to acoustic transmitters. Anglea and others (2004) found no significant difference $(<0.5 \mathrm{Bl} / \mathrm{s})$ in swimming performance $1 \mathrm{~d}$ after surgery for juvenile Chinook salmon tagged with dummy acoustic transmitters. Although not significant, the point estimates reported by Anglea and others (2004) were suggestive of a small, but undetectable effect of surgical tagging on sustained swimming performance. Although they did not test tags with an antenna, Anglea and others (2004) speculated that the lack of a tagging effect in their study was owing to an absence of an external antenna. The authors based this conclusion on the observation that Adams and others (1998a) found a difference in $U_{\text {crit }}$ for surgical-tagged juvenile Chinook salmon with an antenna (length=31 cm), whereas other studies (Moore and others, 1990; Brown and others, 1999, 2006) found no difference in $U_{\text {crit }}$ for surgical-tagged juvenile sockeye salmon (Oncorhynchus nerka), Chinook salmon, rainbow trout (O. mykiss), or Atlantic salmon (Salmo salar), with either a shortened (length 
$2.5 \mathrm{~cm}$ ) or absent antenna. Murchie and others (2004) found a significant reduction in sustained swimming performance of juvenile rainbow trout with increasing antenna length (mean fish size $=33.4-34.5 \mathrm{~g}, \mathrm{SE}=1.2-1.8$ ), although only antennas $30 \mathrm{~cm}$ or more in length were statistically different. Based on the regression equation provided by Murchie and others (2004), a reduction in $U_{c r i t}$ of about $15.5 \mathrm{~cm} / \mathrm{s}$ or $2 \mathrm{Bl} / \mathrm{s}$ ) may be expected between transmitters without an antenna compared to those with a $31-\mathrm{cm}$ antenna. The difference in $U_{\text {crit }}$ estimates for surgical-tagged fish ( $1 \mathrm{~d}$ after surgery) between Adams and others (1998a) and Anglea and others (2004) was, on average, just $0.4 \mathrm{Bl} / \mathrm{s}$, and, thus, a much smaller difference than what might be expected based on a $31-\mathrm{cm}$ difference in antenna length. Importantly, however, the dummy acoustic transmitters used by Anglea and others (2004) were $0.5 \mathrm{~g}$ heavier (weight in air=1.5 g) than the dummy radio transmitters used by Adams and others (1998a; weight in air=1.0 g). Thus, the larger tag used by Anglea and others (2004) may have offset the impact of not having an antenna. However, given the number of factors that can affect $U_{c r i t}$ estimates (Hammer, 1995), there is great uncertainty in comparing $U_{\text {crit }}$ estimates among studies; therefore, conclusions drawn from among different studies are uncertain.

Even though an antenna may have small and often undetectable effects on sustained swimming ability, the hypothesis that the presence of an antenna on radio transmitters will compromise estimates and conclusions from past and future radio telemetry studies is unfounded. We found statistically similar reductions (about $8.3 \mathrm{~cm} / \mathrm{s} ; P>0.29$ ) in $U_{\text {crit }}$ for each transmitter type relative to untagged controls. Once tag size relative to fish size was accounted for, the difference among dummy radio and acoustic transmitters was more apparent and in the anticipated direction of change (i.e., lower $U_{c r i t}$ for transmitters with an antenna; Murchie and others, 2004), but the effect of an antenna on the $U_{c r i t}$ of subyearling Chinook salmon, if it existed, was still not statistically detectable in our study. Given that we were able to detect a difference of about $8.3 \mathrm{~cm} / \mathrm{s}$ (about $1 \mathrm{Bl} / \mathrm{s}$ ) in our analysis, if an antenna had an effect on the $U_{\text {crit }}$ of subyearling Chinook salmon, the effect likely was much smaller than $8 \mathrm{~cm} / \mathrm{s}$. Thus, although we found an effect of a transmitter, we found little evidence that the additional effect of an antenna reduced swimming performance more than a transmitter without an antenna.

Past research also supports relatively small effects of antenna presence on swimming performance. Murchie and others (2004) did not find a statistical difference between untagged and sham-tagged controls and fish tagged with transmitters having antennas less than $30 \mathrm{~cm}$ in size. Robertson and others (2003) failed to detect a difference between untagged juvenile Atlantic salmon and those implanted with transmitters having a $28 \mathrm{~cm}$ antenna. Thus, the non-significant difference in $U_{\text {crit }}$ for a transmitter with an 18-cm antenna compared to a tag without an antenna was not completely unexpected. Moreover, Hockersmith and others (2003) found no difference in travel time (over days) and survival (over kilometers) between surgical-tagged juvenile Chinook salmon implanted with a 1.4$\mathrm{g}$ transmitter having a $30-\mathrm{cm}$ antenna compared to those implanted with a PIT tag weighing $<0.1 \mathrm{~g}$ that migrated through two reservoirs and dams. Furthermore, radio transmitters used in this study and currently used in the field have a much shorter antenna $(16 \mathrm{~cm})$ and are only about one-fifth the weight (per unit length) of the antennas used in Murchie and others (2004) and Adams and others (1998a, 1998b; see also Chapter 4 of this report). Therefore, the effects of an antenna on the radio transmitters used in this study appeared to be minimal. 
A significant, but small reduction in swimming performance also was noted with increasing water temperature (i.e., $-1.38 \mathrm{~cm} / \mathrm{s}$ per $1{ }^{\circ} \mathrm{C}$ ). This result is not surprising given that physiological processes and growth for Chinook salmon (and other temperate freshwater fishes) are known functions of temperature (Stewart and Ibarra, 1991; Hanson and others, 1997). Furthermore, Brett (1967) noted that the relation between sustained swimming performance and temperature for juvenile sockeye salmon $\left(O\right.$. nerka) was parabolic, resulting in $U_{\text {crit }}$ increasing up to a thermal optimum, but then decreasing beyond this optimum. The preferred temperature of subyearling Chinook salmon has been estimated at about $17.7^{\circ} \mathrm{C}$ (Sauter and others, 2001). Our entire study was conducted at temperatures of $18{ }^{\circ} \mathrm{C}$ or greater. Given that $18{ }^{\circ} \mathrm{C}$ is about the thermal optimum for subyearling Chinook salmon, we measured swimming performance at temperatures increasingly warmer than the optimum temperature for that fish. Therefore, the decline in swimming performance during our study matched the expected direction of change described by Brett (1967) with respect to temperatures beyond the thermal optimum for subyearling Chinook salmon.

Importantly, we could not distinguish the effect of temperature from other temporal factors that may have worked independently or in concert with temperature to alter sustained swimming performance. Sauter and others (2001) demonstrated a concomitant decrease in mean temperature preference with an increase in mean gill $\mathrm{Na}^{+}-\mathrm{K}^{+}$ATPase for subyearling Chinook salmon over the progression of summer, indicating that thermal preference decreases with increasing smoltification and time. Given that mean thermal preference for subyearling Chinook salmon has been shown to decrease to as low as $11^{\circ} \mathrm{C}$ with increasing smoltification (Sauter and others, 2001), we measured swimming performance under increasing temperatures as the fish's thermal preference of the fish likely was decreasing and state of smoltification was increasing. Peake and McKinley (1998) associated a sharp increase in sustained swimming performance with parr-to-smolt transformation in juvenile Atlantic salmon. Thus, it is conceivable that the effects of temperature and smoltification on $U_{\text {crit }}$ could interact to result in a less steep decrease in $U_{\text {crit }}$ than what might be expected from temperature alone. However, during the early-summer migration period of subyearling Chinook salmon, water temperature and level of smoltification nearly always increase with time as summer progresses. Thus, whether the ultimate factor affecting the decline in swimming performance was temperature or time, the two are inextricably linked. Nonetheless, temperature is well founded as a critical factor driving physiological function; therefore, water temperature was likely the most important determinant of the observed trend in sustained swimming performance during this study.

Since the early 1990s, when transmitters small enough to implant in juvenile salmon first became available, there has been growing debate and uncertainty about how to best estimate the effect of a transmitter on swimming performance. Winter (1996) recommended that the weight in air of a transmitter should not exceed 2 percent of fish body weight in air, instigating the " 2 percent rule" for biotelemetry and forming the basis for using 'tag ratios' as the criteria for judging the impacts of a transmitter. Subsequently, Adams and others (1998a, 1998b) concluded that transmitters with tag ratios as high as 5 percent of fish body weight may be safely implanted in juvenile Chinook salmon (about 9-35 g). Shortly thereafter, Brown and others (1999) reported that fish with tag ratios as high as 12 percent could be implanted in very small $(5-10 \mathrm{~g})$ juvenile rainbow trout. Brown and others (1999, p. 869) concluded, "the $2 \%$ rule [should] be replaced by an index with a more scientific basis". The utility of using tag ratios was further clouded when Moore and others (1990), Moser and others (1990), Robertson and others (2003), Anglea and others (2004), and Brown and others (2006) found no significant decrease in $U_{\text {crit }}$ for tagged juvenile Atlantic and Chinook salmon. These findings prompted the conclusion by Jepsen and others (2002, p. 242) that, "recommendations on maximum [tag] ratios often seem to be unproved statements". 
In line with Jepsen (2004), we identified important analytical ambiguities and nuances in the relevant literature, which made it difficult to identify common patterns among studies with respect to the effect of tag size relative to fish size. Some studies investigating sustained swimming speeds of tagged juvenile salmonids report $U_{\text {crit }}$ in either absolute units (e.g., cm/s; Brown and others, 1999; Murchie and others, 2004) or relative units (e.g., Bl/s; Moore and others, 1990; Moser and others, 1990; Adams and others, 1998a; Robertson and others, 2003; Anglea and others, 2004), or both (Brown and others, 2006). The absolute $U_{\text {crit }}$ is a better response scale than relative $U_{\text {crit }}$. With relative $U_{c r i t}$, the response variable is scaled by fish size, but the predictors also often include fish size, which can inherently drive spurious relations between the response and predictors. Furthermore, when both absolute and relative measures of $U_{\text {crit }}$ are reported in the literature, the response variable used for statistical tests often is not reported. When both fish weight and length are included in the analysis, the literature often is unclear about whether both predictors were included in the same model.

Furthermore, parameter estimates, such as slopes and intercepts from statistical models, rarely are reported in tag-effect studies, yet these estimates indicate the magnitude of tag effects on fish performance. Thus, it is not surprising that few generalities have arisen about appropriate tag sizes for a given fish size. In this study, we tried to overcome these ambiguities by explicitly detailing the statistical tests, reporting parameter estimates from statistical models, and using these parameter estimates to describe the magnitude with which different factors influenced swimming performance.

In summary, we found significantly reduced swimming performance of tagged fish relative to untagged fish. However, we found that an 18-cm antenna appeared to have little effect on swimming performance over and above the effect of a transmitter without an antenna. Furthermore, we found that increasing temperatures above the thermal optimum reduced swimming performance, but that both tagged and untagged fish exhibited a similar response to temperature. Therefore, conclusions from radio and acoustic telemetry studies with miniaturized tags likely will provide similar estimates of biological parameters from juvenile salmonids during their seaward migration. 


\title{
Chapter 3. Effects of Elevated Water Temperature on the Physiology, Mortality, and Swimming Performance of Radio-Tagged Juvenile Chinook Salmon
}

\author{
By Theresa L. Liedtke, Collin D. Smith, Israel N. Duran, and John W. Beeman
}

\section{Introduction}

Radio telemetry studies are commonly used to estimate the survival of juvenile salmonids passing through dams. Yearling Chinook salmon (Oncorhynchus tshawytscha) in the Columbia Basin are routinely implanted with radio tags during the spring and early summer. However, less is known about the effects of tagging subyearling Chinook salmon during the late summer when water temperatures are elevated $\left(21-24^{\circ} \mathrm{C}\right)$, as these temperatures exceed the typical limits for fish handling.

Slight variations above or below the water temperatures fish normally are subjected to can increase mortality (Baker and others, 1995), induce signs of thermal stress or injury (Logue and others, 1995; Iwama and others, 2004), or decrease performance (Brett, 1964, 1967; Hocutt, 1973; Otto and O'Hara-Rice, 1974; Stevens, 1979; Schneider and Connors, 1982). Longer term exposure can increase susceptibility to predation (Coutant, 1973). More importantly, fish respond at the cellular level to the effects of stress, including increased levels of blood plasma cortisol (Maule and others, 1988) and synthesis of heat shock proteins (hsp; Iwama, Thomas, and others, 1998; Iwama, Vijayan, and others, 1998). Handling, tagging, and releasing fish at high temperatures may aggravate these effects relative to untagged fish or those tagged at lower temperatures. If biologically meaningful differences between tagged fish and untagged fish are realized, then the study would violate the critical assumption of all telemetry studies - that the application or presence of a tag does not affect the behavior of the animals (Guy and others, 1996).

The goal of this study was to determine if the mortality, stress response, and performance of subyearling Chinook salmon gastrically implanted with radio transmitters are different than for untagged (control) fish at elevated water temperatures $\left(>21^{\circ} \mathrm{C}\right)$, and if so, at what water temperature potential differences arise.

\section{Methods}

Testing was conducted in 2004 and 2005 in a controlled laboratory setting at prescribed temperatures as well as in a field setting designed to simulate natural outmigration conditions of subyearling Chinook salmon. The laboratory study involved hatchery-reared subyearling Chinook salmon exposed to four test temperatures $\left(19,21,23\right.$, and $\left.25^{\circ} \mathrm{C}\right)$ and was conducted from September 27 to November 5,2004, and from July 28 to August 19, 2005 (table 3.1a). The field study involved inriver migrants placed in ambient river temperatures (mean water temperatures: $20.6-23.1^{\circ} \mathrm{C}$ ) and involved six field trials in 2004 and five field trials in 2005 (table 3.1b). Both the laboratory and the field study investigated several performance measures to determine the stress response of tagged and untagged salmon at different temperature regimes.

The timing and sample sizes for each experimental trial are shown in table 3.1. Critical swim speeds also were measured during the 2004 laboratory study. Physiological sampling included $\mathrm{Na}^{+} / \mathrm{K}^{+}$ATPase (hereinafter referred to as ATPase) levels as an indicator of fish smoltification, cortisol levels as a general stress indicator, and levels of hsp70 as an indicator of heat stress. In the 2004 field study, cortisol and hsp70 were measured in a 96-hour time series in two separate physiology trials (P1 and P2; table 3.1c) to learn how stress levels changed in the fish after tagging and handling. Levels of the pathogenic bacteria Renibacterium salmoninarum and Flavobacterium columnare also were 
determined as agents of bacterial kidney disease (BKD) and columnaris disease, respectively. Times at which each indicator was sampled in the laboratory and field studies in 2004 and 2005 are shown in table 3.2 .

Table 3.1 Dates and number of samples taken for all trials during the (a) laboratory and (b and c) field study in 2004 and 2005.

[Data are presented as the total number of fish, with the number of tagged fish in parenthesis. Two physiology trials (P1 and P2) were conducted during the 2004 field study (c). hsp, heat shock protein. ${ }^{\circ} \mathrm{C}$, degrees Celsius, $\mathrm{N}=$ sample size]

\begin{tabular}{|c|c|c|c|c|c|c|c|c|c|}
\hline \multicolumn{10}{|c|}{ (a) Laboratory study } \\
\hline Year & $\begin{array}{l}\text { Trial } \\
\left({ }^{\circ} \mathrm{C}\right)\end{array}$ & Month/Day & $\begin{array}{c}\text { All } \\
\text { Physiology }\end{array}$ & $\begin{array}{c}\text { Time }=0 \\
\text { hours } \\
\text { mortality }\end{array}$ & Tagged & & $\begin{array}{l}24 \text { hours } \\
\text { /Cortisol }\end{array}$ & & $\begin{array}{l}96 \text { hours } \\
/ \text { Cortisol }\end{array}$ \\
\hline \multirow[t]{4}{*}{2004} & 19 & $11 / 01$ & 48 & 402 & (174) & 48 & (24) tagged & 48 & (24) taggec \\
\hline & 21 & $110 / 1$ & 48 & 474 & (206) & 48 & (24) & 48 & (24) \\
\hline & 23 & $09 / 27$ & 40 & 337 & (147) & 40 & (20) & 40 & $(20)$ \\
\hline & 25 & $09 / 27$ & 48 & 349 & (157) & 48 & (24) & 23 & $(0)$ \\
\hline \multirow[t]{4}{*}{2005} & & $07 / 28$ & 30 & 498 & $(251)$ & 59 & (29) tagged & 60 & (29) taggec \\
\hline & 21 & $07 / 28$ & 30 & 485 & (246) & 60 & (30) & 61 & (31) \\
\hline & 23 & $08 / 15$ & 30 & 456 & (226) & 60 & (30) & 60 & $(30)$ \\
\hline & 25 & $08 / 15$ & 30 & 308 & (152) & 60 & (30) & 39 & $(10)$ \\
\hline
\end{tabular}

\section{(b) Field study}

\begin{tabular}{|c|c|c|c|c|c|c|c|c|}
\hline Time & Trial & Date & $\begin{array}{c}\text { Temp } \\
\left({ }^{\circ} \mathrm{C}\right)\end{array}$ & Physiology & & & & $\begin{array}{l}96 \text { hours } \\
/ \text { Cortisol }\end{array}$ \\
\hline \multirow[t]{6}{*}{2004} & 1 & $07 / 11$ & 20.7 & 30 & 128 & (64) tagged & \multicolumn{2}{|c|}{ NA } \\
\hline & 2 and 3 & $07 / 29$ & 22.5 & 30 & 222 & $(125)$ & \multicolumn{2}{|c|}{ NA } \\
\hline & 4 and 5 & $08 / 02$ & 22.5 & 40 & 254 & (127) & \multicolumn{2}{|c|}{ NA } \\
\hline & ${ }^{1} 6$ & $08 / 04$ & 22.3 & 12 & 100 & $(50)$ & \multicolumn{2}{|c|}{ NA } \\
\hline & $\mathrm{P} 1$ & $07 / 16$ & 21.0 & 20 & NA & & \multicolumn{2}{|c|}{ Time series, below } \\
\hline & $\mathrm{P} 2$ & $08 / 09$ & 23.1 & 17 & NA & & \multicolumn{2}{|c|}{ Time series, below } \\
\hline \multirow[t]{5}{*}{2005} & 1 & $07 / 14$ & 20.6 & 30 & 129 & (65) tagged & 30 & (15) tagged \\
\hline & 2 & $07 / 22$ & 21.2 & 30 & 128 & (64) & 30 & (15) \\
\hline & 3 & $08 / 02$ & 22.3 & 29 & 116 & (59) & 30 & (15) \\
\hline & 4 & $08 / 08$ & 22.2 & 30 & 128 & (64) & 30 & (15) \\
\hline & 5 & $08 / 22$ & 21.5 & 30 & 82 & (40) & 30 & (15) \\
\hline
\end{tabular}

${ }^{1}$ Terminated trial at time $=72$ hours because of high mortalities.

\begin{tabular}{c|cc|cc}
\hline \multirow{2}{*}{$\begin{array}{c}\text { Time } \\
\text { (hours) }\end{array}$} & \multicolumn{4}{|c}{ C. Field study, 2004-hsp 70/cortisol time series } \\
\cline { 2 - 5 } & \multicolumn{3}{|c}{ N } & \multicolumn{3}{c}{ Trial P2 } \\
\hline 1 & 21 & $(10)$ tagged & 15 & $(7)$ tagged \\
6 & 20 & $(10)$ & 16 & $(8)$ \\
12 & 19 & $(10)$ & 16 & $(8)$ \\
24 & 20 & $(10)$ & 16 & $(8)$ \\
72 & 17 & $(8)$ & 9 & $(4)$ \\
96 & 20 & $(10)$ & 5 & $(3)$ \\
\hline
\end{tabular}


Table 3.2. Indicators and times at which each indicator was measured during laboratory and field studies, in 2004 (shaded dots) and 2005 (white dots).

[Time is referenced from the time of tagging ( 0 hours). The studies terminated at 96 hours. ATPase, $\mathrm{Na}^{+} / \mathrm{K}^{+}-\mathrm{ATPase}$ ]

\begin{tabular}{|c|c|c|c|c|c|c|c|c|c|c|}
\hline \multirow{2}{*}{$\begin{array}{l}\text { 2004 } \\
\text { 2005 } \\
\text { Indicator }\end{array}$} & \multicolumn{3}{|c|}{ Laboratory study } & \multicolumn{7}{|c|}{ Field study } \\
\hline & $\begin{array}{c}0 \\
\text { hours }\end{array}$ & $\begin{array}{c}24 \\
\text { hours }\end{array}$ & $\begin{array}{c}96 \\
\text { hours }\end{array}$ & $\begin{array}{c}0 \\
\text { hours }\end{array}$ & $\begin{array}{c}1 \\
\text { hours }\end{array}$ & $\begin{array}{c}6 \\
\text { hours }\end{array}$ & $\begin{array}{c}12 \\
\text { hours }\end{array}$ & $\begin{array}{c}24 \\
\text { hours }\end{array}$ & $\begin{array}{c}72 \\
\text { hours }\end{array}$ & $\begin{array}{c}96 \\
\text { hours }\end{array}$ \\
\hline Fish size & 00 & & & 00 & & & & & & \\
\hline ATPase & 00 & & & 00 & & & & & & \\
\hline $\begin{array}{l}\text { Cortisol } \\
\text { Heat shock } \\
\text { protein } \\
(\text { hsp) } 70\end{array}$ & 00 & 00 & 00 & 00 & 0 & 0 & 0 & 0 & $\begin{array}{l}0 \\
0\end{array}$ & $\begin{array}{l}00 \\
0\end{array}$ \\
\hline $\begin{array}{l}\text { Bacterial kidney } \\
\text { disease } \\
\text { Flavobacterium } \\
\text { columnare }\end{array}$ & 00 & & & $\begin{array}{l}0 \\
0\end{array}$ & & & & & & \\
\hline $\begin{array}{l}\text { Mortality } \\
\text { Swimming } \\
\text { performance }\end{array}$ & & $\begin{array}{l}0 \\
0\end{array}$ & $\begin{array}{l}0 \\
0\end{array}$ & & & & & 00 & & 00 \\
\hline
\end{tabular}

\section{Fish Collection and Holding}

For the laboratory study elements, hatchery-reared subyearling Chinook salmon were obtained from the Little White Salmon Fish Hatchery in Willard, Washington, and were transported to the U.S. Geological Survey, Columbia River Research Laboratory, in Cook, Washington. Fish were reared indoors in circular fiberglass tanks $(1,556 \mathrm{~L}, 152-\mathrm{cm}$ diameter) under a simulated natural photoperiod. Water flow into the tanks was $9.5 \mathrm{~L} / \mathrm{min}$ and was oriented to produce a circular current. Rearing tanks were supplied with well water, and maintained at $15 \pm 2{ }^{\circ} \mathrm{C}$. Fish were fed $2.5-\mathrm{mm}$ fish food once a day to satiation during rearing, and maintenance rations during experimental periods. Prior to the laboratory temperature trials, the fish were transferred to experimental tanks (61-cm diameter, 21.6 $\mathrm{L} / \mathrm{min}$ ) filled with heated well water and fed a maintenance diet. Water temperature was increased no more than $3^{\circ} \mathrm{C}$ per day until the desired test temperature was reached. Fish were held at the test temperature for at least $7 \mathrm{~d}$ prior to the trials.

In the field study, subyearling Chinook salmon were obtained from the Juvenile Bypass Facility at John Day Dam and moved in transport tanks $(1.2 \times 0.5 \times 1.0 \mathrm{~m}, 227 \mathrm{~L}, 19.6 \mathrm{~L} / \mathrm{min})$ to The Dalles Dam. Fish were held in the transport tanks for 18-24 h, until tagging. In 2004, tagged/untagged pairs were held in $19 \mathrm{~L}$ perforated buckets placed in an experimental tank $(1.2 \times 0.6 \times 4.3 \mathrm{~m} ; 2,907 \mathrm{~L})$. In 2005, tagged fish and control fish were released into an experimental tank $(2.1 \times 0.8 \times 5.6 \mathrm{~m} ; 8,869$ L) with rounded interior corners, a rock substrate, and a continuously circulating current. All field holding tanks were continuously supplied with Columbia River water at ambient river temperatures $\left( \pm 0.5^{\circ} \mathrm{C}\right)$. Mean water temperatures during the field study were similar between $2004\left(20.7-23.1^{\circ} \mathrm{C}\right)$ and $2005\left(20.6-22.3^{\circ} \mathrm{C}\right)$. 


\section{Tagging and Handling}

To prepare fish for tagging and physiological sampling, food was withheld for $24 \mathrm{~h}$ before and after tagging. Test fish were netted from experimental tanks and anesthetized in $50 \mathrm{mg} / \mathrm{L}$ tricane methanesulfonate (MS-222) buffered with $50 \mathrm{mg} / \mathrm{L}$ sodium bicarbonate $\left(\mathrm{NaHCO}_{3}\right)$ for no longer than $5 \mathrm{~min}$. Weight (in grams) and fork length (FL, in millimeters) were recorded for all fish. Fish were randomly assigned to a treatment group (tagged or control). Fish to be tagged were then gastrically implanted with inactive transmitters (Lotek Wireless Incorporated ${ }^{\mathcal{C}}$, Newmarket, Ontario, Canada) following the procedures of Adams and others (1998a) and Martinelli and others (1998). The transmitter dimensions in 2004 were $6.3 \times 4.5 \times 14.5 \mathrm{~mm}$ and weighed $0.80 \mathrm{~g}$ in air (model NTC-3-1). In 2005, the dimensions were $5.3 \times 3.3 \times 13.5 \mathrm{~mm}$ with a weight of $0.43 \mathrm{~g}$ in air (model NTC-M-2).

In 2004, control fish were handled in the same manner as tagged fish excluding transmitter insertion. In the laboratory study, in order to identify the treatment group of fish that regurgitate their transmitter, we randomly selected one treatment group in each tank to be ink-marked on the dorsal fin. No ink-marking occurred during any field study. In both studies in 2004, tagged/untagged pairs were transferred to 19-L perforated buckets with oxygenated water until they recovered from the anesthesia, after which they were released into an experimental tank. In 2005, only tagged fish were paired in buckets for anesthesia recovery, as the control fish were not anesthetized or handled, but instead were transferred directly to experimental tanks without sedation or measurement. Only tagged fish were inkmarked during the 2005 laboratory study.

\section{Physiological Sampling}

We measured several physiological indicators in both the laboratory and field studies. We used ATPase activity in gill tissue as an indicator of smoltification, which primarily was used to compare fish in experiments across the season to see if fish became more smolted through time. To examine general fish health, we sampled for Renibacterium salmoninarum, the causative agent of BKD in salmon, and Flavobacterium columnare, which causes columnaris disease. Both of these pathogens are common in the Columbia River and could influence how fish respond to handling and tagging. We evaluated BKD levels in fish for both the field and laboratory studies, although only for trials P1 and P2 in the 2004 field study. Tests for columnaris disease were only conducted during the field study. To evaluate the sub-lethal effects of tagging, we measured plasma cortisol and hsp 70. Cortisol is an accepted indicator of stress, and measuring it in our studies allowed a comparison between our results and other studies described in the literature. Hsp70 is a less common indicator, and may not be a measure of generalized stress (Iwama and others, 2004), but may provide protection from thermal stress (Iwama and others, 1999) and may be an indicator of pathogenic response (Forsyth and others, 1997; Ackerman and Iwama, 2001). Because both cortisol and hsp70 can change rapidly, we measured them using a time series sampling approach.

Prior to physiological sampling, subyearling Chinook salmon were placed in $200 \mathrm{mg} / \mathrm{L} \mathrm{MS}-$ 222 buffered with $200 \mathrm{mg} / \mathrm{L} \mathrm{NaHCO}_{3}$ until gill movement ceased. For ATPase samples, scissors were used to remove a small piece $(2 \times 3 \mathrm{~mm})$ of gill filament tissue from the center of the outermost gill arch (Schrock and others, 1994). The sample was placed in a $0.5-\mathrm{mL}$ buffer solution (0.3 M sucrose, $0.02 \mathrm{M}$ disodium EDTA, and $0.1 \mathrm{M}$ imidazole at $\mathrm{pH} 7.1)$ and stored at $-80{ }^{\circ} \mathrm{C}$ until assayed by enzyme incubation and inorganic phosphate analysis (Schrock and others, 1994). To assess the level of BKD in test fish, we removed the kidneys and stored them at $-80{ }^{\circ} \mathrm{C}$ until they were homogenized and analyzed using an enzyme-linked immunosorbent assay (ELISA) as described by Pascho and Mulcahy (1987). Samples for columnaris disease were collected from gill tissue using a plastic loop and were spread onto a petri dish coated with tryptone yeast extract salt agar (TYES; Holt, 1987) and incubated for 3-5 d at $15-17^{\circ} \mathrm{C}$. Plates were visually inspected for $F$. columnare and subjected to a Gram stain test for positive identification. 
Cortisol and hsp70 were measured using a time series sampling approach. We sampled at 0, 24, and $96 \mathrm{~h}$ after tagging in the laboratory study (table 3.2). In the field study in 2004, we sampled at 0,1 , $6,12,24,72$, and $96 \mathrm{~h}$ after tagging (table 3.1c) during two physiological experiments (P1 and P2) that were initiated on July 16 and August 9, respectively. During the 2005 field study, we conducted an abbreviated time series for cortisol (table 3.2). No hsp70 sampling was conducted during the laboratory or field studies in 2005. Blood samples for cortisol were collected from each fish by severing the caudal peduncle and collecting blood into a heparinized capillary tube. Using a centrifuge, the plasma component was separated and stored at $-80{ }^{\circ} \mathrm{C}$ until analyzed using an ELISA (Carey and McCormick, 1998). Samples of hsp 70were collected by removing the liver from each fish, avoiding rupture and contamination by the gall bladder. Livers were stored at $-80{ }^{\circ} \mathrm{C}$ until they were homogenized and analyzed using an ELISA (Forsyth and others, 1997).

\section{Mortality and Swimming Performance}

The mortality of tagged and control fish in the experimental tanks was visually determined in both the laboratory and the field study at 24 and $96 \mathrm{~h}$ post-treatment (table 3.2). In the 2004 laboratory study, swimming performance also was evaluated at three water temperatures $\left(21,23\right.$, and $\left.25^{\circ} \mathrm{C}\right)$. We measured swimming performance at 24 and $96 \mathrm{~h}$ after tagging or handling. Study fish were subjected to a single swimming performance trial and then euthanized.

The swimming performance of tagged and control fish was determined using two swim tunnels modeled after a Blazka-style respirometer. The swim tunnels were $30.5 \mathrm{~cm}$ long with an inner diameter of $9 \mathrm{~cm}$, and a motor-driven propeller to circulate water. A screen at either end of the tunnel kept the fish protected from the propeller. Transmitter antennas were trimmed $(20.5 \mathrm{~cm}$ long) to eliminate interference with the respirometer propeller, making the weight of the transmitter $0.77 \mathrm{~g}$ in air. Tagged and control fish were randomly assigned to one of the two swim tunnels. The relation between motor speed and water velocity in each tunnel was determined by linear regression and calibration curves were developed.

Swimming performance was determined using critical swimming speeds $\left(U_{c r i t}\right)$ based on a modified ramped protocol (Jain and others, 1997). To measure $U_{c r i t}$, a fish was netted, anesthetized, weighed, measured, and placed in the tunnel. After the fish regained equilibrium, it was allowed to adjust to the tunnel at a water velocity of $0.5 \mathrm{Bl} / \mathrm{s}$ for $1 \mathrm{~h}$. Following the acclimation period, water velocity was gradually increased (by $0.003 \mathrm{Bl} / \mathrm{s}$ ) over $10-15 \mathrm{~min}$ to $2.5 \mathrm{Bl} / \mathrm{s}$. Water velocity was held at $2.5 \mathrm{Bl} / \mathrm{s}$ for $30 \mathrm{~min}$, and then increased by $0.5 \mathrm{Bl} / \mathrm{s}$ every $30 \mathrm{~min}$ until the fish fatigued. If the fish became impinged on the downstream screen, the motor was momentarily stopped to allow the fish to swim off the screen. A fish was considered fatigued after being impinged on the downstream screen three consecutive times. $U_{\text {crit }}$ was then calculated using the formula from Brett (1964):

$$
U_{\text {crit }}=\mathrm{u}_{\mathrm{i}}+\left(\left(\mathrm{t}_{\mathrm{i}} / \mathrm{t}_{\mathrm{ii}}\right) \mathrm{u}_{\mathrm{ii}}\right.
$$

where

$\mathrm{u}_{\mathrm{i}} \quad$ is the highest swimming velocity reached that was maintained over an entire 30minute increment $(\mathrm{Bl} / \mathrm{s})$,

$\mathrm{u}_{\mathrm{ii}} \quad$ is the velocity increment $(0.5 \mathrm{Bl} / \mathrm{s})$,

$\mathrm{t}_{\mathrm{i}} \quad$ is the time swimming at the highest speed reached (in minutes), and

$\mathrm{ti}_{\mathrm{i}} \quad$ is the increment time (30 minutes). 
Swimming performance tests were not conducted at $19^{\circ} \mathrm{C}$, as no temperature effect was expected, nor were they conducted on tagged fish at $25^{\circ} \mathrm{C}$ because of high mortality during $96 \mathrm{~h}$ holding and overall poor condition of fish. Very few control fish were tested at $25^{\circ} \mathrm{C}$ and no statistical comparisons were made. Tagged fish were not able to tolerate the $0.5 \mathrm{Bl} / \mathrm{s}$ adjustment period in the swim tunnel and, therefore, could not be challenged to swim at higher velocities.

\section{Analyses}

Statistical comparisons of fish size between control and tagged fish in the 2004 laboratory and field trials was done using a $t$-test with statistical significance defined as $P<0.05$. Significant differences between control-tag pairs for both cortisol and hsp70 also were determined by $t$-tests. A comparison of ATPase activities among trials was conducted using ANOVA and the Duncan-Waller test. Statistical differences in levels of BKD among trials were determined using ANOVA, whereas in the field study, significance of columnaris among trials was tested using Fisher's Exact Test.

\section{Results}

\section{Fish Size}

The mean fork lengths (FL) and weights of subyearling Chinook salmon at the time of tagging $(0 \mathrm{~h})$ are shown in table $3.3 \mathrm{a}$ and $3.3 \mathrm{~b}$ during the laboratory and field studies, respectively. In 2004, the mean size of tagged fish was greater than that of controls in most trials for both the laboratory (table 3.3a) and the field studies (table 3.3b). As our tagging procedure required that tags comprise no more than 5 percent of fish body weight, this disparity is owing to assignment of more small fish to the control groups. In most cases, the size differences between groups were small, averaging $2.8 \mathrm{~mm}$ for FL and $1.6 \mathrm{~g}$ for weight in the 2004 laboratory study, and $3.1 \mathrm{~mm}$ for FL and $1.4 \mathrm{~g}$ for weight in the 2004 field study.

Mean fish size was not significantly different between temperature trials in the 2005 laboratory study (table 3.3a). The size of tagged fish in the 2005 field study was significantly different between trials with regard to both mean FL $(P<0.0001)$ and weight $(P<0.0001)$, with the largest size occurring during trial 5 (table $3.3 \mathrm{~b}$ ).

\section{Physiological Sampling}

\section{(a) ATPase}

The specific activity of gill ATPase in subyearling Chinook salmon at time 0 (time of tagging) for the laboratory and field study is shown in figures 3.1 and 3.2, respectively. The 2004 laboratory study indicated an inverse relation between ATPase activity in the fish and temperature (fig. 3.1a). The specific activity at $19{ }^{\circ} \mathrm{C}(1.22 \mu \mathrm{moles} / \mathrm{hr} / \mathrm{mg}$ protein) was significantly higher (Duncan-Waller test, $P=0.01)$ than the activities at $21{ }^{\circ} \mathrm{C}(1.04 \mu$ moles $/ \mathrm{hr} / \mathrm{mg}$ protein $), 23{ }^{\circ} \mathrm{C}(0.94 \mu$ moles $/ \mathrm{hr} / \mathrm{mg}$ protein $)$, and $25^{\circ} \mathrm{C}(0.87 \mu \mathrm{moles} / \mathrm{hr} / \mathrm{mg}$ protein). In 2005 , the laboratory study showed no correlation between ATPase activity and temperature (fig. 3.1b). The specific activities of the fish at 21 and $23{ }^{\circ} \mathrm{C}$ were equivalent (1.37 and $1.39 \mu \mathrm{moles} / \mathrm{hr} / \mathrm{mg}$ protein, respectively), but significantly higher $(P=0.0001)$ than the activity at both $19^{\circ} \mathrm{C}(0.53 \mu$ moles $/ \mathrm{hr} / \mathrm{mg}$ protein $)$ and $25^{\circ} \mathrm{C}(0.84 \mu$ moles $/ \mathrm{hr} / \mathrm{mg}$ protein $)$. There was no correlation between ATPase activity and the date of trials in the laboratory study; the 19 and $21{ }^{\circ} \mathrm{C}$ trials were run concurrently, as were the 23 and $25^{\circ} \mathrm{C}$ trials (table $3.1 \mathrm{a}$ ). 
Table 3.3. Means and ranges of fork lengths and weights of subyearling Chinook salmon at time of tagging in (a) laboratory study and (b) field study for each trial in 2004 and 2005.

[In the field study (b), the mean river temperature in degrees Celsius $\left[{ }^{\circ} \mathrm{C}\right]$ for each trial is shown in parentheses. $\mathbf{N}$, number of fish]

\begin{tabular}{|c|c|c|c|c|c|c|c|}
\hline \multicolumn{8}{|c|}{ (a). Laboratory study } \\
\hline \multirow[b]{2}{*}{ Year } & \multirow[b]{2}{*}{ Trial } & \multirow[b]{2}{*}{ Group } & \multirow[b]{2}{*}{$N$} & \multicolumn{2}{|c|}{ Fork length(millimeters) } & \multicolumn{2}{|c|}{ Weight(grams) } \\
\hline & & & & Mean & Range & Mean & Range \\
\hline \multirow[t]{8}{*}{2004} & \multirow{2}{*}{$19^{\circ} \mathrm{C}$} & Control & 221 & $116.1^{*}$ & $95.0-136.0$ & $15.9 *$ & $7.3-28.4$ \\
\hline & & Tagged & 173 & $117.9 *$ & $104.0-134.0$ & $17.1 *$ & $11.1-26.8$ \\
\hline & \multirow{2}{*}{$21^{\circ} \mathrm{C}$} & Control & 253 & $116.6^{*}$ & $102.0-14-.0$ & 16.8 & $9.8-31.3$ \\
\hline & & Tagged & 206 & $117.5^{*}$ & $102.0-137.0$ & 17.7 & $11.5-30.2$ \\
\hline & \multirow{2}{*}{$23{ }^{\circ} \mathrm{C}$} & Control & 184 & $108.5^{*}$ & $98.0-125.0$ & $13.3 *$ & $8.6-22.5$ \\
\hline & & Tagged & 147 & $111.8^{*}$ & $100.0-127.0$ & $15.2 *$ & $10.8-23.2$ \\
\hline & \multirow{2}{*}{$25^{\circ} \mathrm{C}$} & Control & 194 & $105.4 *$ & $95.0-115.0$ & $11.6^{*}$ & $8.0-17.5$ \\
\hline & & Tagged & 157 & $110.5^{*}$ & $101.0-124.0$ & $13.9^{*}$ & $10.8-23.8$ \\
\hline \multirow[t]{4}{*}{2005} & $19^{\circ} \mathrm{C}$ & Total & 251 & 101.3 & $94.0-113.0$ & 11.6 & $9.5-17.5$ \\
\hline & $21{ }^{\circ} \mathrm{C}$ & Total & 246 & 100.9 & $93.0-115.0$ & 11.5 & $9.5-16.4$ \\
\hline & $23{ }^{\circ} \mathrm{C}$ & Total & 227 & 102.2 & $94.0-117.0$ & 11.4 & $9.5-18.4$ \\
\hline & $25^{\circ} \mathrm{C}$ & Total & 152 & 101.9 & $94.0-122.0$ & 11.6 & $9.5-18.0$ \\
\hline
\end{tabular}

\begin{tabular}{|c|c|c|c|c|c|c|c|}
\hline \multicolumn{8}{|c|}{ (b). Field study } \\
\hline \multirow[b]{2}{*}{ Year } & \multirow[b]{2}{*}{ Trial } & \multirow[b]{2}{*}{ Group } & \multirow[b]{2}{*}{$N$} & \multicolumn{2}{|c|}{$\begin{array}{l}\text { Fork length } \\
\text { (millimeters) }\end{array}$} & \multicolumn{2}{|c|}{$\begin{array}{l}\text { Weight } \\
\text { (grams) }\end{array}$} \\
\hline & & & & Mean & Range & Mean & Range \\
\hline \multirow{12}{*}{2004} & \multirow{2}{*}{$1\left(20.7^{\circ} \mathrm{C}\right)$} & Control & 64 & 117.1 & $101.0-146.0$ & 17.0 & $11.6-33.0$ \\
\hline & & Tagged & 64 & 118.0 & $107.0-160.0$ & 18.0 & $13.1-43.0$ \\
\hline & \multirow{2}{*}{2 and $3\left(22.5^{\circ} \mathrm{C}\right)$} & Control & 97 & 113.1 & $102.0-129.0$ & 16.1 & $12.1-24.3$ \\
\hline & & Tagged & 125 & 114.5 & $101.0-114.0$ & 16.7 & $13.0-25.1$ \\
\hline & \multirow{2}{*}{4 and $5\left(22.5^{\circ} \mathrm{C}\right)$} & Control & 127 & $111.8^{*}$ & $97.0-135.0$ & $15.3^{*}$ & $10.3-26.3$ \\
\hline & & Tagged & 127 & $115.0^{*}$ & $103.0-138.0$ & $16.6^{*}$ & $13.1-27.7$ \\
\hline & \multirow{2}{*}{$6\left(22.3^{\circ} \mathrm{C}\right)$} & Control & 60 & 110.5 & $101.0-150.0$ & $14.9 *$ & $11.2-40.4$ \\
\hline & & Tagged & 60 & 113.7 & $103.0-142.0$ & $16.2 *$ & $12.2-30.9$ \\
\hline & \multirow{2}{*}{$\mathrm{P} 1\left(21.0^{\circ} \mathrm{C}\right)$} & Control & 60 & $116.4^{*}$ & $101.0-159.0$ & $17.1 *$ & $11.5-45.2$ \\
\hline & & Tagged & 60 & $122.8^{*}$ & $105.0-145.0$ & $19.3 *$ & $13.1-30.7$ \\
\hline & \multirow{2}{*}{$\mathrm{P} 2\left(23.1^{\circ} \mathrm{C}\right)$} & Control & 50 & $108.7 *$ & $103.0-117.0$ & $14.0^{*}$ & $11.2-19.4$ \\
\hline & & Tagged & 50 & $112.6^{*}$ & $105.0-124.0$ & $15.8^{*}$ & $13.1-21.3$ \\
\hline \multirow{5}{*}{2005} & $1\left(20.6^{\circ} \mathrm{C}\right)$ & Tagged & 65 & 110.2 & $95.0-140.0$ & 14.7 & $10.0-30.4$ \\
\hline & $2\left(21.2^{\circ} \mathrm{C}\right)$ & Tagged & 64 & 102.2 & $95.0-118.0$ & 12.1 & $10.4-14.9$ \\
\hline & $3\left(22.3^{\circ} \mathrm{C}\right)$ & Tagged & 62 & 113.4 & $100.0-133.0$ & 16.7 & $11.7-26.2$ \\
\hline & $4\left(22.2^{\circ} \mathrm{C}\right)$ & Tagged & 64 & 118.0 & $101.0-133.0$ & 19.0 & $11.9-28.9$ \\
\hline & $5\left(21.5^{\circ} \mathrm{C}\right)$ & Tagged & 40 & $122.4^{*}$ & $104.0-142.0$ & $21.7 *$ & $12.5-38.2$ \\
\hline
\end{tabular}

Asterisks (*) indicate a significant difference between tagged and control fish ( $t$-test, $P$ less than 0.05$)$. 
(a) 2004, Laboratory Study

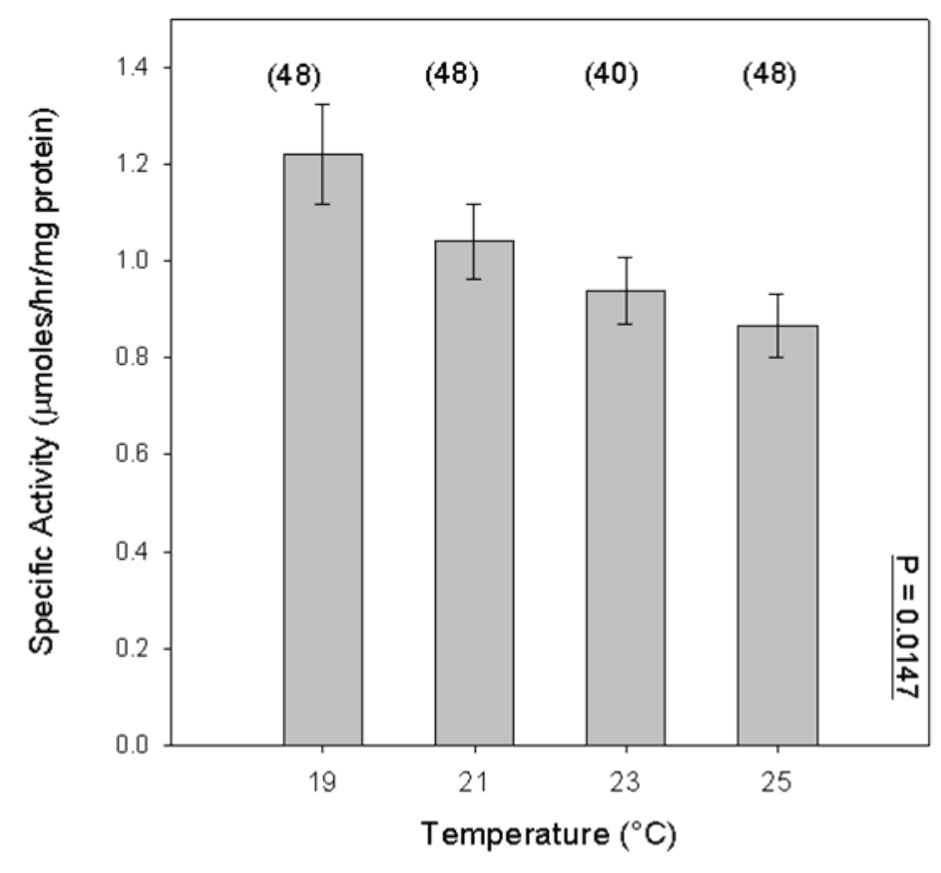

(b) 2005, Laboratory Study

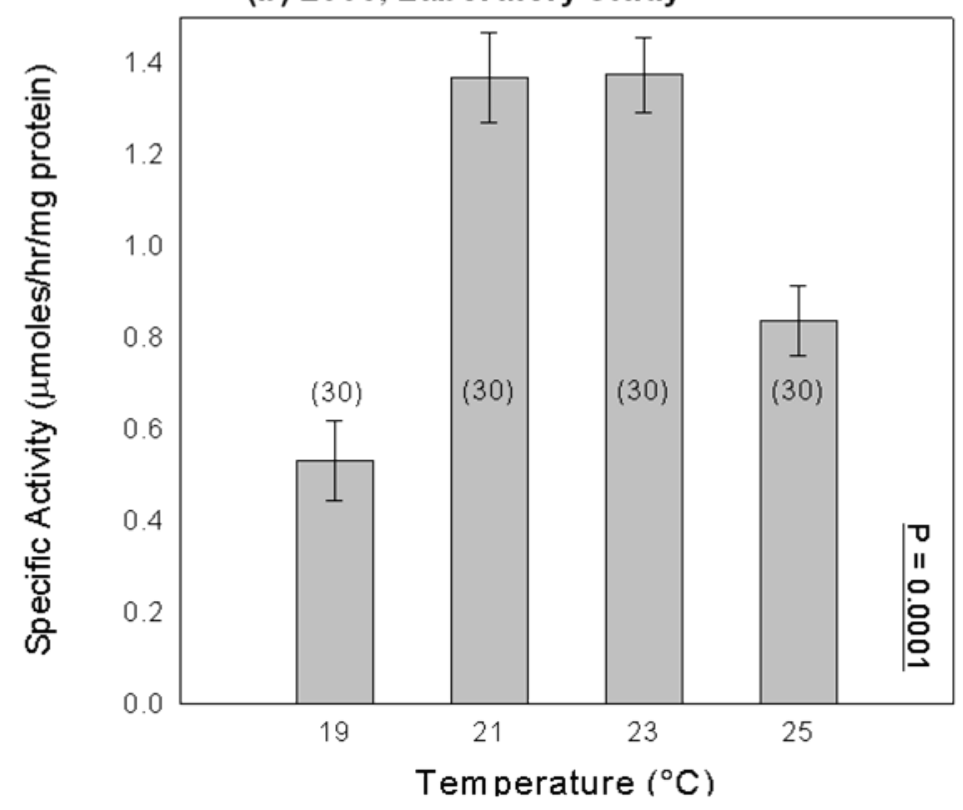

Figure 3.1. Boxplots showing specific activity of gill ATPase in subyearling Chinook salmon, measured at the time of tagging at four test temperatures in the laboratory study in (a) 2004, and (b) 2005. Numbers in parentheses indicate sample size, bars represent standard errors, and $P$-values were determined using an ANOVA. 
(a) 2004, Field Study
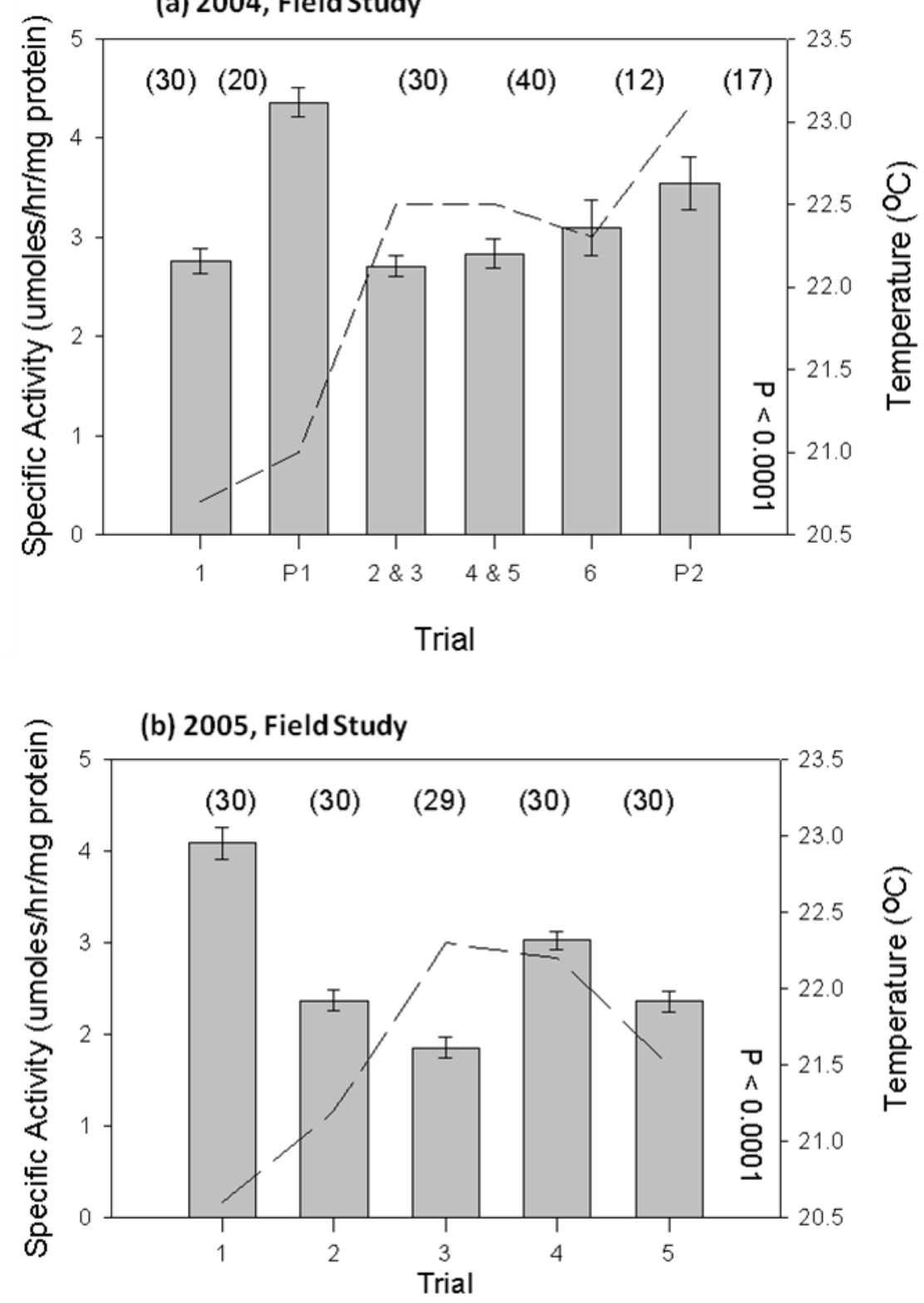

Figure 3.2. Boxplots of specific activity of gill ATPase in subyearling Chinook salmon at the time of tagging during field study in (a) 2004, and (b) 2005. Numbers in parentheses indicate sample size. Temperature of ambient river water (Temp, ${ }^{\circ} \mathrm{C}$ ) is shown as a dashed line. Trials are presented in the order they were conducted. See table 3.1 for trial dates. Bars represent standard errors.

There was no clear relation between ATPase and water temperature. In the 2004 field study, although there was no apparent correlation between ATPase activity and temperature (fig. 3.2a), ATPase activity increased over the season (July 11-August 9) with the exception of trial P1 (July 16). Trial P1 had ATPase levels that were significantly higher than the other trials $(4.4 \mu \mathrm{moles} / \mathrm{hr} / \mathrm{mg}$ protein, $P=0.0001$; fig. $3.2 \mathrm{a}$ ). In the 2005 field study, ATPase activity did not increase throughout the season, although there was an apparent inverse relation with temperature, with the exclusion of trial 4 (fig. 3.2b). In this case, all trials were significantly different from each other, with the exception of trials 2 and $5(P<0.0001)$. 


\section{(b) Cortisol}

The laboratory study provided a comparison of cortisol levels at different temperatures, whereas the 2004 field study was designed to investigate plasma cortisol levels through a detailed time series. In the laboratory study, samples for cortisol in the blood plasma of subyearling Chinook salmon were taken at the time of tagging ( 0 hours), at $24 \mathrm{~h}$ post-tagging, and at the end of each trial ( $96 \mathrm{~h}$, fig. 3.3). In the 2005 field study, samples were taken at 0 and $96 \mathrm{~h}$. In the 2004 field study, samples were collected at $0,1,6,12,24,72$, and $96 \mathrm{~h}$ in two separate physiology field trials. In both years, results from all trials were averaged at each time point for both tagged and control fish (fig. 3.4a and 3.4b).
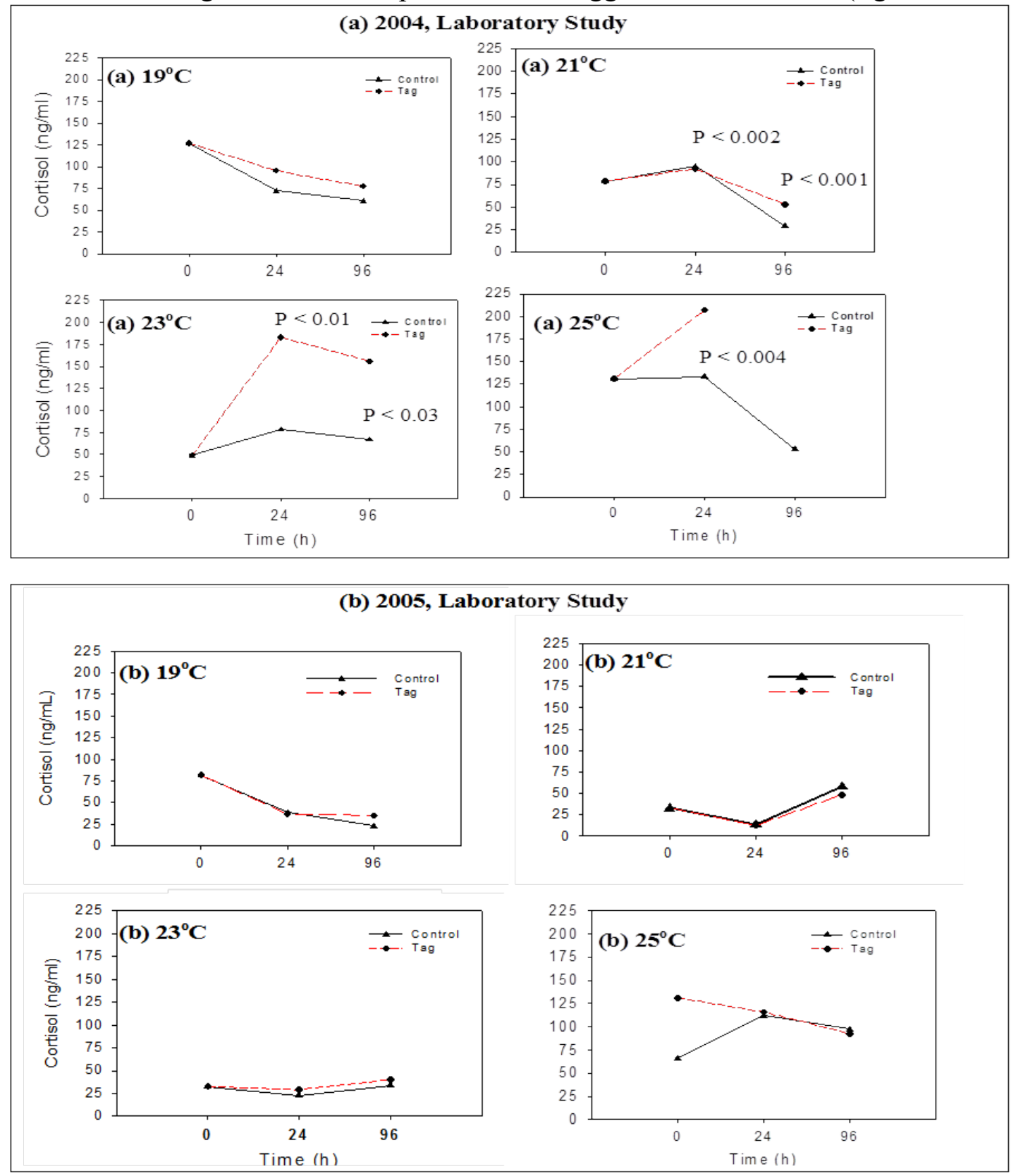

Figure 3.3. Graphs showing cortisol levels in blood plasma at various water temperatures from subyearling Chinook salmon during laboratory study in (a) 2004, and (b) 2005. Time (h) indicates time since handling and tagging. Significant differences are indicated for control-tag pairs, as determined by $t$ tests. 
In the laboratory study, cortisol levels were plotted over time for each test temperature in 2004 (fig. 3.3a) and 2005 (fig. 3.3b). The graphs show that cortisol was more concentrated in fish in 2004 relative to 2005 at each temperature. Additionally, while cortisol levels in tagged fish (after $0 \mathrm{~h}$ ) generally were higher than in control fish in 2004, this was not apparent in 2005. In 2004, a peak in cortisol levels was measured at $24 \mathrm{~h}$ in both groups at all but the lowest temperature $\left(19^{\circ} \mathrm{C}\right)$, with the highest levels measured at $25^{\circ} \mathrm{C}$. Cortisol was markedly higher in tagged fish than controls at 23 and $25{ }^{\circ} \mathrm{C}$.

Plasma cortisol from the field studies in 2004 and 2005 are graphed in figure $3.4 \mathrm{a}$ and $3.4 \mathrm{~b}$, respectively. In both years, cortisol levels decreased in tagged and control fish over the course of 96 hours. The endpoint occurred at a level that was less than the initial levels at $0 \mathrm{~h}$ (time of tagging), suggesting acclimatization of the fish. Fine-scaled reporting of cortisol levels occurred in 2004 and showed that despite this decrease, there was a sharp spike $(>350 \mathrm{ng} / \mathrm{mL})$ during the first hour after tagging (fig. 3.4a). This spike was seen in both tagged and control fish. Cortisol levels in controls dropped at a slightly faster rate than those in tagged fish in both 2004 and 2005. This difference was not significant except at $6 \mathrm{~h}$ in 2004, where cortisol levels in tagged fish $(335.0 \mathrm{ng} / \mathrm{mL})$ were significantly higher $(P<0.001)$ than in controls $(258.0 \mathrm{ng} / \mathrm{mL})$, indicating that whereas both tagged and control fish showed a distinct stress response at $1 \mathrm{~h}$, the control fish had a faster initial recovery. 


\section{(a) 2004, Field Study}

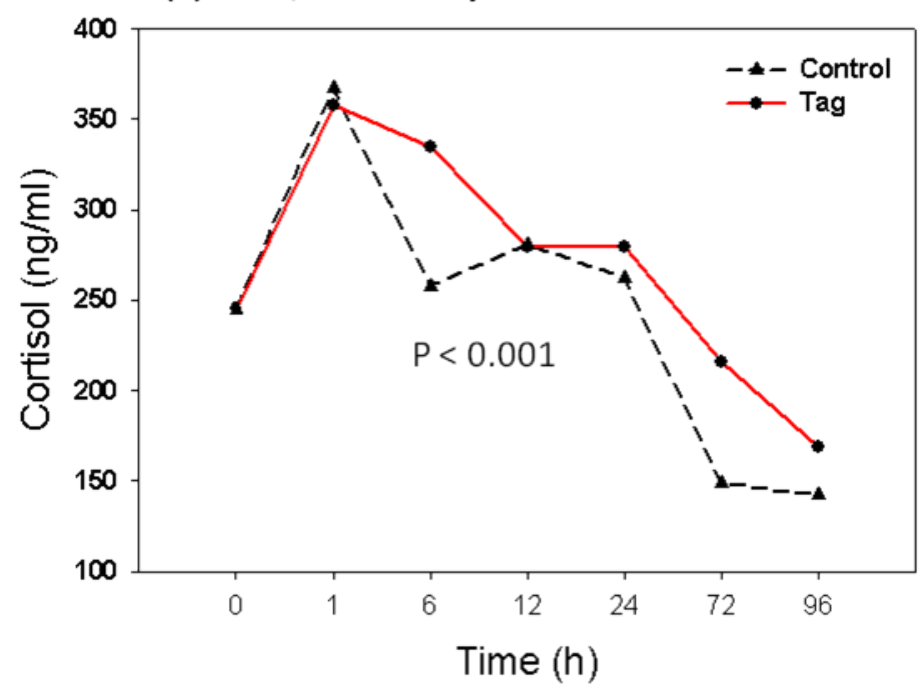

(b) 2005, Field study

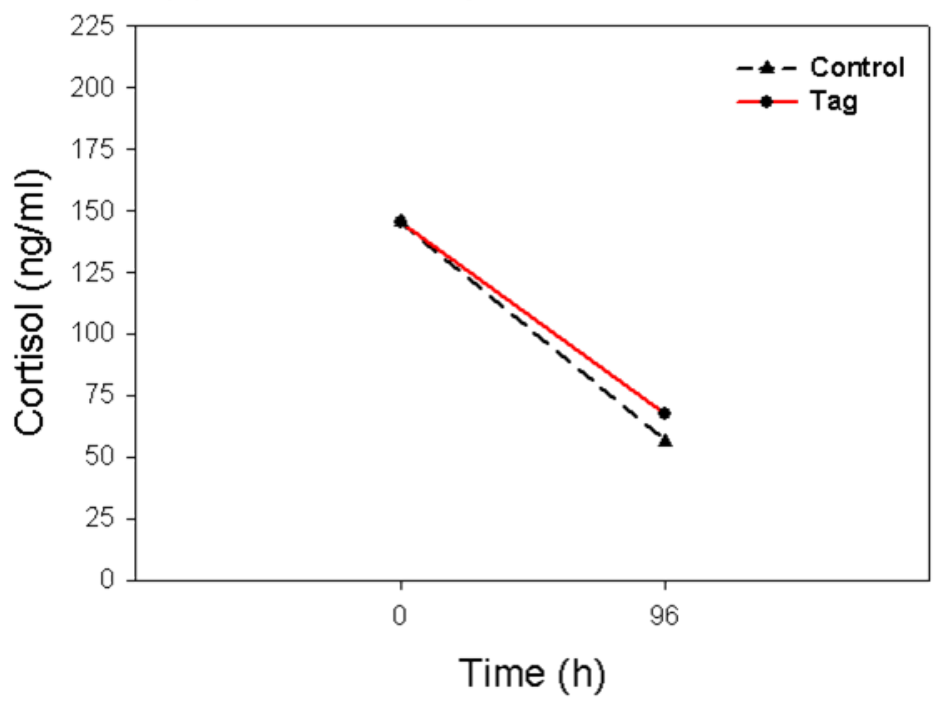

Figure 3.4. Graphs showing cortisol levels in blood plasma from subyearling Chinook salmon during time series in field study in (a) 2004, and (b) 2005. Significant differences are indicated for control-tag pairs as determined by $t$-tests.

\section{(c) Hsp70}

Levels of hsp70, the heat stress indicator, in subyearling Chinook salmon were sampled using the same time series as cortisol in 2004. No samples were taken in 2005. Initial levels of hsp70 at the time of tagging show that tag and control levels were similar and that levels increased with temperature, with the highest levels at $25^{\circ} \mathrm{C}$ (fig. 3.5a). Levels in both control and tagged fish peaked 1 day after tagging $(24 \mathrm{~h})$ in both the field (fig. $3.5 \mathrm{~b}$ ) and the laboratory study (fig. 3.5a), with the exception of control fish at 19 and $21^{\circ} \mathrm{C}$.

At the $24 \mathrm{~h}$ peak, hsp 70 was distinctly higher in tagged fish than in controls, in both the laboratory and field studies. The field study shows that this divergence between tagged and control fish began at $6 \mathrm{~h}$, and that by $72 \mathrm{~h}$, both groups again had comparable levels of hsp70 (fig. 3.5b). After 24 $\mathrm{h}$, both tagged and control subyearling Chinook salmon appeared to recover from handling and tagging. At $96 \mathrm{~h}$, there was a positive relationship between hsp70 levels and water temperature for both control and tagged fish (fig. 3.5a). 
(a) 2004, Laboratory Study

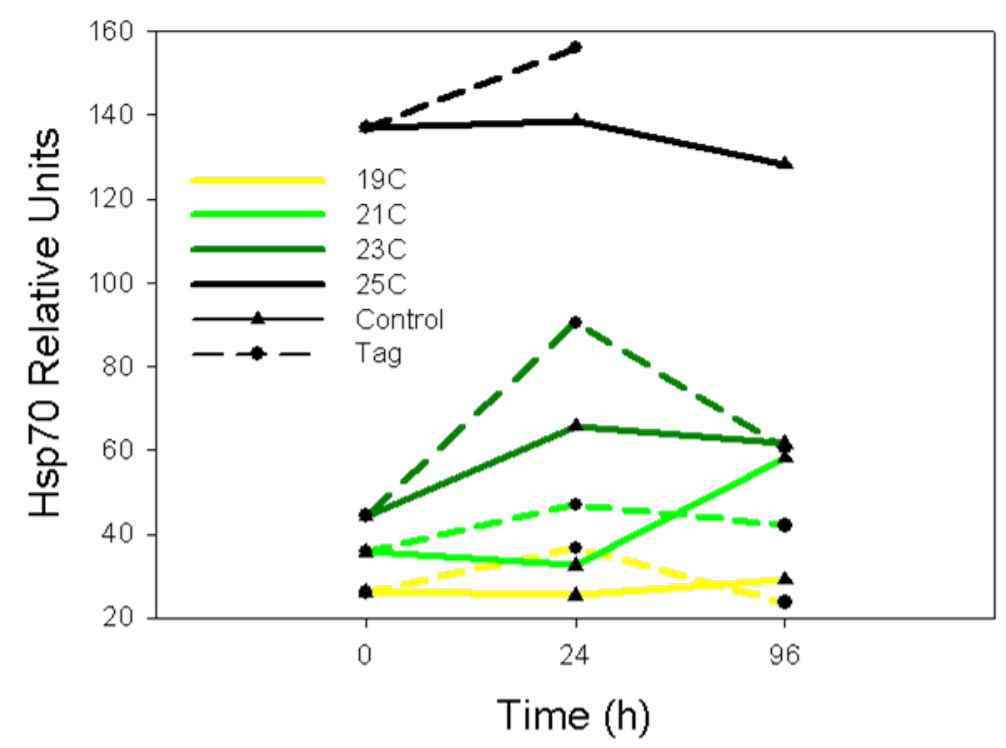

(b) 2004, Field Study

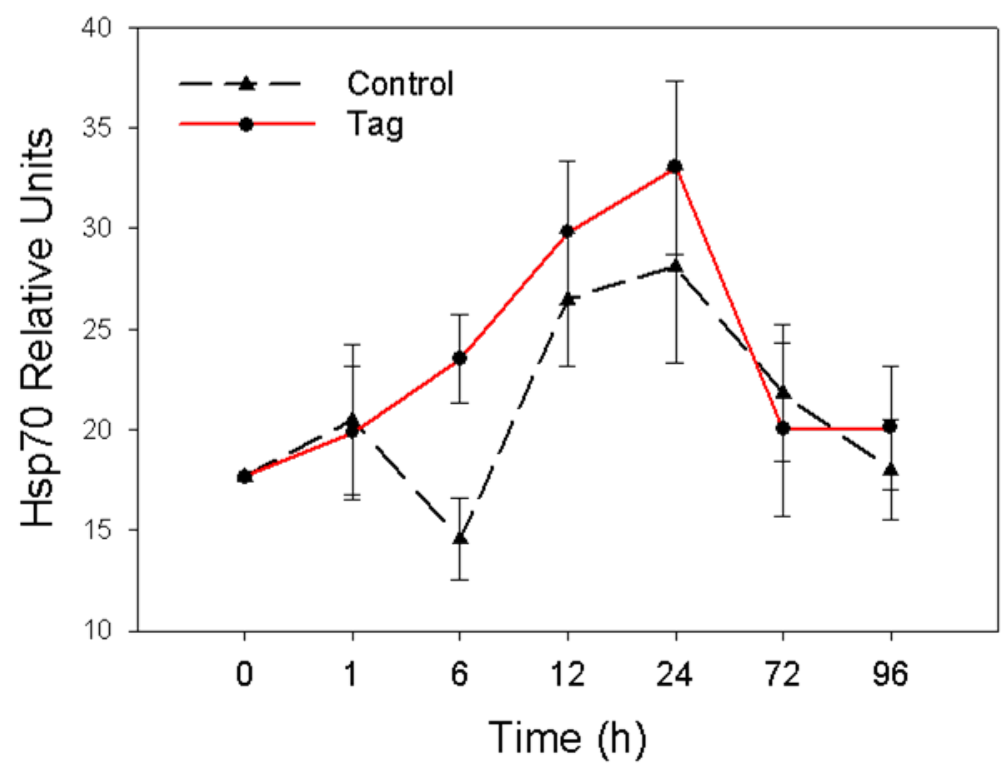

Figure 3.5. Graphs showing hsp70 levels obtained from liver tissue as a heat stress indicator in control and tagged subyearling Chinook salmon in 2004. Samples were taken (a) in laboratory study at four different temperature regimes and (b) from field study (at ambient river temperatures). Time is hours from the time of tagging $(0 \mathrm{~h})$. 


\section{(d) Pathogenic Bacteria}

No significant amount of BKD was detected in fish in either the laboratory or the field study. In 2004 , there was no change in the percentage of fish at each level of BKD infection among the different temperatures, in either the laboratory study (fig. 3.6a) or the field study (fig. 3.7a). In 2005, there was a slight increase in the number of fish with BKD at elevated temperatures in the laboratory study (fig. 3.6b), although levels appeared to decrease with temperature in the field study (fig. 3.7b).

Columnaris infection rates generally were low and were not correlated with water temperature. In 2004, the incidence of columnaris was between 0.20 and 0.30 for trials $1, \mathrm{P} 1$, and $\mathrm{P} 2$, with no incidence for trials 2 and 3 and 4 and 5 (fig. 3.8a). Infection rates were highest for trial $6(0.75$, with no apparent temperature or seasonal trend. In 2005, fish had no significant rates of columnaris infection $(<0.10)$ during any of the trials (fig. 3.8b).

(a) 2004, Laboratory Study

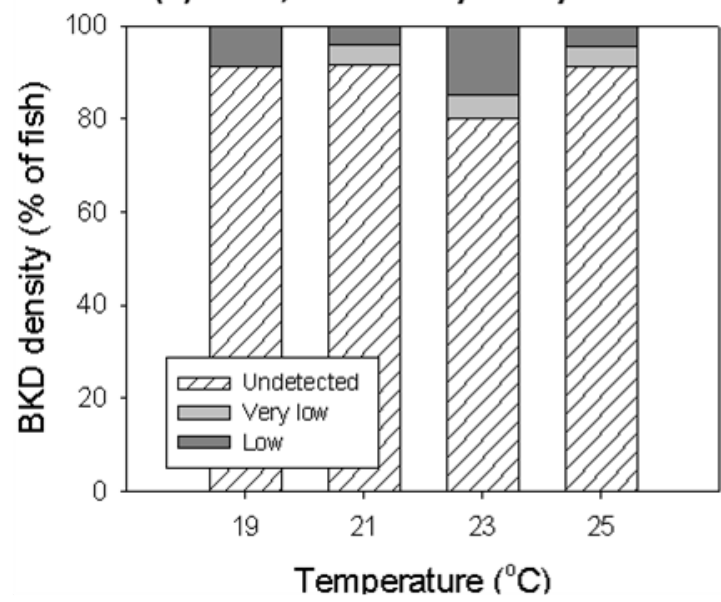

(b) 2005, Laboratory Study

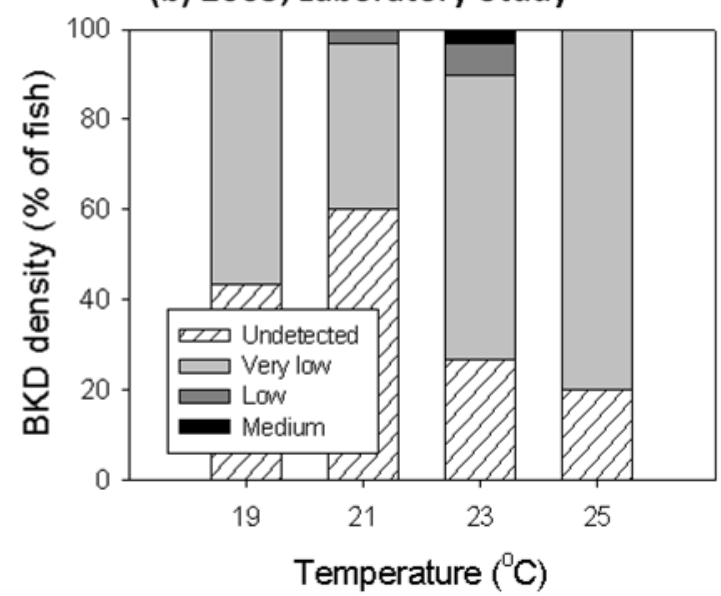

Figure 3.6. Graphs showing percentage of fish at each density level of Bacterial Kidney Disease (BKD), as determined from kidney tissue in subyearling Chinook salmon during laboratory study in (a) 2004, and (b) 2005. BKD density was determined to be undetected $(0.0)$, very low $(0.0$ to 0.099$)$, low $(0.100$ to 0.199$)$, or medium $(0.200$ to 0.499$)$ for each fish. There were no significant differences detected, as determined using ANOVA. 
(a) 2004, Field Study

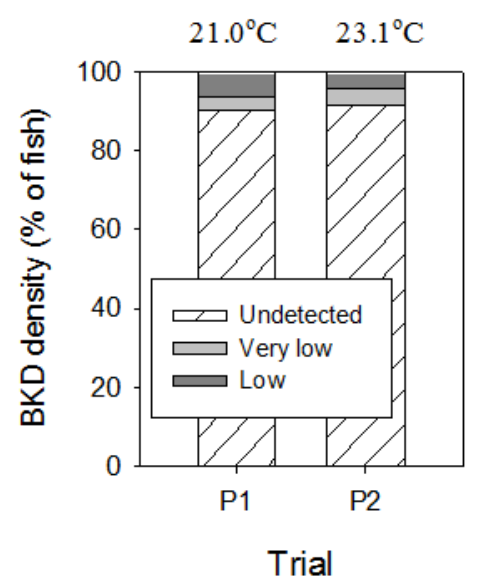

(b) 2005, Field Study

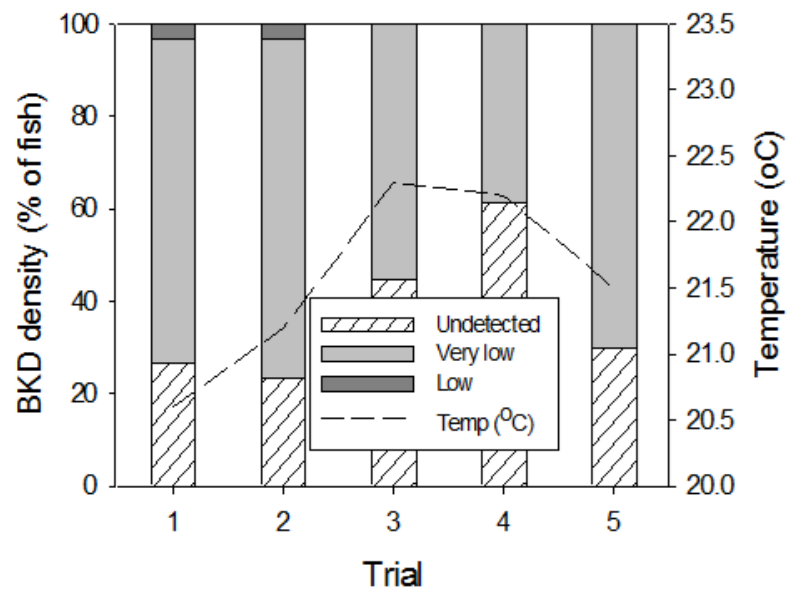

Figure 3.7. Graphs showing percentage of fish at each density level of Bacterial Kidney Disease (BKD), as determined from kidney tissue in subyearling Chinook salmon during (a) physiological field study in 2004, and (b) field study in 2005 . BKD density was determined to be undetected $(0.0)$, very low $(0.0$ to 0.099$)$, low $(0.100$ to $0.199)$, or medium (0.200 to 0.499$)$ for each fish. There were no significant differences detected, as determined using ANOVA. Temperature $\left({ }^{\circ} \mathrm{C}\right)$ is plotted as a dashed line in figure $b$. 

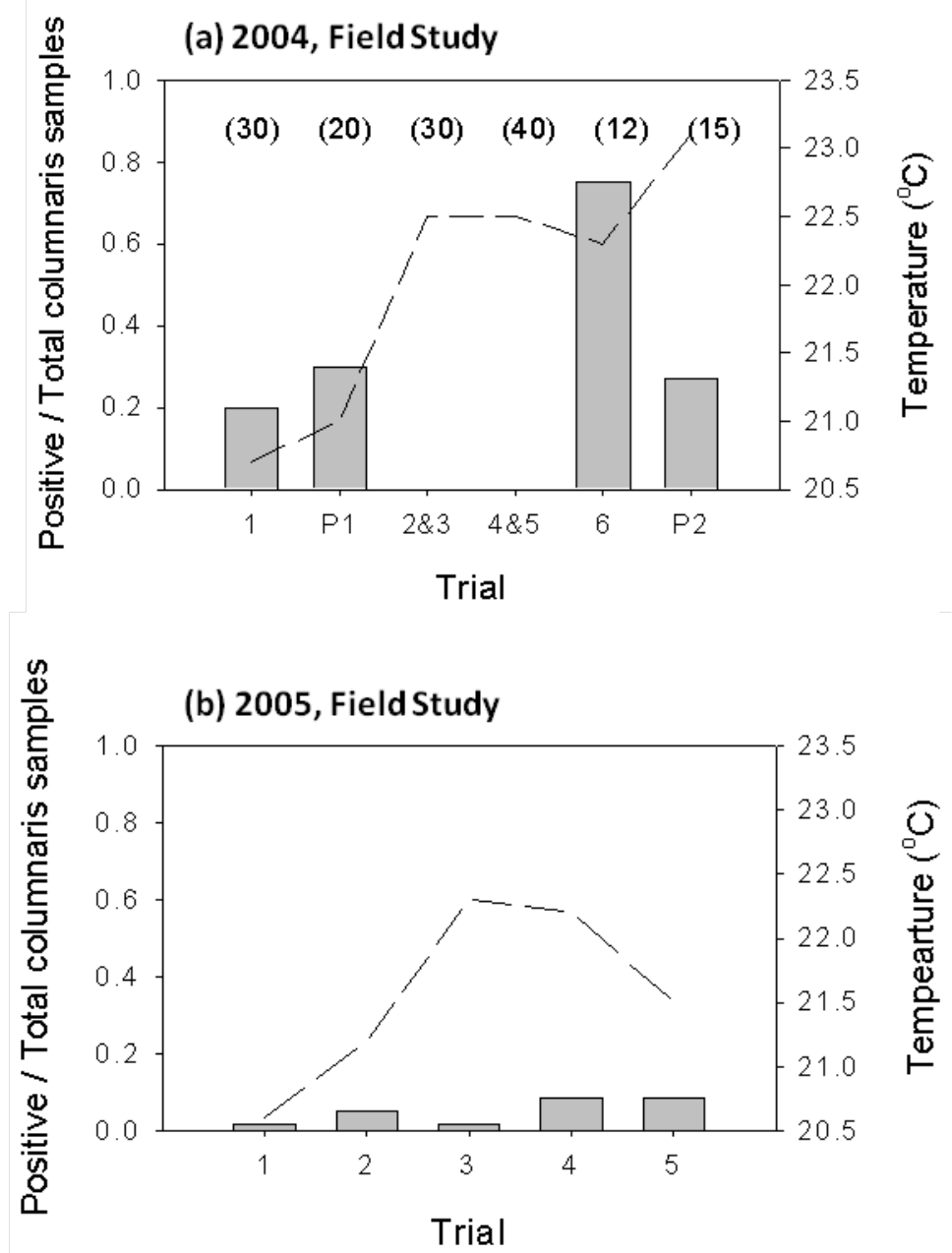

Figure 3.8. Graphs showing fraction of sampled subyearling Chinook salmon that were infected with Favobacterium columnare (columnaris) during field study in (a) 2004, and (b) 2005. Mean water temperature $\left({ }^{\circ} \mathrm{C}\right.$ ) is plotted as a dashed line. Number of samples for each trial is (a) shown in parenthesis for the 2004 trials, and (b) 60 for each 2005 trial. 


\section{Mortalities}

Mortality of tagged and control subyearling Chinook salmon was visually determined at 24 and $96 \mathrm{~h}$ after tagging. At $24 \mathrm{~h}$, there were no significant differences in mortality between tagged fish and controls in either the laboratory or the field study (table 3.4a and 3.4b, respectively). Overall, mortalities were low at $24 \mathrm{~h}$, with the exception of the $25^{\circ} \mathrm{C}$ trial in the 2004 laboratory study (table $3.4 a)$.

At $96 \mathrm{~h}$ in the laboratory study, the mortalities of tagged and control fish were significantly different at 19,23 , and $25^{\circ} \mathrm{C}$. At $19{ }^{\circ} \mathrm{C}$, the difference was most likely owing to an outbreak of coldwater disease contributing to elevated mortalities in tagged fish. The mortality of both tagged and control fish increased from 21 to $23^{\circ} \mathrm{C}$ in the laboratory study. At $25^{\circ} \mathrm{C}$, there was significant mortality in both tagged and control groups, with 50 percent or higher mortality at $96 \mathrm{~h}$.

In the field study, mortalities at $96 \mathrm{~h}$ generally were higher in 2004 than in 2005. In 2004, the highest mortality rates for both tagged and control fish were measured at the highest mean temperature $\left(22.5^{\circ} \mathrm{C}\right.$, trials 2 and 3$)$, with a significant difference between tagged and control fish during trial 2 $(P=0.03)$. In 2005 , the highest mortality for both groups was in the last trial $\left(21.5^{\circ} \mathrm{C}\right.$, trial 5$)$ rather than at the highest temperature $\left(22.3^{\circ} \mathrm{C}\right)$. 
Table 3.4. Number $(N)$ and percentage (\%) of mortalities in groups of tagged and control subyearling Chinook salmon at various water temperature 24 and 96 hours after tagging in (a) laboratory study, and (b) field study, in 2004 and 2005.

[Significant differences between tagged and control fish $\left(^{*}\right)$ at each temperature were determined using Fisher's exact test. Circles $(\bullet)$ indicate percentage mortalities that were estimated because of pump failure and physical damage to fish. n/a, not applicable]

(a) Laboratory study

\begin{tabular}{|c|c|c|c|c|c|c|c|c|c|}
\hline & Trial & & & & & & & & \\
\hline \multicolumn{10}{|c|}{ 24-hour mortalities } \\
\hline Year & Group & $N$ & $\%$ & $N$ & $\%$ & $N$ & $\%$ & $N$ & $\%$ \\
\hline \multirow{2}{*}{2004} & Control & 1 & 0.6 & 0 & 0 & 2 & 1.5 & 13 & 10.8 \\
\hline & Tagged & 1 & 0.7 & 1 & 0.5 & 8 & 6.3 & 92 & 69.9 \\
\hline \multirow{2}{*}{2005} & Control & 0 & 0 & 0 & 0 & 0 & 0 & 0 & 0 \\
\hline & Tagged & 0 & 0 & 0 & 0 & 0 & 0 & 0 & 0 \\
\hline \multicolumn{10}{|c|}{ 96-hour mortalities } \\
\hline \multirow{2}{*}{2004} & Control & 1 & $0.7 *$ & 4 & 2.2 & 1 & $0.8^{*}$ & 40 & $33.9 *$ \\
\hline & Tagged & 7 & $5.0 *$ & 3 & 1.8 & 20 & $16.4^{*}$ & 131 & $100.0 *$ \\
\hline \multirow{2}{*}{2005} & Control & 2 & 0.9 & 0 & 0 & 0 & $0.0 *$ & 69 & $54.8^{*}$ \\
\hline & Tagged & 3 & 1.4 & 2 & 0.9 & 7 & $3.6^{*}$ & 109 & $91.6^{*}$ \\
\hline
\end{tabular}

(b) Field study

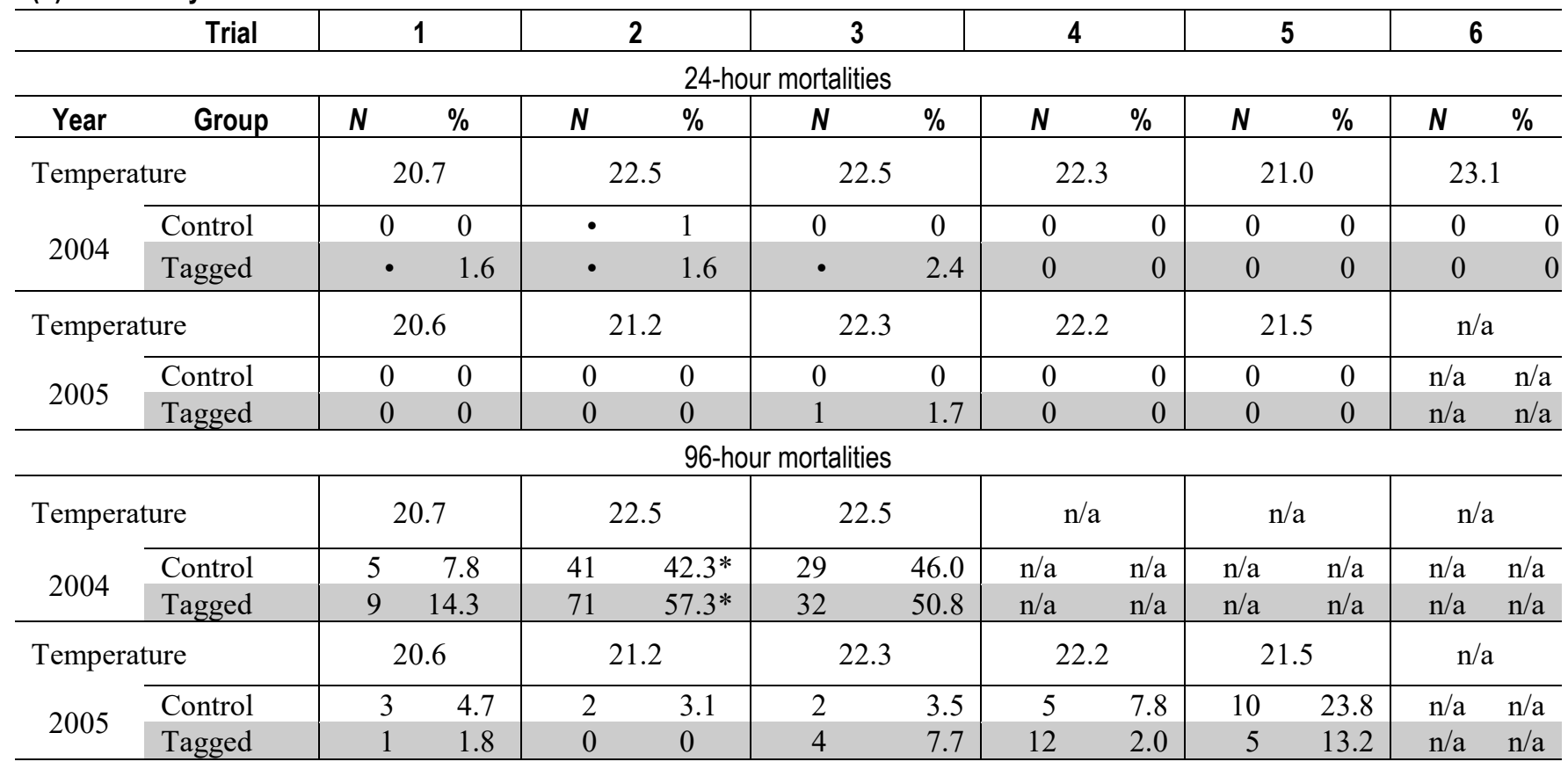




\section{Swimming Performance}

The swimming performance of tagged and control fish was influenced by water temperature. At $21{ }^{\circ} \mathrm{C}$, there was no significant difference between the $U_{\text {crit }}$ values for tagged fish and controls at 24 and $96 \mathrm{~h}$ after tagging (fig. 3.9). Mean $U_{\text {crit }}$ ranged from 53.1 to $57.8 \mathrm{~cm} / \mathrm{s}$ at $21{ }^{\circ} \mathrm{C}$. At $23{ }^{\circ} \mathrm{C}$, the swimming performance of tagged fish was significantly lower than that of controls at both 24 and $96 \mathrm{~h}$ after tagging (fig. 3.9). The $U_{\text {crit }}$ values for tagged and control fish at $23{ }^{\circ} \mathrm{C}$ were similar to those observed at $21^{\circ} \mathrm{C}$, ranging from 53.2 to $60.6 \mathrm{~cm} / \mathrm{s}$ (fig. 3.9). During the $25^{\circ} \mathrm{C}$ trials, fish introduced into the swim chamber $24 \mathrm{~h}$ after tagging generally were unable to acclimate to the baseline flow $(0.5$ $\mathrm{BL} / \mathrm{s}$ ) without showing signs of fatigue. This observation was particularly true of tagged fish. Although we were able to collect $U_{\text {crit }}$ values on small numbers of control fish at $25^{\circ} \mathrm{C}$, none of the tagged fish were able to swim the required $1 \mathrm{~h}$ at the baseline velocity, so no $U_{\text {crit }}$ could be measured. The mean $U_{\text {crit }}$ values for control fish at 24 and $96 \mathrm{~h}$ after tagging were lower at $25^{\circ} \mathrm{C}$ than during the 21 or $23^{\circ} \mathrm{C}$ temperature trials (fig. 3.9).

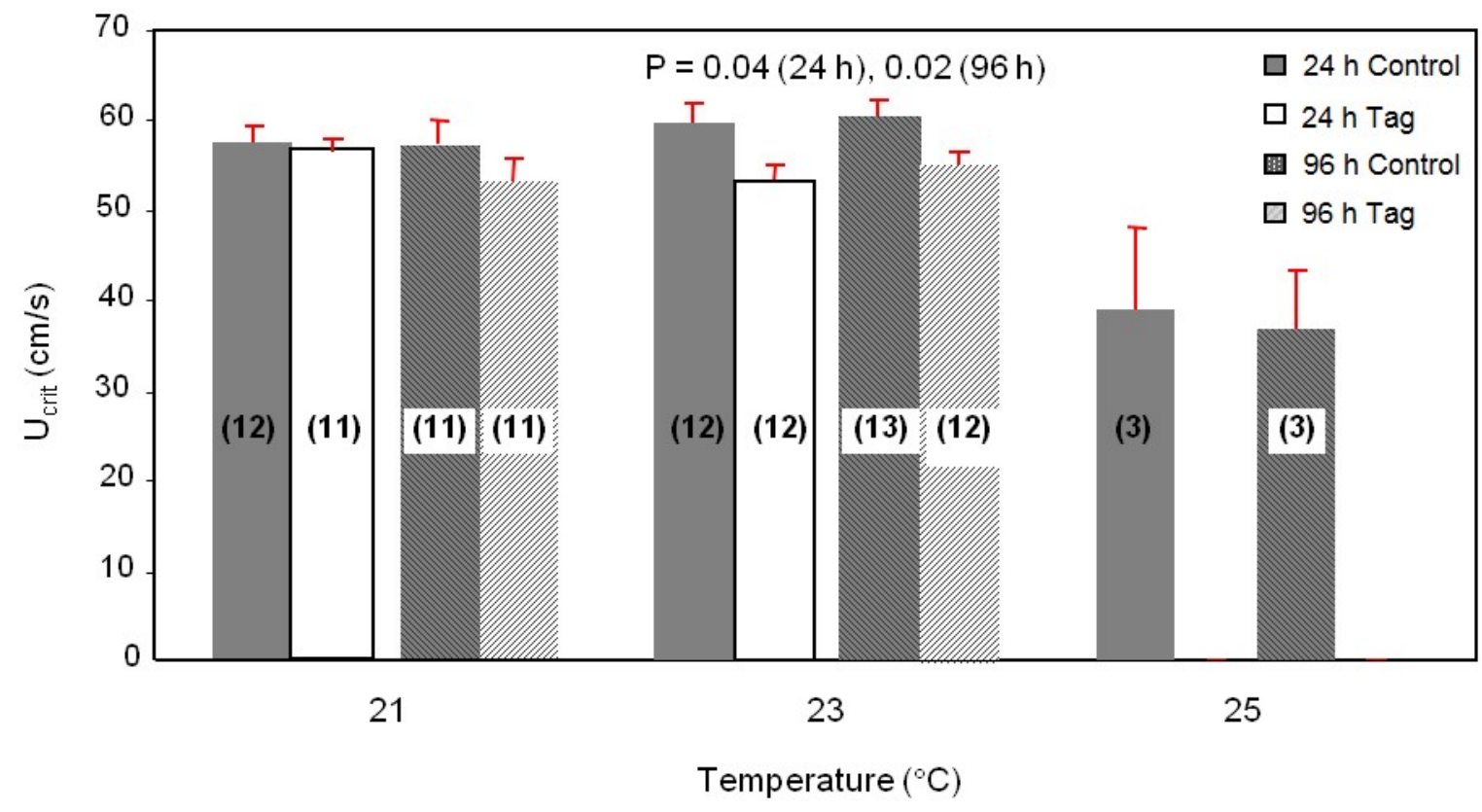

Figure 3.9. Graph showing swimming performance $\left(U_{\text {crit }}\right)$ of tagged and control fish at various water temperatures measured in the laboratory study in 2004. Sample sizes are shown in parentheses. Red bars represent standard errors. 


\section{Discussion}

In 2004 and 2005, we investigated the effects of elevated water temperature on subyearling Chinook salmon gastrically implanted with radio transmitters and on untagged controls. The objective was to determine if fish tagged at elevated temperatures showed elevated stress responses or mortality relative to untagged controls and, additionally, to determine the temperature threshold at which tagged and control fish show reduced performance. Experiments were conducted with laboratory-held hatchery fish and lower Columbia River active migrants during 2004 and 2005. We measured mortality, critical swimming speed, plasma cortisol, ATPase, hsp70, and pathogenic bacteria over a range of temperatures in the laboratory and the field. Results indicate that subyearling Chinook salmon generally showed elevated stress response, elevated mortality, and reduced performance as water temperature increased.

The levels of hsp 70 and cortisol we measured in study fish were somewhat variable between the laboratory and field trials, and between the 2 years of study, but the general trend showed higher levels of both of these stress indicators at the highest water temperatures. The laboratory data for hsp 70 shows a clear relation between elevated water temperatures and elevated hsp 70 for both tagged fish and controls. Similarly for cortisol, higher levels were noted at the higher temperatures. For both hsp 70 and cortisol, tagged fish commonly had higher levels compared to controls, suggesting that the tagging procedure or the tag itself added to the stress response. Statistically significant differences between the stress responses of tagged fish and controls more commonly were observed at the higher experimental water temperatures.

Mortality was influenced by water temperature in our evaluations. The clearest trends were noted in the laboratory studies where mortalities were minimal at $19{ }^{\circ} \mathrm{C}$ and $21{ }^{\circ} \mathrm{C}$, were somewhat elevated at $23{ }^{\circ} \mathrm{C}$, and were close to 100 percent at $25^{\circ} \mathrm{C}$. The highest mortality rates at $25^{\circ} \mathrm{C}$ were for tagged fish, but the elevated water temperature clearly affected the control fish as well. The mortality trends were less clear for the field evaluations. During 2004, we noted significant mortality at $22.5^{\circ} \mathrm{C}$, but during similar water temperatures in 2005, mortality was less severe. Considering that the run timing, passage history, and condition of the migrating salmon change from week to week and year to year, the differences we observed in mortality in the field are not unexpected.

The swimming performance of fish was reduced at elevated water temperatures. No difference was noted in the swimming performance of tagged fish and controls at $21^{\circ} \mathrm{C}$, the lowest water temperature tested. At $23^{\circ} \mathrm{C}$, there were significant reductions in the swimming performance of tagged fish relative to controls at both 24 and $96 \mathrm{~h}$ after tagging. At $25^{\circ} \mathrm{C}$, tagged fish were so compromised that they could not complete the baseline swimming acclimation stage of our protocol. There was very high mortality among tagged fish at this temperature, beginning immediately after tagging, and the fish were clearly unable to swim effectively at even low water velocities. We measured the $U_{\text {crit }}$ of several control fish at $25^{\circ} \mathrm{C}$, and their swimming ability was significantly reduced compared to their swimming ability at $23^{\circ} \mathrm{C}$. 
The study fish, for both the laboratory and field studies, generally were healthy. We tested for BKD and columnaris in the study fish and found infection levels to be low. There were no trends to suggest that the incidence of these pathogens in the study was correlated with water temperature. We are confident that our findings were not influenced by undetected BKD or columnaris disease processes.

We conducted laboratory and field studies to evaluate the influence of water temperature on fish mortality and performance. The laboratory approach allowed us to have strict temperature controls, but forced the use of hatchery fish. The field approach allowed the use of actively migrating hatchery fish, which are the perfect study animal, but not fine-scale temperature controls. Overall, the field findings supported the laboratory findings, with the inherent increase in variability expected in studies where fewer variables are under the control of the researcher. A complication for the field study was the use of fish from different points in the summer outmigration period. The condition of fish throughout the run can change dramatically in some years, and is a likely source of confounding results in the field study datasets. We noted, especially in the mortality dataset, that fish condition was compromised later in the season. In some cases, elevated mortality for late-season trials was noted, even when water temperature was similar or lower than earlier trials with lower mortality rates. We ascribe some of the elevated mortality to the condition of the migrants late in the migration season, and recommend that future studies consider fish condition and seasonal timing along with water temperature during study design.

The water temperature threshold for handling and tagging fish with minimal impacts to stress, mortality, and swimming performance appears to be near $23^{\circ} \mathrm{C}$. There was no evidence of any impacts at $21^{\circ} \mathrm{C}$. At $25^{\circ} \mathrm{C}$, we documented very high mortality and substantially reduced swimming performance of tagged fish relative to controls, which would clearly violate the critical assumption of telemetry studies that the application or presence of the tag does not affect the behavior of the study animal. 


\title{
Chapter 4. Effects of Antenna Length and Material on Output Power and Detection of Miniature Radio Transmitters
}

\author{
By John W. Beeman' ${ }^{1}$ Steve D. Juhnke1, Laura L. Dingmon'1, Neil Bower², Mike van den Tillaart², and Tom \\ Thomas $^{2}$ \\ 1 U.S. Geological Survey \\ 2 Lotek Wireless Incorporated ${ }^{\odot}$, Newmarket, Ontario, Canada
}

\section{Introduction}

The use of radio telemetry in studies of fish behavior has become commonplace and its application is growing through advances in technology and miniaturization. The use of smaller internal components has decreased the size and weight such that tags weighing less than $1.0 \mathrm{~g}$ are readily available, enabling studies of smaller fish than ever before. Radio telemetry has proven useful in many studies, including evaluations of dam passage behavior, habitat use, and responses to environmental conditions (Cheek and others, 1985; Martinelli and Shively, 1997; Johnson and others, 2000; Moser and others, 2002). Evaluations of the effects of radio transmitter (tag) presence on fish performance and behavior have been conducted on a variety of species, providing recommended tag-weight to body-weight ratios, attachment procedures, and detection methods (Winter, 1996; Martinelli and Shively, 1997; Beeman and others, 2004). However, little information has been published to guide researchers in the choice of antenna length or material.

Perhaps the most critical assumption in studies of tagged animals is that the application or presence of a tag does not affect the behavior of the animal (Guy and others, 1996). Despite availability of tags weighing less than $1.0 \mathrm{~g}$, this assumption may be easily violated in studies of some fishes because of their small size relative to the tag. Failing to meet this assumption is a common problem and probably will always remain as tags become miniaturized further and their use is extended to smaller fish. However, although tags have been continually reduced in size, antenna configuration has changed little. Thus, as tags are miniaturized further, a greater proportion of the tag effect on fish behavior will be attributable to the antenna, making antenna choice important.

The length and construction material of antennas can be modified to reduce their contribution to tag weight, but the effects on tag power must be evaluated to ensure that the resulting product is still useful for its intended purpose. The lengths of efficient radio antennas are inversely proportional to the frequency of operation, typically in some fraction of the wavelength. For example, the elements of aerial and underwater dipole antennas are commonly 0.5 wavelengths (DeMaw, 1987; Beeman and others, 2004). Lengths of efficient antennas also are a function of circuit design, the properties of the antenna material, and the medium in which the antennas will be used. However, little is known about the effects of modifying the length of tag antennas on the output power or detection probability. Thus, the lengths of tag antennas in studies of aquatic animals have been variable, ranging from about 10 to $44 \mathrm{~cm}$, and are rarely mentioned in the literature.

The objectives of this study were to (1) explore the relation between antenna material, length, and tag output power in a laboratory setting, and (2) test the effects of two antenna materials and lengths on tag reception in a field setting. The goal of the study was to lower overall tag weight without compromising detection. 


\section{Materials and Methods}

All tests were performed by altering antennas on Lotek Wireless Incorporated ${ }^{\complement}$ (Newmarket, Ontario, Canada) model NTC-3-1 pulse-coded tags with an operating frequency near $150 \mathrm{MHz}$. The tags were $6.3 \mathrm{~mm}$ in width, $4.5 \mathrm{~mm}$ in height, and $14.5 \mathrm{~mm}$ in length, and weighed $0.84 \mathrm{~g}$ in air with a 30-cm Sava (Type 1) antenna and $0.72 \mathrm{~g}$ with a 30-cm Minfish (Type 2) antenna. The Type 1 antenna was composed of a 49-strand stainless steel braided wire with an outer Teflon ${ }^{\mathrm{TM}}$ sheath, had a diameter of $0.58 \mathrm{~mm}$, and weighed $0.254 \mathrm{~g}$ per $30 \mathrm{~cm}$ length. The Type 2 material was composed of a 63 -strand stainless steel braided wire with an outer Teflon ${ }^{\mathrm{TM}}$ sheath, had a diameter of $0.41 \mathrm{~mm}$, and weighed $0.135 \mathrm{~g}$ per $30 \mathrm{~cm}$.

\section{Laboratory Tests of Tag Output Power}

Tests of tag output power were conducted indoors at Lotek Wireless Incorporated ${ }^{\odot}$ in Newmarket, Ontario, Canada in July 2004. The output powers of five $150.460 \mathrm{MHz}$ tags of each antenna type were measured with antenna lengths ranging from $30 \mathrm{~cm}$ to $10 \mathrm{~cm}$ in $2 \mathrm{~cm}$ decrements. Tests were begun with $30 \mathrm{~cm}$ antennas and were repeated each time the antennas were cut $2 \mathrm{~cm}$ shorter. Each tag, held in a plastic jig to maintain the antenna in a straight and horizontal position, was tested individually in a plastic cylindrical tank $(75 \mathrm{~cm}$ diameter, $77 \mathrm{~cm}$ water depth) in tap water with a temperature of $24^{\circ} \mathrm{C}$ and a conductivity of $780 \mu \mathrm{S} / \mathrm{cm}$. The water was allowed to stand for at least 48 $\mathrm{h}$ prior to the experiments to permit chlorine to dissipate. The tags were placed at approximately $30 \mathrm{~cm}$ of water depth. The tag output power was measured using a Hewlett Packard (Palo Alto, California) $8560 \mathrm{E}$ spectrum analyzer with a $30 \mathrm{kHz}$ bandwidth resolution connected to a Cushcraft (Manchester, New Hampshire) 4 element Yagi antenna placed $2.73 \mathrm{~m}$ above and pointed toward the water surface. The Yagi had a gain of 6.5 decibels relative to an isotropic radiator $(6.5 \mathrm{dBi})$; the elements of the receiving antenna were held parallel to the transmit antenna. A 32-decibel preamplifier was used to increase the received signal to improve the measurement accuracy across the dynamic range of the spectrum analyzer by shifting the level of the readings sufficiently above its noise floor.

\section{Detection Distance of Tags in Controlled Field Conditions}

The effects of antenna length and material on detection distances from a boat-mounted receiving system were evaluated in the Columbia River near Bingen, Washington, (river kilometer 274) from October 18-28, 2004. The tests were conducted by placing five tags at a time in a polyvinyl chloride (PVC) rack to hold the antennas in a consistent orientation and to expedite the tests. The tags were held $23 \mathrm{~cm}$ apart from each other (about 1 wavelength underwater) to reduce the impact of the presence of the other tags on transmission properties of individual tags. The lack of an effect of this procedure was confirmed prior to testing by comparing detection distances of individual tags in the rack with the same tags in the rack together. The rack was affixed to a line anchored at a depth of 12.5 $\mathrm{m}$, enabling adjustment to the test depths of 2,6 , and $10 \mathrm{~m}$. The rack was oriented in such a way that antennas were parallel to the thalweg of the river. Daily water temperatures at the study site ranged from 14.4 to $16.8{ }^{\circ} \mathrm{C}$ during the trials and conductivity was $146 \mu \mathrm{S} / \mathrm{cm}$ on at a nearby monitoring station on October 20, 2004 (Warrendale, Oregon, river kilometer 227; J. Morace, U.S. Geological Survey, written communication, 2004)

Three lengths of each antenna material were tested based on results of the laboratory trials. The lengths tested were the length with the greatest output power (medium), the greatest length tested (30 $\mathrm{cm}$; control), and the shortest length with an output power similar to the $30-\mathrm{cm}$ antenna (short). Five tags of each material and antenna length were tested at each of 2-, 6-, and 10-m depths. To mimic conditions when using a gastric implantation method, which is commonly used in studies of juvenile salmonid survival in the Columbia River, we bent the tag antennas in a 180-degree arc $5 \mathrm{~cm}$ from the end of the tag body, which allows the antenna to protrude from the mouth of the fish and trail back 
along the body of the fish. The effect of bending the antenna wire back on itself in this manner was assessed in the laboratory using the materials and methods as the tag power output studies. The outcome was a loss of signal strength roughly equivalent to a $2-\mathrm{cm}$ decrease in straight antenna length, so we added $2 \mathrm{~cm}$ to the medium and short antennas to offset this loss. The control length was unchanged, although it, too, was bent, so the control antenna represented a $28-\mathrm{cm}$ straight antenna. Antenna lengths were measured from the union of the antenna and the tag body to the terminus of the antenna.

To determine the detection distances of tags at several water depths, we followed the methods of Beeman and others (1998). The receiving system consisted of a six-element Yagi antenna (Cushcraft Model PLC1506) about $3 \mathrm{~m}$ above water surface connected to a Lotek SRX-400 receiver with approximately $6 \mathrm{~m}$ of Belden (Indianapolis, Indiana) 9311 coaxial cable. The receiver gain was set at 50 (on a range of 0-99). The location of the tag rack was recorded using a Trimble ${ }^{\circledR}$ (Sunnyvale, California) model TSC $1{ }^{\mathrm{TM}}$ GPS for reference to subsequent positions. The boat was moved beyond the range of audible detection and advanced slowly toward the tag rack with the receiver antenna perpendicular to the tag antennas, and the location was recorded with the GPS when the operator could hear the tag, or when the receiver could determine the code of (hereinafter, decode) the tag identity, depending on the objective. After the location of the first audible detection was recorded, the boat retreated out of audible range and the process was repeated twice more for audible detections and three times for tag identification. Both audible detection and tag identification trials were repeated with the tag rack at each of the three depths.

Analyses of the detection distances were conducted using a repeated measures analysis of variance (ANOVA). The analyses were based on data from the three repeated measurements from each of the five tags at each antenna length and type at each of the three depths. The analyses were conducted using the SAS ${ }^{\circledR}$ (Cary, North Carolina) mixed procedure specifying the Kenward-Roger method of calculating the denominator degrees of freedom for $t$-tests, the first-order autoregressive covariance matrix to model within-subjects variation with the REPEATED statement, and the Bonferroni adjustment to control Type-I error rates in comparisons of least squares means (Littell and others, 1996). Two-way ANOVAs were specified with the distance to either hear a tag or decode the signal as the dependent variables and depth and antenna length along with their interaction term as independent variables.

\section{Percent Detection of Tagged Fish at a Hydroelectric Dam}

The effects of antenna length and material on detection of tagged fish at a receiving system mounted to a hydroelectric dam were evaluated at The Dalles Dam on the Columbia River (river kilometer 274). As part of a concurrent study of passage and survival at The Dalles Dam, subyearling Chinook salmon (Oncorhynchus tshawytscha) were implanted with short (16-cm) Type 2 antennas, medium $(23-\mathrm{cm})$ Type 1 antennas, and control $(30-\mathrm{cm})$ Type 1 antennas and then released. Tags were gastrically implanted using methods of Martinelli and others (1998) and were held in tanks at John Day Dam for about $24 \mathrm{~h}$ to allow recovery from the procedure prior to release. Approximately equal numbers of tagged fish were released mid-river about $3.5 \mathrm{~km}$ downstream of John Day Dam at 1800 hours on July 27, 2004, and at 0600 hours and 1800 hours on July 28, 2004. The proportion of each group detected by an array of aerial and underwater receiving systems, which enabled detection of fish within about $100 \mathrm{~m}$ of the forebay and tailrace sides of The Dalles Dam, were compared. The percentage of detections of the tags with the medium Type 1 or short Type 2 antennas were compared to those of the control Type 1 antennas using a logistic regression procedure with Chi-square tests of odds ratios (Allison, 1999; Stokes and others, 2000). Statistical significance throughout the study was assumed when $P \leq 0.05$. 


\section{Results}

\section{Laboratory Tests of Tag Output Power}

The relation between tag output power and antenna length was curvilinear and slightly different between antenna types (fig. 4.1). The maximum output power of Type 1 and Type 2 antennas were at 20 and $22 \mathrm{~cm}$, respectively, which is similar to the $21.8-\mathrm{cm}$ wavelength of a $150-\mathrm{MHz}$ radio wave underwater. The power of the 8-cm Type 1 antenna and the 14-cm Type 2 antenna were similar to their respective $30-\mathrm{cm}$ antennas, so these lengths, plus $2 \mathrm{~cm}$ to account for the bend for gastric implantation, were used as "short" lengths in subsequent tests.

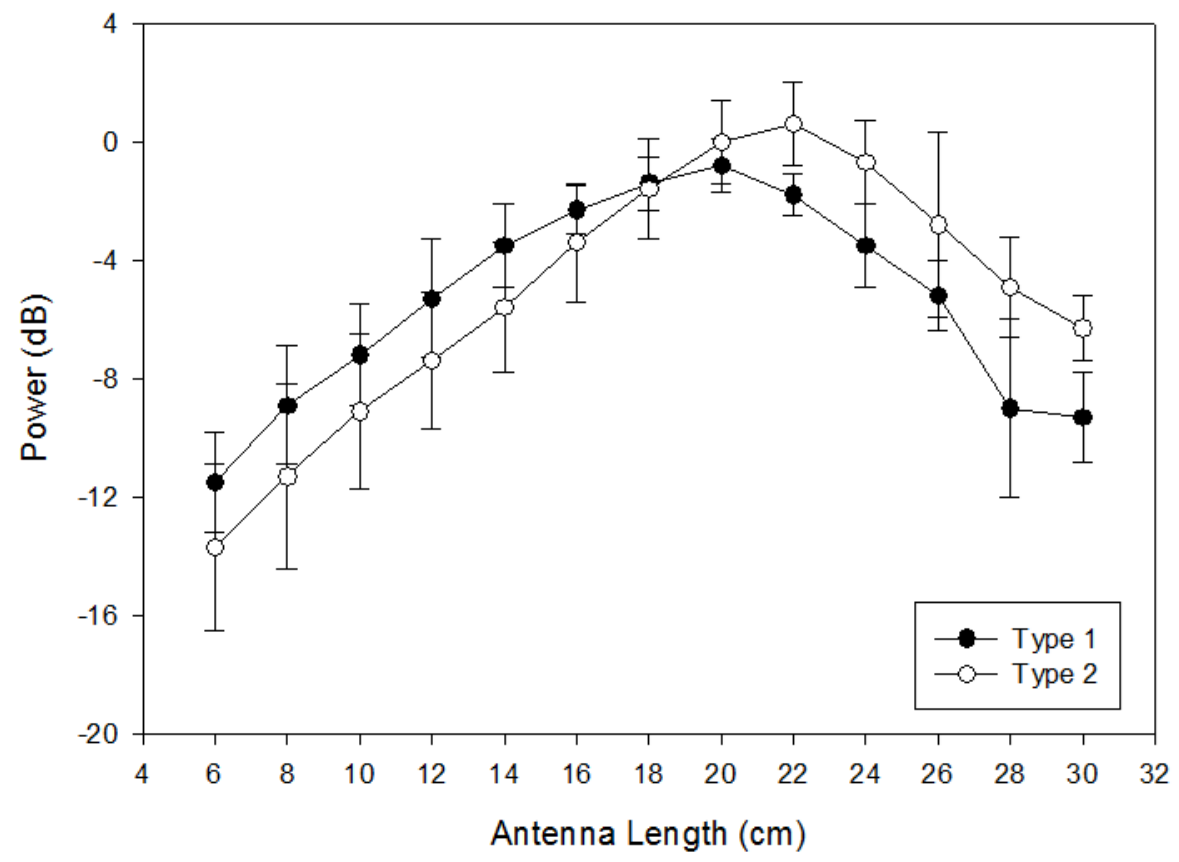

Figure 4.1. Graph showing mean and 95-percent confidence intervals of relative output power (in decibels [dB]) of tags with two antenna types of various lengths (in centimeters [cm]) measured in laboratory.

\section{Detection Distance of Tags in Controlled Field Conditions}

Significant differences were present in detection distances for Type 1 antennas at the 2-m depth, but none were present at 6- or 10-m depths (fig. 4.2). The effects of antenna length were assessed at each depth separately because of a significant length*depth interaction term in the 2-way ANOVA model $(\mathrm{F}=19.00, \mathrm{df}=4,114, P<0.0001)$. A significant difference among antenna lengths was present at $2 \mathrm{~m}(\mathrm{~F}=4.90, \mathrm{df}=2,12, P=0.0279)$, but none were present at $6 \mathrm{~m}(\mathrm{~F}=2.32, \mathrm{df}=2,12$, $P=0.1403)$, or $10 \mathrm{~m}(\mathrm{~F}=3.27, \mathrm{df}=2,12, P=0.0737)$. The detection distance at $2 \mathrm{~m}$ was significantly greater for medium than for short antennas; however, the detection distance for control-length antennas was similar to them both (table 4.1).

Few significant differences were present in distances to decode tags with Type 1 antennas (fig. 4.2). There was a significant difference in decoding distance among tags with different length antennas at $10 \mathrm{~m}(\mathrm{~F}=5.49, \mathrm{df}=1,8, P=0.0473)$, but not at $2 \mathrm{~m}(\mathrm{~F}=2.00, \mathrm{df}=2,12, P=0.1779)$ or $6 \mathrm{~m}(\mathrm{~F}=1.65$, $\mathrm{df}=2,12, P=0.2333)$. At $10 \mathrm{~m}$, the tags with medium length antennas were decoded at a greater distance than the control length, and the short length could not be decoded (table 4.1). 


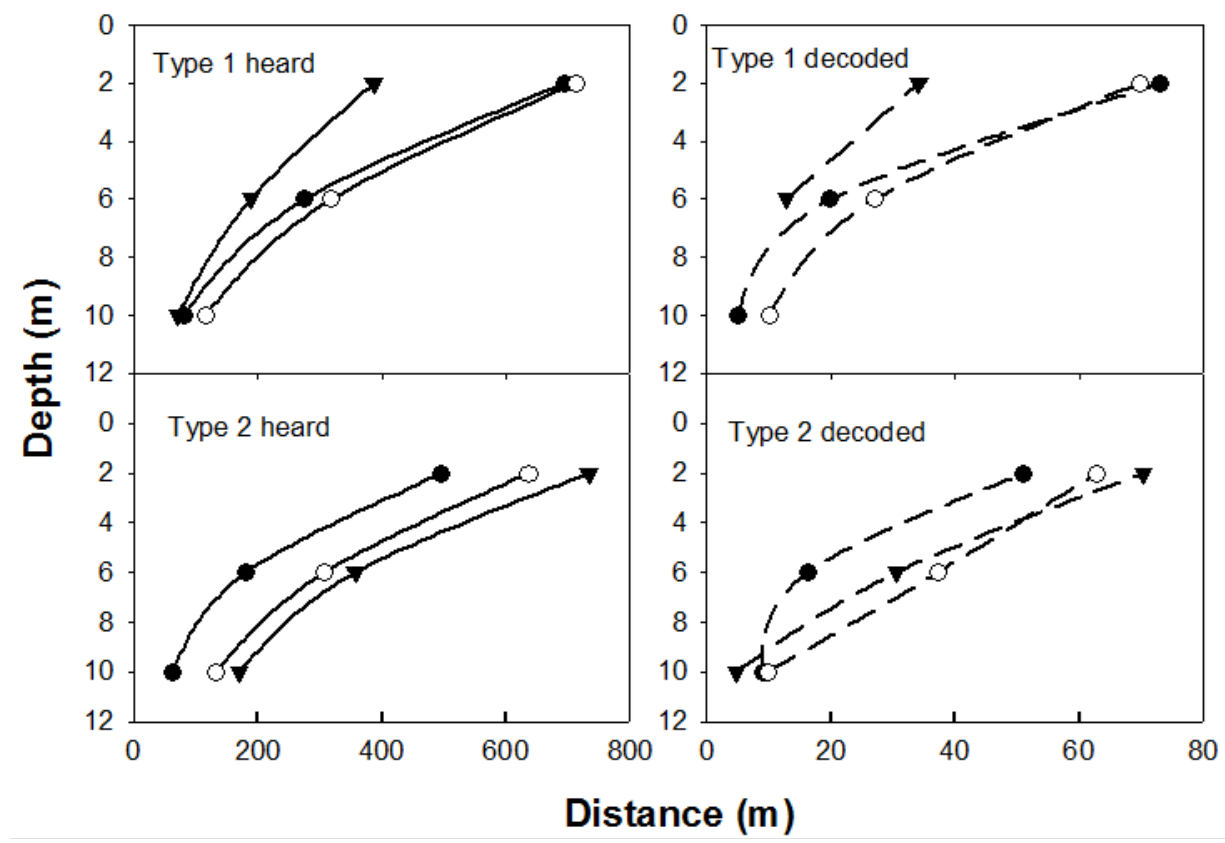

Figure 4.2. Graphs showing distances at various depths for hearing and decoding tags with Type 1 and Type 2 antennas of short (closed triangle), medium (open circle), and control (closed circle) lengths from a boat-mounted receiving system in the Columbia River, Oregon and Washington. Smoothed lines drawn between points are for clarity and may not represent the relation between tag depth and reception distance.

Modified Type 2 antennas generally were heard from greater distances than the control antennas (fig. 4.2). A significant interaction between antenna length and depth was present in the 2way ANOVA, so the effect of antenna length was tested at each depth separately $(\mathrm{F}=5.02, \mathrm{df}=4,114$, $P=0.0009)$. Significant differences in detection distance among antenna lengths were present at $2 \mathrm{~m}$ $(\mathrm{F}=12.70, \mathrm{df}=2,12, P=0.0011), 6 \mathrm{~m}(\mathrm{~F}=10.74, \mathrm{df}=2,12, P=0.0021)$, and $10 \mathrm{~m}(\mathrm{~F}=9.44, \mathrm{df}=2,12, P=$ $0.0034)$. At $2 \mathrm{~m}$ and $6 \mathrm{~m}$, the detection distance for the control antennas was significantly shorter than for the medium and short antennas, which were not significantly different from each other (table 4.1). At $10 \mathrm{~m}$, the detection distance for the control antennas was significantly less than for the short antennas, and the distance for medium antennas was not significantly different from the others. 
Table 4.1. Distances at various depths at which tags were heard or decoded using boat-mounted receiving system.

[Values represent means of three measurements from each of five tags of each antenna material type and length. Within an antenna material and distance category (hear or decode), distances within each depth with letters in common were not significantly different from each other $(P>0.05)$. n/a, not applicable. The short Type 1 antenna could not be decoded at 10 meters]

\begin{tabular}{|c|c|c|c|c|}
\hline \multirow{2}{*}{$\begin{array}{l}\text { Antenna } \\
\text { material }\end{array}$} & \multirow{2}{*}{$\begin{array}{l}\text { Antenna } \\
\text { length }\end{array}$} & \multicolumn{3}{|c|}{$\begin{array}{c}\text { Depth } \\
\text { (meters) }\end{array}$} \\
\hline & & 2 & 6 & 10 \\
\hline \multicolumn{5}{|c|}{ Distance to hear } \\
\hline Type 1 & $\begin{array}{c}\text { Short } \\
\text { Medium } \\
\text { Control }\end{array}$ & $\begin{array}{l}386.6 \mathrm{z} \\
712.8 \mathrm{y} \\
694.2 \mathrm{zy}\end{array}$ & $\begin{array}{l}188.5 \mathrm{z} \\
318.0 \mathrm{z} \\
275.6 \mathrm{z}\end{array}$ & $\begin{array}{r}80.7 \mathrm{z} \\
115.3 \mathrm{z} \\
71.1 \mathrm{z}\end{array}$ \\
\hline Type 2 & $\begin{array}{c}\text { Short } \\
\text { Medium } \\
\text { Control }\end{array}$ & $\begin{array}{l}733.4 \mathrm{z} \\
636.4 \mathrm{z} \\
496.4 \mathrm{y}\end{array}$ & $\begin{array}{l}356.9 \mathrm{z} \\
307.0 \mathrm{z} \\
180.5 \mathrm{y}\end{array}$ & $\begin{array}{r}170.1 \mathrm{z} \\
132.1 \mathrm{zy} \\
63.1 \mathrm{y}\end{array}$ \\
\hline \multicolumn{5}{|c|}{ Distance to decode } \\
\hline Type 1 & $\begin{array}{c}\text { Short } \\
\text { Medium } \\
\text { Control }\end{array}$ & $\begin{array}{l}34.2 \mathrm{z} \\
69.9 \mathrm{z} \\
73.1 \mathrm{z}\end{array}$ & $\begin{array}{l}19.9 \mathrm{z} \\
27.0 \mathrm{z} \\
12.8 \mathrm{z}\end{array}$ & $\begin{array}{c}\mathrm{n} / \mathrm{a} \\
10.1 \mathrm{z} \\
5.1 \mathrm{y}\end{array}$ \\
\hline Type 2 & $\begin{array}{c}\text { Short } \\
\text { Medium } \\
\text { Control }\end{array}$ & $\begin{array}{l}70.3 \mathrm{z} \\
62.8 \mathrm{z} \\
51.0 \mathrm{z}\end{array}$ & $\begin{array}{l}30.6 \mathrm{zy} \\
37.2 \mathrm{z} \\
16.2 \mathrm{y}\end{array}$ & $\begin{array}{l}4.8 \mathrm{z} \\
9.9 \mathrm{z} \\
9.0 \mathrm{z}\end{array}$ \\
\hline
\end{tabular}

Few significant differences were present in the decoding distances of tags with different length Type 2 antennas (fig. 4.1). A significant interaction between antenna length and tag depth was present in the 2-way ANOVA ( $\mathrm{F}=6.61, \mathrm{df}=4,106, P<0.0001)$, so the effect of antenna length was tested for each depth separately. No significant difference in decoding distance was observed among the different antenna lengths at $2 \mathrm{~m}(\mathrm{~F}=3.65, \mathrm{df}=2,12, P=0.0577)$ or $10 \mathrm{~m}(\mathrm{~F}=1.30, \mathrm{df}=2,9, P=0.3184)$. However, at the 6-m depth $(\mathrm{F}=4.47, \mathrm{df}=2,12, P=0.0299)$, there was a significant difference. At this depth, the decoding distance of the medium antennas was significantly greater than for the control antennas, and the decoding distance for the short antennas was similar to them both (table 4.1).

\section{Percent Detection of Tagged Fish at a Hydroelectric Dam}

Detection rates of tags with modified antennas were similar or greater than detection rates of tags with control antennas. There was no significant difference between detection rates of tags with short Type 2 antennas and the control $\left(\chi^{2}=0.69, \mathrm{df}=1, P=0.4061\right)$, but the tags with $23-\mathrm{cm}$ Type 1 antennas were detected at a significantly greater rate than the control antennas $\left(\chi^{2}=4.20, \mathrm{df}=1\right.$, $P=0.0405$; table 4.2). There were no significant differences among the replicates, or within the replicate*antenna type interaction terms of either test. 
Table 4.2. Radio-tagged subyearling Chinook salmon tagged and released to test effects of antenna type and length on detection percentage as fish passed a hydroelectric dam.

[Overall detection percentages with letters in common were not significantly different from each other $(P>0.05)$ ]

\begin{tabular}{|c|c|c|c|c|c|c|c|}
\hline \multirow{2}{*}{$\begin{array}{l}\text { Antenna type } \\
\text { and length }\end{array}$} & \multirow{2}{*}{ Replicate } & \multirow{2}{*}{$\mathbf{N}$} & \multicolumn{2}{|c|}{$\begin{array}{l}\text { Fork length } \\
\text { (millimeters) }\end{array}$} & \multicolumn{2}{|c|}{$\begin{array}{l}\text { Fish weight } \\
\text { (grams) }\end{array}$} & \multirow{2}{*}{$\begin{array}{c}\text { Detection } \\
\text { (percentage) }\end{array}$} \\
\hline & & & Mean & Range & Mean & Range & \\
\hline Type 1 & 1 & 23 & 109.3 & $103-129$ & 14.7 & $13.0-23.0$ & 82.6 \\
\hline \multirow[t]{3}{*}{ Medium } & 2 & 24 & 114.9 & 104-130 & 17.4 & $13.0-22.8$ & 95.8 \\
\hline & 3 & 25 & 111.9 & $103-133$ & 17.2 & $13.8-27.5$ & 80.0 \\
\hline & Overall & 72 & 112.1 & $103-133$ & 16.4 & $13.0-27.5$ & $86.1 \mathrm{z}$ \\
\hline Type 2 & 1 & 24 & 111.9 & $103-136$ & 16.2 & $13.3-16.2$ & 75.0 \\
\hline \multirow[t]{3}{*}{ Short } & 2 & 24 & 114.0 & $104-130$ & 17.1 & $13.0-25.8$ & 79.2 \\
\hline & 3 & 22 & 109.2 & $103-126$ & 16.6 & $13.7-22.5$ & 81.8 \\
\hline & Overall & 70 & 111.8 & $103-136$ & 16.7 & $13.0-26.0$ & $78.6 \mathrm{zy}$ \\
\hline Type 1 & 1 & 35 & 110.4 & $103-130$ & 15.5 & $13.2-25.7$ & 65.7 \\
\hline \multirow[t]{3}{*}{ Control } & 2 & 32 & 112.4 & $102-136$ & 16.4 & $13.0-27.8$ & 78.1 \\
\hline & 3 & 46 & 109.5 & $101-130$ & 16.5 & $13.0-26.8$ & 76.1 \\
\hline & Overall & 113 & 110.6 & $101-136$ & 16.2 & $13.0-27.8$ & $73.4 \mathrm{y}$ \\
\hline
\end{tabular}

\section{Discussion}

The results of this study indicate that the output power and subsequent reception of radio tags was a function of the antenna material and length. The greatest reception ranges and detection rates generally were at the antenna lengths predicted from laboratory measurements of tag output power. These optimal antenna lengths were considerably shorter than the $30 \mathrm{~cm}$ many researchers have used in the past; so by simply reducing the length of the tag antenna to the proper length, one can increase output power and reception and decrease tag weight and potential effects of the antenna on fish behavior.

The primary goal of this study was to determine if tag weight could be reduced by changes in antenna material or weight without compromising detectability. The result that best satisfied this goal during our tests was the short (16-cm) Type 2 antenna, although results from the medium $(24-\mathrm{cm})$ Type 2 antennas were similar. The short antenna was $2 \mathrm{~cm}$ greater than the short length indicated in the laboratory test because of the bend in the antenna for use with a gastric implant method; use with a straight antenna, such as in a surgical or external attachment, would be optimal at a length of $14 \mathrm{~cm}$. This configuration resulted in a decrease in tag weight in air from $0.84 \mathrm{~g}$ for a tag with the 30-cm Type 1 antenna, which is commonly used in studies of juvenile salmon in the Columbia River, to $0.65 \mathrm{~g}$ for a tag with a 16-cm Type 2 antenna. This is a substantial decrease in overall weight relative to the tag used, was achieved at little cost compared to redesign of internal components to achieve the same result, and resulted in no significant difference in detection (78.6 percent) than the tag with the $30-\mathrm{cm}$ Type 1 antenna (73.4 percent). Use of the medium Type 1 antenna resulted in significantly greater detection (86.1 percent) than the 30-cm Type 1 antenna, indicating it would be a logical choice if the goal was to maximize detection of tags with this antenna material. This study was based on external antennas, but it is conceivable that the output power and weight of tags with internal antennas also could be improved by altering antenna length and material. 
Some differences between results of field and laboratory tests were evident. Based on laboratory tests, we expected the field performance of tags with medium antennas to be greater than the control and short antennas, which were expected to be similar to each other. In field trials of Type 1 antennas, the control medium lengths were similar and the short length had the shortest range. In field trials with Type 2 antennas, the short and medium distance were similar to each other and the control length had the shortest range. One difference between laboratory and field studies was control of the orientation of the transmitting and receiving antennas. These orientations were tightly controlled in laboratory tests, but variation in river current, wind, and other environmental factors affected the consistency of the antenna orientations during field tests, introducing an additional source of error. Received signals are of greatest power when transmit and receive antennas are parallel (Beeman and others, 2004). Differences between laboratory and field results also may have been owing to the conductivity and temperature of the water in the two settings. The conductivity and temperature of the water used in laboratory tests in Ontario, Canada, were $780 \mu \mathrm{S} / \mathrm{cm}$ and $24{ }^{\circ} \mathrm{C}$, respectively, and the conductivity and temperature of the water during field tests in Washington were $146 \mu \mathrm{S} / \mathrm{cm}$ and 14.4 $16.8{ }^{\circ} \mathrm{C}$, respectively. The propagation of radio waves through water is affected by conductivity and temperature, and the differences in our study may have affected the results by altering the velocity factor, and, therefore, the wavelength of the transmitted signal.

The benefits of understanding the relation between antenna material, length, and output power are threefold. First, weight of small tags can be simply reduced. This reduction could allow smaller fish to be tagged, enabling telemetry to be applied to smaller species, or a greater proportion of the population of species already studied, such as subyearling Chinook salmon, which range in weight from about 5 to $23 \mathrm{~g}$ in the Columbia River. Decreases in tag weight through changes in antennas will become more important as tags are further reduced in size, because antenna weight will represent a larger proportion of the overall tag weight. Second, the increase in tag output power and the resulting increase in detection could result in increased precision of survival or passage estimates, a means to decrease sample sizes while maintaining existing precision in ongoing studies, or to simply gather more data from tagged fish. These considerations are important in recent studies of juvenile salmon passage and survival at dams throughout the Columbia River Basin, which have recently required about 40,000 tagged fish annually. Finally, fish behavior may be less affected by lighter tags with shorter antennas. Little direct study of the effects of antenna length on fish behavior or performance has been published, but Anglea and others (2004) described fewer effects of acoustic tag (i.e., no antenna) implantation on swimming performance and susceptibility to predation of juvenile Chinook salmon than typically seen in studies of tags with antennas (Adams and others, 1998b, Martinelli and others, 1998), suggesting that external antennas may affect fish performance or behavior. If so, a shorter or lighter antenna may impart less of an effect on the fish. In some studies, using radio tags with antennas coiled within the embedding material could obviate the need for "shorter" trailing antennas. Coiled antennas generally result in lower output power than trailing antennas (Cooke and Bunt, 2001) and may be inappropriate in cases where output power is important, such as for determining accurate pulse intervals or where reception distances need to be maximized because of large study areas or small detection fields (Beeman and others, 1998; Johnson and others, 2000).

There can be no universally-applied "optimum" antenna length for radio tags, as many biological and technical factors must be considered. We only tested antenna lengths ranging from 6 to $30 \mathrm{~cm}$ because our goal was to use the tags in small fish. The antenna lengths resulting in the greatest output power were near 1 wavelength of the tag frequency underwater, but this may not be true with all tags or antenna materials. The wavelength of a $150 \mathrm{MHz}$ radio wave underwater is about $22 \mathrm{~cm}$ (at temperature $=10^{\circ} \mathrm{C}$ and conductivity $=150 \mu \mathrm{S} / \mathrm{cm}$ ), which is near the peak output power of the two antenna types we tested (20 and $22 \mathrm{~cm}$ ). However, we have since tested other antenna materials in the laboratory and found one with peak output power at $16 \mathrm{~cm}$. The effect of the antenna on tag output is controlled by many factors, including the size and shape of the tag and the properties of the antenna 
wire. Tag size and shape are important because the body of the transmitter (including its battery) is a significant part of the total radiating aperture. The conductivity of the antenna wire depends on the material, the number and thickness of strands, and the wire diameter. These factors determine the distributed capacitance between the antenna and the surrounding medium. The thickness and dielectric properties of the insulating material also contribute to the antenna properties. In addition to preventing leakage of conducting charges from the antenna, the insulation material reduces the sensitivity of the distribution of current in the antenna to the electrical properties of the ambient medium. Hence, the optimal antenna length for any given frequency may vary for different antenna materials. Finally, the propagation properties of a wire antenna will vary considerably with the conductivity of water. We suggest that tests of the effects of antenna length and material on tag output power be conducted for specific tag/antenna combinations, or that further studies be conducted to determine the relations among these factors.

Future studies using radio telemetry may be improved by careful selection of antenna material and length. Increases in output power and detection can be realized through the use of studies of the effects of tag material and length on output power. We determined that the output power of tags with $30-\mathrm{cm}$ antennas and tags with antennas as short as $8 \mathrm{~cm}$ were similar, depending on the antenna material, and that intermediate lengths provided the greatest detection range and percentage. Information about the effect of antennas on tag output power enables researchers to balance needs for tags with low weight, short antennas, or optimal detection depending on study requirements. Decisions about antenna lengths and materials will be of increasing importance as tags are miniaturized and used in smaller fish. Results from laboratory studies generally were indicative of performance in field studies. However, we determined that the relation between antenna length and output power was a function of the antenna material and likely is affected by the tag itself, warranting tests with other tag types or models.

\section{Acknowledgments}

We thank individuals in the U.S. Army Corps of Engineers at the Portland District and The Dalles and John Day Dams for their cooperation and assistance on the project. We are especially grateful to Pacific States Marine Fisheries Commission, Greg Kovalchuk and colleagues at the John Day Dam Fish Collection Facility; colleagues at Spring Creek National Fish Hatchery; and colleagues

at U.S. Fish and Wildlife Service Lower Columbia River Fish Health Center for their assistance during this study. We thank Russell Newman, Lisa Wright, Jamie Sprando, Joshua Morse, Adam Pope, Matt Mesa, Will Simpson, Lisa Gee, Ryan Tomka and the rest our colleagues at the Columbia River Research Laboratory for their hard work and dedication.

\section{References Cited}

Ackerman, P.A. and Iwama, G.K., 2001, Physiological and cellular stress responses of juvenile rainbow trout to vibriosis: Journal of Aquatic Animal Health, v. 13, p.173-180.

Adams, N.S., Rondorf, D.W., Evans, S.D., Kelly, J.E., and Perry, R.W., 1998b, Effects of surgically and gastrically implanted radio transmitters on growth and feeding behavior of juvenile Chinook salmon: Transactions of the American Fisheries Society, v. 127, p.128-136.

Adams, N.S., Rondorf, D.W., Evans, S.D., Kelly, J.E., and Perry, R.W., 1998a, Effects of surgically and gastrically implanted radio transmitters on swimming performance and predator avoidance of juvenile Chinook salmon (Oncorhynchus tshawytscha): Canadian Journal of Fisheries and Aquatic Sciences, v. 55, p.781-787.

Allison, P.D., 1999, Logistic regression using the SAS ${ }^{\circledR}$ system-Theory and application: Cary, North Carolina, SAS ${ }^{\circledR}$ Institute Incorporated, 304 p. 
Anglea, S.M., Geist, D.R., Brown, R.S., and Deters, K.A., 2004, Effects of acoustic transmitters on swimming performance and predator avoidance of juvenile Chinook salmon: Transactions of the American Fisheries Society, v. 24, p. 162-170.

Baker, P.F., Speed, T.P., and Ligon, F.K., 1995, Estimating the influence of temperature on the survival of Chinook salmon smolts (Oncorhynchus tshawytscha) migrating through the Sacramento San Joaquin River Delta of California: Canadian Journal of Fisheries and Aquatic Sciences, v. 52, p.855-863.

Bell, W.H., and Terhune, L.D.B., 1970, Water tunnel design for fisheries research: Journal of the Fisheries Research Board of Canada Technical Report, v. 195, p.1-69.

Beeman, J.W., Grant, C., and Haner, P.V., 2004, Comparison of three underwater antennas for use in radio telemetry: North American Journal of Fisheries Management, v. 24, p.275-281.

Beeman, J.W., Haner, P.V., and Maule, A.G., 1998, Evaluation of a new miniature pressure-sensitive radio tag: North American Journal of Fisheries Management, v. 8, p.458-464.

Bernatchez, L., and Dodson, J.J., 1985, Influence of temperature and current speed on the swimming capacity of lake whitefish (Coregonus clupeaformis) and cisco (C. artedii): Canadian Journal of Fisheries and Aquatic Sciences, v. 42, p.1,522-1,529.

Brett, J.R., 1964, The respiratory metabolism and swimming performance of young sockeye salmon: Journal of the Fisheries Research Board of Canada, v. 21, p. 1,183-1,225.

Brett, J.R., 1967, Swimming performance of sockeye salmon (Oncorhynchus nerka) in relation to fatigue time and temperature: Journal of the Fisheries Research Board of Canada, v. 24, p. 1,7311,741 .

Bridger, C.J., and Booth, R.K., 2003, The Effects of biotelemetry transmitter presence and attachment procedures on fish physiology and behavior: Reviews in Fisheries Science, v. 11, p. 13-34.

Brown, R.S., Cooke, S.J., Anderson, W.G., and McKinley, R.S., 1999, Evidence to challenge the '2 percent rule' for biotelemetry: North American Journal of Fisheries Management, v. 19, p. 867-871.

Brown, R.S., Geist, D.R., Deters, K.A., and Grassell, A., 2006, Effects of surgically implanted acoustic transmitters $>2 \%$ of body mass on the swimming performance, survival and growth of juvenile sockeye and Chinook salmon: Journal of Fish Biology, v. 69, p. 1,626-1,638, doi: 10.1111/j.10958649.2006.01227.x.

Cain, M.L., 1989, The analysis of angular data in ecological field studies: Ecology, v. 70, p. 1,5401,543 .

Carey, J.B., and McCormick, S.D., 1998, Atlantic salmon smolts are more responsive to an acute handling and confinement stress than parr: Aquaculture, v. 168, p. 237-253.

Cheek, T.E., Van den Avyle, M.J., and Coutant, C.C., 1985, Influences of water quality in distribution of striped bass in a Tennessee River impoundment: Transactions of the American Fisheries Society, v. 114, p.67-76.

Cooke, S.J., and Bunt, C.M., 2001, Assessment of internal and external antenna configurations of radio tags implanted in smallmouth bass: North American Journal of Fisheries Management, v. 21, p. 236241.

Connor, W.P., Sneva, J.G., Tiffan, K.F., Steinhorst, R.K., and Ross, D., 2005, Two alternative juvenile life history types for fall Chinook salmon in the Snake River Basin: Transactions of the American Fisheries Society, v. 134, p. 291-304.

Coutant, C.C., 1973, Effect of thermal shock on vulnerability of juvenile salmonids to predation: Journal of the Fisheries Research Board of Canada, v. 30, p. 965-973.

Crowder, L.B., and Magnuson, J.J., 1983, Cost-benefit analysis of temperature and food resource use-A synthesis with examples from the fishes, in Aspey, W.P., and Lustick, S.I., eds., Behavioural energetics - The cost of survival in vertebrates: Columbus, Ohio State University Press, p. 189-221.

DeMaw, D., 1987, W1FB's antenna notebook: Newington, Connecticut, The American Radio Relay League, $124 \mathrm{p}$. 
Forsyth, R.B., Candido, E.P.M., Babich, S.L., and Iwama, G.K., 1997, Stress protein expression in coho salmon with bacterial kidney disease: Journal of Aquatic Animal Health, v. 9, p. 18-25.

Fried, S.M., McCleave, J.D., and Stred, V., 1976, Buoyancy compensation by Atlantic salmon (Salmo salar) smolts tagged internally with dummy telemetry transmitters: Journal of the Fisheries Research Board of Canada, v. 33, p. 1,377-1,380.

Guy, C., Blankenship, H., and Nielsen, L., 1996, Tagging and marking, in Murphy, B. W., and Willis, D. W., eds., Fisheries techniques (2d ed.): Bethesda, Maryland, American Fisheries Society, p. 353384.

Hammer, C., 1995, Fatigue and exercise tests with fish: Comparative Biochemistry and Physiology, v. 112, p. 1-20.

Hanson, P.C., Johnson, T.B., Schindler, D.E., and Kitchell, J.F., 1997, Fish bioenergetics 3.0: Madison, University of Wisconsin, Sea Grant Institute, WISCU-T-97-001.

Harper, D.G. and Blake, R.W., 1990, Fast-start performance of rainbow trout Salmo gairdneri and northern pike Esox iucius: Journal of Experimental Biology, v. 150, p. 321-342.

Hockersmith, E.E., Muir, W.D., Smith, S.G., Stanford, B.P., Perry, R.W., Adams, N.D., and Rondorf, D.W., 2003, Comparison of migration rate and survival between radio-tagged and PIT-tagged migrant yearling Chinook salmon in the Snake and Columbia Rivers: North American Journal of Fisheries Management, v. 23, p. 404-413.

Hocutt, C.H., 1973, Swimming performance of three warm water fishes exposed to rapid temperature change: Chesapeake Scientific, v. 14, p. 11-16.

Holt, R.A., 1987, Cytophaga psychrophila, the causative agent of bacterial cold-water disease in salmonid fish: Corvallis, Oregon State University, Ph.D. thesis, 166 p.

Iwama, G.K., Thomas, P.T., Forsyth, R.B., and Vijayan, M.M., 1998, Heat shock protein expression in fish: Reviews in Fish Biology and Fisheries, v. 8, p. 35-56.

Iwama, G.K., Vijayan, M.M., Forsyth, R.B., and Ackerman, P.A., 1998, Heat shock protein expression in fish: American Zoology, v. 39, p. 901-909.

Iwama, G. K., Vijayan, V. M., Forsyth, R. B., Ackerman, P. A., 1999, Heat Shock Proteins and Physiological Stress in Fish: American Zoologist, v. 39, p. 901-909.

Iwama, G.K., Afonso, L.O.B., Todgham, A., Ackerman, P., and Nakano, K., 2004, Are hsps suitable for indicating stressed stated in fish?: The Journal of Experimental Biology, v. 207, p. 15-19.

Jain, K.E., Hamilton, J.C, and Farrell, A.P., 1997, Use of a ramp velocity test to measure critical swimming speed in rainbow trout (Oncorhynchus mykiss): Comparative Biochemistry and Physiology, v. 117A, p. 441-444.

Jepsen, N., Davis, L.E., Schreck, C.B., and Siddens, B., 2001, The physiological response of Chinook salmon smolts to two methods of radio-tagging: Transactions of the American Fisheries Society, $\mathrm{v}$. 130, p. 495-500.

Jepsen, N., Koed, A., Thorstad, E.B., and Baras, E., 2002, Surgical implantation of telemetry transmitters in fish-How much have we learned?: Hydrobiologia, v. 483, p. 239-248.

Jepsen, N., Schreck, C., Clement, S., Thorstad, E., 2004, A brief discussion of the $\%$ tag/bodymass rule, in Spedicato, M.T., Marmulla, G., Lembo, G., eds., Aquatic telemetry: Advances and applications, FAO - COISPA, Rome, p 255-259.

Johnson, G.E., Adams, N.A., Johnson, R.L., Rondorf, D.W., Dauble, D.D., and Barila, T.L., 2000, Evaluation of the prototype surface bypass for salmonid smolts in spring 1996 and 1997 at Lower Granite Dam on the Snake River, Washington: Transactions of the American Fisheries Society, v. 129, p. 381-397.

Lima, S.L., and Dill, L.M., 1990, Behavioural decisions made under the risk of predation-A review and prospectus: Canadian Journal of Zoology, v. 68, p. 619-640.

Littell, R.C., Milliken, G.A., Stroup, W.W., and Wolfinger, R.D., 1996, SAS ${ }^{\circledR}$ System for mixed models: Cary, North Carolina, SAS Institute Incorporated, $633 \mathrm{p}$. 
Logue, J., Tiku, P., and Cossins, A.R., 1995, Heat injury and resistance adaptation in fish: Journal of Thermal Biology, v. 20, p. 191-197.

Magnuson, J.J., Crowder, L.B., and Medvick, P.A., 1979, Temperature as an ecological resource: American Zoologist, v. 19, p. 331-343.

Martinelli, T.L., Hansel, H.C., and Shively, R.S., 1998, Growth and physiological responses to surgical and gastric radio transmitter implantation techniques in subyearling Chinook salmon (Oncorhynchus tshawytscha): Hydrobiologia, v. 371/372, p.79-87.

Martinelli, T.L., and Shively, R.S., 1997, Seasonal distribution, movements and habitat associations of northern squawfish in two lower Columbia River reservoirs: Regulated Rivers-Research and Management, v. 13, p. 543-556.

Maule A.G., Schreck, C.B., Bradford, C.S., and Barton, B.A., 1988, Physiological effects of collecting and transporting juvenile Chinook salmon past dams on the Columbia River: Transactions of the American Fisheries Society, v. 117, p. 245-261.

McCleave, J.D., and Stred, K.A., 1975, Effects of dummy telemetry transmitters on stamina of Atlantic salmon (Salmo salar) smolts: Journal of the Fisheries Research Board of Canada, v. 32, p. 559-563.

Mesa, M.G., Weiland, L.K., and Kydlewski, G.B., 2004, Critical swimming speeds of wild bull trout: Northwest Science, v. 78, p. 59-65.

Moore, A., Russel, I.C., and Potter, E.C.E., 1990, The effects of intraperitoneally implanted dummy acoustic transmitters on the behavior and physiology of juvenile Atlantic salmon: Journal of Fish Biology, v. 37, p. 713-721.

Moser, M.L., Olsen, A.F., and Quinn, T.P., 1990, Effects of dummy ultrasonic transmitters on juvenile coho salmon, in Parker, N.C., and others (eds.), Fish-marking techniques: Bethesda, Maryland, American Fisheries Society, Symposium 7, p. 353-356.

Moser, M.L., Matter, A.L., Stuehrenberg, L.C., and Bjorn, T.C., 2002, Use of an extensive radio receiver network to document Pacific lamprey (Lampetra tridentata) entrance efficiency at fishways in the lower Columbia River, USA: Hydrobiologia, v. 483, p. 45-53.

Muir, W.D., Zaugg, W.S., Giorgi, A.E., and McCutcheon, S., 1994, Accelerating smolt development and downstream movement in yearling Chinook salmon with advanced photoperiod and increased temperature: Aquaculture, v. 123, p. 387-399.

Murchie, K.J., Cooke, S.J., and Schreer, J.F., 2004, Effects of radio-transmitter antenna length on swimming performance of juvenile rainbow trout: Ecology of Freshwater Fish, v. 13, p. 312-316.

Otto, R.G., and O'Hara-Rice, J., 1974, Swimming speeds of yellow perch, Perca flavescens, following an abrupt change in temperature: Journal of the Fisheries Research Board of Canada, v. 31, p. 1,7311,734 .

Pascho, R.J. and Mulcahy, V., 1987, Enzyme-linked immunosorbent assay for a soluble antigen of Renibacterium salmoninarum, the causative agent of salmonid bacterial kidney disease: Canadian Journal of Fisheries and Aquatic Sciences, v. 44, p. 183-191.

Peake, S., and McKinley, R.S., 1998, A re-evaluation of swimming performance in juvenile salmonids relative to downstream migration: Canadian Journal of Fisheries and Aquatic Sciences, v. 55, p. 682-687.

Perry, R.W., Adams, N.S., and Rondorf, D.W., 2001, Buoyancy compensation of juvenile Chinook salmon implanted with two different size dummy transmitters: Transaction of the American Fisheries Society, v. 130, p. 46-52.

Quinn, G.P., and Keough, M.J., 2005, Experimental design and data analysis for biologists: Cambridge, United Kingdom, Cambridge University Press.

R Development Core Team, 2006, R-A language and environment for Statistical. R Foundation for Statistical Computing: Vienna, Austria. ISBN 3-900051-07-0, http://www.R-project.org. 
Robertson, M.J., Scruton, D.A., and Brown, J.A., 2003, Effects of surgically implanted transmitters on swimming performance, food consumption and growth of wild Atlantic salmon parr: Journal of Fish Biology, v. 62, p. 673-678.

Sauter, S.T., Crawshaw, L.I., and Maule, A.G., 2001, Behavioral thermoregulation by juvenile spring and fall Chinook salmon, Oncorhynchus tshawytscha, during smoltification: Environmental Biology of Fishes, v. 61, p. 295-304.

Schneider M.J., and Connors, T.J., 1982, Effects of elevated water temperature on the critical swim speeds of yearling rainbow trout, Salmo gairdneri: Journal of thermal Biology, v. 7, p. 227-229.

Schrock, R.M., Beeman, J.W., Rondorf, D.W., and Haner, P.V., 1994, A microassay for gill sodium, potassium activated ATPase in juvenile Pacific salmonids: Transactions of the American Fisheries Society, v. 12, p. 223-229.

Stewart, D.J., and Ibarra, M., 1991, Predation and production by salmonine fishes in Lake Michigan, 1978-88: Transactions of the American Fisheries Society, v. 119, p. 314-336.

Stevens, E.D., 1979, The effect of temperature on tail beat frequency of fish swimming at constant velocity: Canadian Journal of Zoology, v. 57, p. 1,628-1,635.

Stokes, M.E., Davis, C.S., and Koch, G.G., 2000, Categorical data analysis using the SAS ${ }^{\circledR}$ system $(2 \mathrm{~d}$ ed.): Cary, North Carolina, SAS Institute Incorporated, 626 .

Webb, P.W., 1975, Acceleration performance of rainbow trout Salmo gairdneri and green sunfish Lepomis cyanellus: Journal of Experimental Biology, v. 63, p. 451-465.

Webb, P.W. 1995, Locomotion, in Brett, J.R., and Clark, C., eds., Physiological-ecology of Pacific Salmon: Government of Canada, Department of Fisheries and Oceans, Ottawa, Ontario, p. 70-99.

Webb, P.W. 1998. Swimming, in Evans, D.H., ed., The physiology of fishes (2d ed.): Marine Science Series, CRC Press, Boca Raton, p. 3-24.

Winter, J.D., 1996, Advances in underwater biotelemetry, in Murphy, B.R., and Willis, D.W., eds., Fisheries techniques (2d ed.): Bethesda, Maryland, American Fisheries Society, p.555-590.

Zaugg, W.S., and Wagner, H.H., 1973, Gill ATPase activity related to parr-smolt transformations and migration in steelhead trout (Salmo gairdneri) - Influence of photoperiod and temperature: Comparative Biochemistry and Physiology, v. 45, p. 955-965. 
Publishing support provided by the U.S. Geological Survey

Science Publishing Network, Tacoma Publishing Service Center

For more information concerning the research in this report, contact the Director, Western Fisheries Research Center

U.S. Geological Survey

6505 NE 65th Street

Seattle, Washington 98115

https://wfrc.usgs.gov/ 
